Portland State University

PDXScholar

Spring 5-21-2015

\title{
Challenges, Experiences, and Future Directions of Senior Centers Serving the Portland Metropolitan Area
}

Melissa Lynn Cannon

Portland State University

Follow this and additional works at: https://pdxscholar.library.pdx.edu/open_access_etds

Part of the Social Welfare Commons, and the Urban Studies Commons Let us know how access to this document benefits you.

Recommended Citation

Cannon, Melissa Lynn, "Challenges, Experiences, and Future Directions of Senior Centers Serving the Portland Metropolitan Area" (2015). Dissertations and Theses. Paper 2317.

https://doi.org/10.15760/etd.2314

This Dissertation is brought to you for free and open access. It has been accepted for inclusion in Dissertations and Theses by an authorized administrator of PDXScholar. For more information, please contact pdxscholar@pdx.edu. 
Challenges, Experiences, and Future Directions of Senior Centers

Serving the Portland Metropolitan Area

\author{
by \\ Melissa Lynn Cannon
}

A dissertation submitted in partial fulfillment of the requirements for the degree of

\author{
Doctor of Philosophy \\ in \\ Urban Studies \\ Dissertation Committee: \\ Sy Adler, Chair \\ Margaret B. Neal \\ Charles Heying \\ William “Ted” Donlan
}

Portland State University

2015 
(C) 2015 Melissa Lynn Cannon 


\begin{abstract}
A growing body of research emphasizes the development of an understanding of the relationship between older adults and their physical and social environments (Wahl \& Weisman, 2003). Researchers, planners, policymakers, and community residents have been increasingly interested in shaping urban environments as places that foster active aging and independence among older adults. Senior centers have served a critical role in their communities as focal points for older adults, as individuals or in groups, to participate in services and activities that support their independence and encourage their involvement in and with the community (NCOA, 1979). The aging of the population and influx of baby boomers into the older demographic, along with declines in participation rates and funding, are challenging senior center staff to be innovative and adaptive in order to demonstrate senior centers' relevance to future older adults while maintaining the programming and services for their current participants. This research is a multiplecase study of five unique senior centers located throughout the Portland metropolitan area in Oregon. Different types and models of senior centers are represented by the selected cases, as they operate under different governance structures and vary in aspects such as administration, funding, participant characteristics, community partnerships, transportation options, physical environments, and range of services and programs offered. This study aims to better understand challenges, strengths, and future directions for different types of senior centers serving a metropolitan area. Data collection at each site included interviews with staff as well as focus groups with senior center participants. Interviews with key informants enriched the findings and provided outside perspectives of senior center experiences. Data analysis revealed challenges and strengths that were
\end{abstract}


common across and unique to the different senior centers in this study. This research contributes to the literature in urban studies, community development, and gerontology by exploring potential opportunities for urban senior centers to adapt and continue to serve older adults. Recommendations were developed for how senior centers might capitalize on these opportunities and for how their communities might provide mechanisms of support to facilitate the continuation and contributions of senior centers in metropolitan areas. 


\section{Dedication}

This dissertation is dedicated to my grandparents, all of whom have shown me unwavering love and support, and inspire me to age with much laughter and grace. 


\section{Acknowledgments}

I would like to express my deep appreciation and gratitude to the members of my committee: Dr. Sy Adler, Committee Chair, for his guidance and confidence in me, and for sharing his enduring wisdom; Dr. Margaret Neal, for her support and mentorship during my time as a graduate student, and for helping shape my path throughout this process; Dr. Charles Heying, for his generosity and interest in my success since I came to Portland State University as an undergraduate student; and Dr. Ted Donlan, for his kindness and willingness to extend his time and expertise to serve on my committee. I also want to acknowledge Dr. Daniel Sullivan, who previously served on my committee, and who provided thought-provoking suggestions and input for the design of my data collection. He is greatly missed by a wealth of individuals, including many from the PSU community.

I cannot imagine completing this program without the bountiful love and support of my parents and of my sister. Each of them has provided unique contributions that cannot be adequately described here.

Thank you to my partner, with whom I am so grateful to be sharing my life, and whose encouragement and patience has often exceeded what I thought was possible.

I would also like to thank my extensive network of family and friends who have been a great source of encouragement and feedback throughout this process.

Finally, I would like to acknowledge the faculty and partners of the Institute on Aging and the many older adults in my life who have inspired me to dedicate my research to the goal of developing communities for people across the life course. 


\section{TABLE OF CONTENTS}

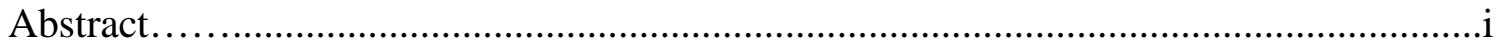

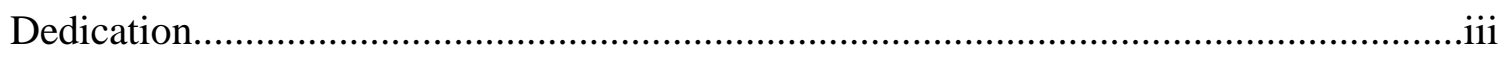

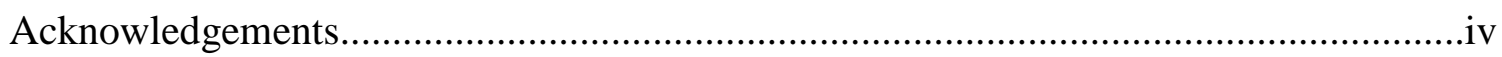

List of Tables.........................................................................................................

Chapter One: Literature Review............................................................................. 1

Changing Population Age Structure............................................................. 1

A growing and increasingly diverse population......................................

Who are the baby boomers? ................................................................4

Aging in urban areas......................................................................

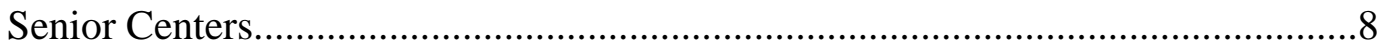

Origins and theoretical background.....................................................8

Senior center research..................................................................13

Future of senior centers..............................................................17

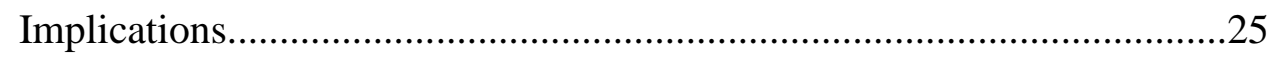

Chapter Two: Research Design and Methods...........................................................27

Research Questions....................................................................................28

Use of a Case Study Design..........................................................................28

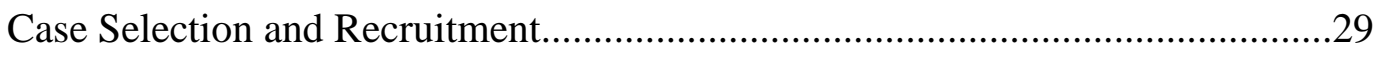

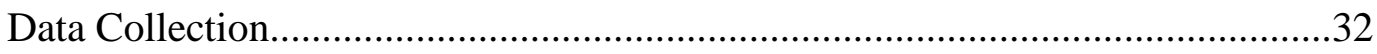

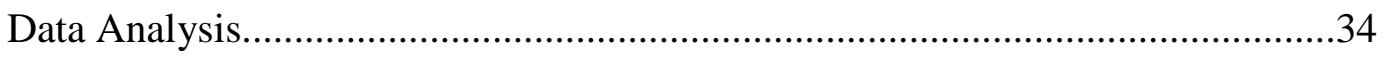

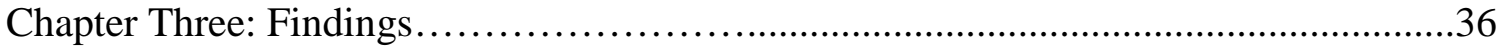

Part One: Participation and Community Engagement.........................................36

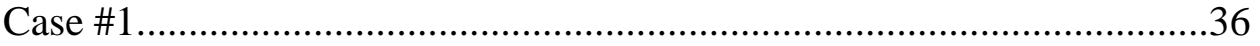

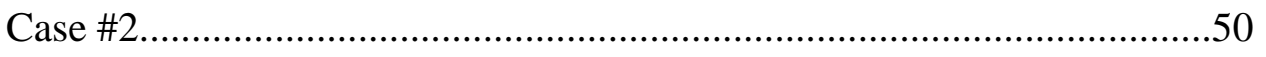

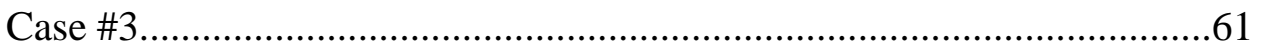

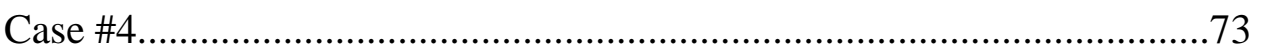

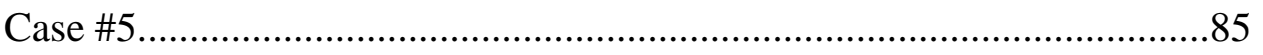

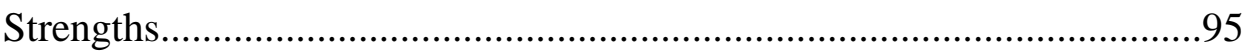

Challenges...............................................................................98

Part Two: Administrative Structure and Funding...........................................102

Case \#1.........................................................................................102

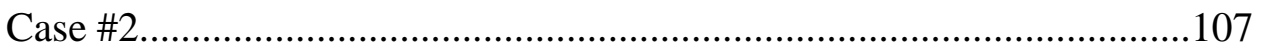

Case \#3............................................................................................... 111

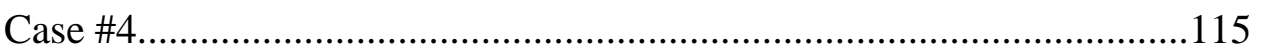

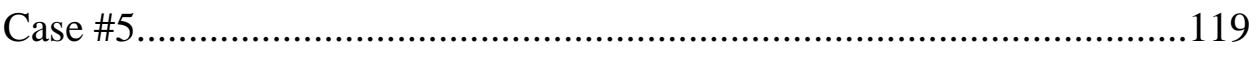

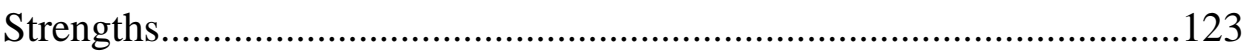

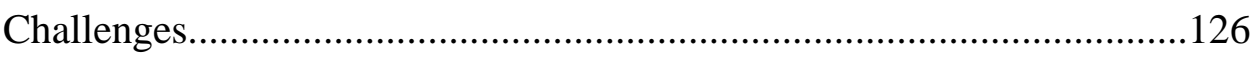


Part Three: Transportation and Physical Environment....................................129

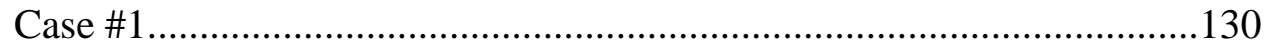

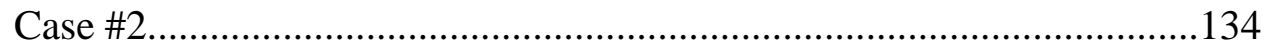

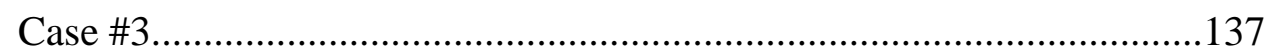

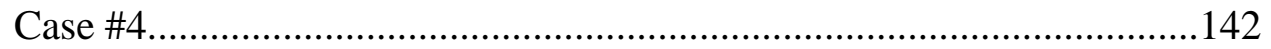

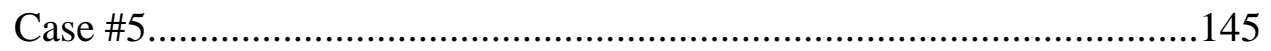

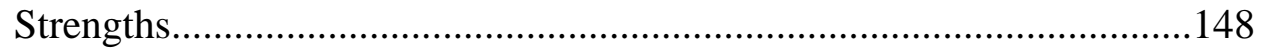

Challenges...................................................................................150

Part Four: Programming, Activities, and Services..........................................152

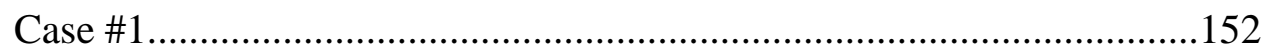

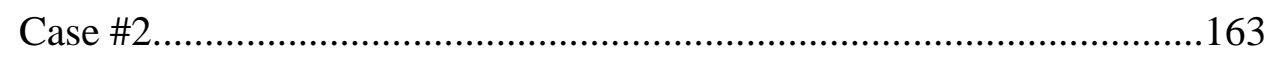

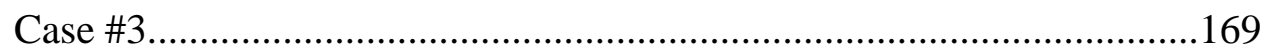

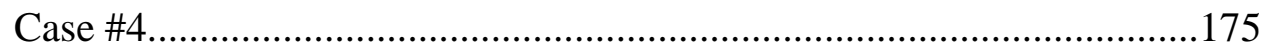

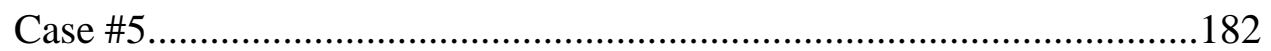

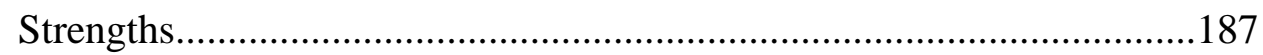

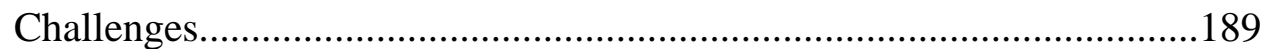

Chapter Four: Key Findings and Recommendations.................................................192

Participation and Community Engagement...................................................192

Administrative Structure and Funding..........................................................198

Transportation and Physical Environment....................................................201

Programming, Activities, and Services........................................................203

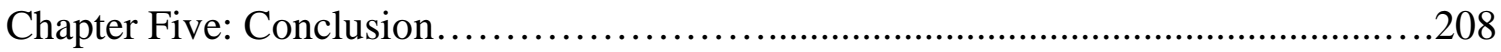

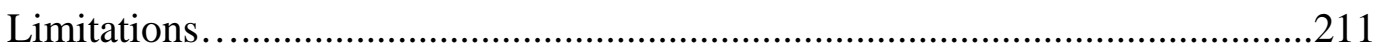

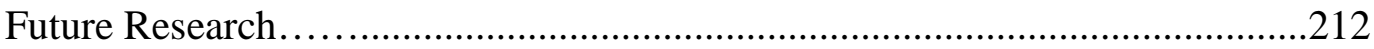

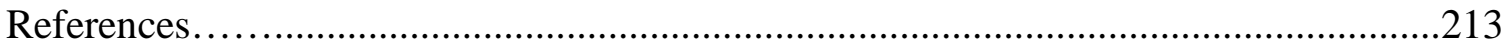

Appendices

Appendix A: Portland State University Institutional Review Board

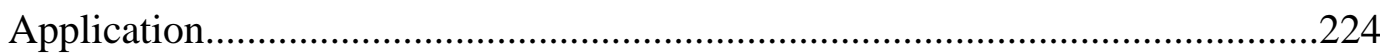

Appendix B: National Institute of Senior Centers Standards............................255 


\section{List of Tables}

Table 1. Selected Cases...........................................................

Table 2. Research Participants..................................................34

Table 3. Focus group \#1 Survey Responses...................................47

Table 4. Focus group \#2 Survey Responses........................................58

Table 5. Focus group \#3 Survey Responses....................................70

Table 6. Focus group \#4 Survey Responses....................................82

Table 7. Focus group \#5 Survey Responses......................................92 


\section{Chapter One: Literature Review}

\section{Changing Population Age Structure}

Population aging is a phenomenon associated with rising numbers and proportions of the older population within a society. Improvements in life expectancy, along with fertility decline and urbanization that characterized the second half of the $20^{\text {th }}$ century, have been dominant global demographic trends (Kinsella \& He, 2009). As Quadagno (2011) explained, the population age structure changes based on three demographic processes: fertility rates (i.e., incidence of births in the population), mortality rates (i.e., incidence of death in a population), and migration (i.e., the movement of people across borders). In the post-World War II era beginning in 1946, fertility began climbing and peaked at an average of 3.17 children per woman in 1958 in what has come to be known as the "baby boom.” Fertility then dropped back down to an all-time low between 1971 and 1980, to an average of 1.7 children per woman. The greatest declines in mortality occurred during the 1940s, when medical advances helped reduce infant and maternal mortality, and the 1970s, when deaths from heart disease began dropping dramatically. Immigration, which has the least influence of the three processes on current population aging, has brought in large numbers of young people who migrated to the U.S. who are now aging and will result in a much more racially and ethnically diverse older population than previously existed in the U.S. (Quadagno, 2011).

A growing and increasingly diverse older population. By the year 2030, 20\%

of the total U.S. population will be 65 years of age or older, compared to $13 \%$ in 2010 . 
The number of older adults ${ }^{1}$ will have nearly doubled from 43.1 million in 2012 to a projected 83.7 million in 2050 (Ortman, Velkoff, \& Hogan, 2014).

The increase in the number of older adults, particularly in the oldest old (i.e., people aged 85 and older) age demographic, will place increasing demands on services and resources throughout the U.S. Life expectancy has risen for people aged 65 and older from about 15 years in 1972 to about 19 years in 2010, and for people aged 85 and older, from about 5.5 to 6.5 years during that time period. The projected total number in the oldest old demographic will rise from 5.9 million in 2012, to 8.9 million in 2030, to 18 million in 2050. In other words, the population aged 85 years and older will triple between 2012 and 2050 (Ortman, Velkoff, \& Hogan, 2014). Although gerontologists are aware of placing too much credence in a number when defining old age, the chronological age groupings do have some value (Whitborne \& Whitborne, 2011). For example, using activities of daily living (ADLs; e.g., bathing, dressing, eating) and instrumental activities of daily living (IADLs; e.g., preparing meals, shopping, managing finances) to measure disability, the rates of limitations in ADLs among noninstitutionalized individuals aged 85 years and older are much higher than those among individuals aged 65-74 years (Administration for Community Living, 2012, p. 15).

Along with the aging of the population, the U.S. is experiencing increasing racial and ethnic diversity. The aggregate minority population (i.e., everyone who is not classified as non-Hispanic White alone) will become the majority in 2043 (Colby \& Ortman, 2014). Although the older population is not expected to become "majority-

\footnotetext{
${ }^{1}$ Older adults will refer to people age 65 and over throughout this document.
} 
minority" by 2050, this population is projected to climb to $39.1 \%$ percent minority from $20.7 \%$ in 2012. The percentage of the older adult population that is non-Hispanic White alone will decrease from about 79\% to 61\% between 2012 and 2050. While the older adult cohort that is aged 85 and over is less racially diverse than the cohort aged 65 and over, both groups will increase in diversity over the next four decades; the percent of minority individuals in the oldest-old demographic will increase from 16.3\% in 2012 to nearly 30\% in 2050 (Ortman, Velkoff, \& Hogan, 2014).

Despite impressive gains in public health over the last century, many historically disadvantaged groups within the U.S. older adult population continue to experience higher levels of illness, disability, and premature death. (Fredriksen-Goldsen et al., 2011; IOM, 2011). A 2004 National Research Council report documented ongoing racial and ethnic disparities in health, activity limitations, and active life among older adults in the U.S. Non-Hispanic Black, Native American, and, to a lesser degree, Mexican American and other Hispanic older adults displayed overall worse health across numerous indicators compared to non-Hispanic Whites (although Asian and Pacific Islander older adults showed more favorable patterns across some of the indicators; p. 3). Meanwhile, LGBT $^{2}$ older individuals experience unique health disparities: nearly 50\% have a disability; around 30\% experience depression; 13\% have been denied healthcare or received inferior care; and over $20 \%$ do not disclose their sex or gender identities to their physicians (Fredriksen-Goldsen et al., 2011). Moreover, the health needs of the diverse communities included within the LGBT umbrella term are often grouped together, and

\footnotetext{
${ }^{2}$ This term, which stands for Lesbian, Gay, Bisexual, and Transgender, will be used to refer to anyone who is non-heterosexual (or non-cisgender), although not to exclusively refer to people who are lesbian, gay, bisexual, or transgender.
} 
this broad LGBT group includes subpopulations of various other communities (e.g., racial, ethnic, socioeconomic; IOM, 2011).

Who are the baby boomers? Of importance to people working in aging services, particularly, is an understanding of the large U.S. cohort born between 1946 and 1964. Known as the baby boomers, this cohort has been driving significant change in the age structure of the country's population and will continue to do so for decades to come. The baby boomers began turning 65 in 2011 and will all have reached this traditional retirement age by the year 2030 (Colby \& Ortman, 2014).

The baby boom cohort has been described as a "demographic anomaly” (Schulz \& Binstock, 2006). It is significant for its size and diverse characteristics and has been having a noticeable impact on society (Ortman, Velkoff, \& Hogan, 2014). Communities in the U.S. are observing potential challenges associated with the aging of the baby boom cohort and potential opportunities for boomers to utilize their skills and talents. Many of the baby boomers are better educated, healthier, and likely to work longer than prior cohorts; however, although they were all born within an 18-year period, they are heterogeneous with respect to many factors such as race, ethnicity, sexual orientation, politics, work histories, family structures and health behaviors (Pruchno, 2012).

Taylor (2014) pointed out that the boomers have been part of a divisive generation; they led the countercultural upheavals of the 1960s, whereas those in the generation before them, the Silent Generation (born between 1928 and 1945), tend to be more conservative and conformist, and somewhat uneasy with the pace of change. Around $15 \%$ of boomers are unaffiliated with a religion compared to $9 \%$ of those in the Silent Generation (p. 30). A 2010 Pew Research Center survey explored what 
respondents believe makes their generations unique; based on open-ended responses, the top five features that make the Silent Generation unique include (a) World War II/Depression, (b) smarter, (c) honest, (d) work ethic, and (e) values/morals. According to the boomer generation respondents, the top five features that make the boomer generation unique include (a) work ethic, (b) respectful, (c), values/morals, (d) "baby boomers,” and (e) smarter (Taylor, 2014).

The baby boomers have been impacting the U.S. dependency ratio, which has been used to measure societal impacts based on the number of potential dependents (i.e., persons aged 65 and older, and persons aged 18 and younger) compared to people of working age (aged 18 to 64). Though not totally accurate, as many people who work are under the age of 18 and over the age of 65 , this ratio provides an illustration of the impacts of the baby boom cohort on the U.S. age structure. After 1964, when the last of the boomers were born, the youth dependency ratio declined, stabilizing at about 37 (per 100 working-age adults) over the next several decades. The old age dependency ratio, however, has increased gradually, from 12 in 1945 to nearly 21 in 2010, and is expected to surpass the youth dependency ratio in 2056 to just under 40 (Colby \& Ortman, 2014).

Policymakers and others are concerned that this shift in the dependency ratio will place increased burden on the younger population in terms of health care costs and income support. For example, fewer workers, proportionately, will be paying into Social Security, while health care, housing, and transportation for older adults, among other things, will be sought out at higher levels than ever before (Quadagno, 2011).

There is also growing recognition that societies should re-engineer their physical, social, and spiritual environments in order to empower older adults to fully participate in 
society. The recent focus on population aging can shed light on opportunities for individual participation and self-fulfillment for older adults, as well as opportunities to integrate and mainstream aging and older persons into national development strategies (AARP, 2009).

Aging in urban areas. The field of environmental gerontology has evolved over the past several decades, focusing on optimizing the relationship between older adults and their socio-spatial surroundings, which include the physical, social, and cultural environment (Wahl \& Weisman, 2002; Wahl \& Weisman, 2003). Cities have not always been viewed as places that cultivate active aging, although recent efforts have been concerned with shaping urban environments to foster resilience in individuals as they age (Netherland, Finkelstein, \& Gardner, 2011).

These efforts are important, as regular surveys through AARP reveal that at least $80 \%$ of older adults report that they prefer to remain in their homes and communities as they age, rather than move to retirement communities or facilities (Ball, 2003). This process of aging in place has been defined as "the ability to live in one’s own home and community safely, independently, and comfortably, regardless of age, income, or ability level” (CDC, 2013, para. 4).

Portland, Oregon is one of the metropolitan areas expected to increase dramatically over the next several decades in its number of older residents. According to an Oregon Health Authority report (2014), the state of Oregon "seems to be on an accelerated aging schedule: according to the 2013 population forecast, one in five Oregonians will be aged greater than or equal to 65 years by 2025 ... At the moment, $14.9 \%(581,693)$ of us are greater than or equal to 65 years old" (para. 3). The Portland 
metropolitan area's density of baby boom cohort has grown each decade over the past 20 years, especially in the urban cores and periphery of urban areas (DeLaTorre et al., 2012). Between 2010 and 2030, Metro ${ }^{3}$ projects an increase of 106\% in the number of older adults in the Portland metropolitan area compared to an increase of $34.6 \%$ in the general population (The Age-Friendly Portland Advisory Council, 2013, p. 2).

Since 1989, research faculty and students from the Institute on Aging (IOA) at Portland State University (PSU) have been exploring how to inform growth planning and policy development to create livable communities for older adults (Neal, DeLaTorre, \& Carder, 2014). In 2006, the World Health Organization (WHO) approached the IOA as a collaborator in its Global Age-Friendly Cities Project to conduct research on Portland's age friendliness (Age-Friendly Portland, 2015). The age-friendly cities model is rooted in the belief that the urban environment is a key determinant in active aging, which is defined by WHO as "the process of optimizing opportunities for health, participation and security in order to enhance quality of life as people age” (WHO, 2007, p. 5). Portland was the only U.S. city of 33 cities in 22 countries around the world to participate in the original project, and in 2010, Portland was one of nine cities selected as a member of WHO’s new Network of Age-Friendly Cities (Age-Friendly Portland, 2015).

Following the acceptance of Portland into WHO's Network, an expanded AgeFriendly Portland Advisory Council was formed, composed of members from the public, private, nonprofit and higher education sectors. The Advisory Council developed an agefriendly action plan for the City, which was adopted by the Portland City Council in 2013

\footnotetext{
${ }^{3}$ Metro is the regional government responsible for managing the Portland metropolitan area's urban growth boundary. Metro serves 25 cities and three counties in the region (Metro, 2015).
} 
(Age-Friendly Portland, 2015; Neal, DeLaTorre, \& Carder, 2014). The plan includes a number of action items to make Portland a "place for all generations," such as advancing opportunities for aging in place in Portland's neighborhoods and promoting organizations such as senior centers (The Age-Friendly Portland Advisory Council, 2013).

Senior centers have long been key components of healthy communities for older adults as part of the network of home and community based services that assist with aging in place. This next section describes the origins of senior centers, past research that has been conducted on them, and some of their existing challenges and attempts to adapt that led to the development of the research questions for this study.

\section{Senior Centers}

Origins and theoretical background. As Fredrickson and Carstensen (1990) discussed, propensity toward social interaction is a prominent and perhaps innate trait among humans; during the late part of adulthood, rates of social interaction begin to decline, the meaning of which has been a disputed issue in gerontology (Carstensen, 1986; Palmore, 1981).Research in gerontology psychology has shown, however, that social identity enables older adults to cope with aging-related changes and fosters a positive and meaningful sense of self. Generational identification, in particular, has been perceived as positive and serves as a basis for self-definition used by older adults (Weiss \& Lang, 2012).

Assumptions about older individuals and the aging process have evolved over the years (Wagner, 1995); for example, much of gerontological research in the 1960s and 1970s was framed using disengagement theory, which Cumming and Henry (1961) developed as an explanation for the "inevitable process" in which social relationships of 
an aging individual become severed or altered in quality (Morgan \& Kunkel, 2011; Wagner, 1995). This theory argued that it was beneficial, or functional, for both the aging individual and society for disengagement to occur before the person's impending death led to social disruption. For example, retirement was seen as a way for society to remove older people from employment and to bring new cohorts into their roles to replace them, and a way for the older person to be freed of work responsibilities and pursue voluntary, flexible activities (Morgan \& Kunkel, 2011).

Disengagement theory was met with criticism from those who felt that the theory represented a threat to the goal of promoting positive, engaged roles for individuals later in life (Kastenbaum 1993; Morgan \& Kunkel, 2011). Activity theory, which subsequently emerged, argued that individuals must be active by maintaining social roles and interaction in order to age well; that "there is a positive relationship between activity and life satisfaction, and that the greater the role loss, the lower the life satisfaction” (Lemon, Bengston, \& Peterson, 1972, p. 511; Morgan \& Kunkel, 2011). Similar to activity theory, the theory of continuity theory was spawned with the idea that adults adapting to old age should attempt to preserve and maintain self-concepts, relationships, and ways of living, perhaps by replacing a lost activity or relationship with an equivalent one (Atchley,1989; Morgan \& Kunkel, 2011).

More recently, Carstensen $(1987,1989)$ proposed selectivity theory to address the role that older individuals play in this reduction of social contact. Selectivity theory diverges theoretically from previous models of socioemotional aging, arguing that throughout life, individuals become more selective in choosing their social partners which allows them to maximize investments in closer relationships and minimize 
interactions with less familiar social partners (Fredrickson \& Carstensen ,1990). This theory is congruent with models of late-life adaptation such as the process of selective optimization with compensation, which P.B. Baltes and M.M. Baltes described as a way of adapting to losses in competence by "selecting and concentrating on other domains that are of high priority” (Fredrickson \& Carstensen ,1990, para. 6). Lawton (1987) similarly argued that the field of gerontology had not focused enough on the roles of individual competencies and suggested that individuals orchestrate their own environments based on choice of what is desirable or relevant to themselves.

The emergence of senior centers relates to the desires of older adults to engage in socialization with other individuals of similar ages. Senior centers originated in 1870 as clubs for older adults, and in 1943, the New York City Welfare Department expanded these clubs with the idea that they should provide more than just a meeting place, contributing games and refreshments to foster sociability. This idea quickly spread to private groups across the country that set up centers, such as the San Francisco Senior Center in 1947, which was created by the United Community Fund, the American Woman's Volunteer Services, the Recreation Department, and local citizens (Gelfand, 2006; Kent, 1978). The New York program was designed primarily for low-income and socially isolated older adults who were seen as the likely candidates for participation in a senior center; it became the prototype for the social agency model, one of the two conceptual models of the senior center that developed over time. The other conceptual model was embodied by the "Little House” created in 1949 in Menlo Park, CA, which attracted white-collar and professional older adults. This became known as the voluntary organization model, which hypothesized that older people who are active in voluntary 
organizations and manifest strong attachments to the community would be likely candidates for participation in a senior center (Gelfand, 2006; Taietz, 1976). Senior centers have historically been more commonly designed according to the voluntary organization model, emphasizing socialization and leisure (Fitzpatrick \& McCabe, 2008; Taietz, 1976). They are designed, however, to reflect and respond to the features and needs of the communities they serve (Dal Santo, 2009).

By the late 1970s, senior centers were rapidly becoming ubiquitous organizations for patterned age peer interaction for non-institutionalized older adults (Taietz, 1976). Local-based institutions, either public or non-profit, established senior centers to respond to local needs, although most of their growth did not occur until the passage of the Older Americans Act (OAA) in 1965; in 1970, around 1,200 senior centers existed in the United States (Gelfand, 2006). Between 1970 and 1985, senior centers increased in number from 1,200 to 10,000 (Gelfand, 2006; Krout, 1987). The total number of senior centers has remained relatively stable at over 10,000, and by 2003 senior centers had a usage rate greater than any other community-based program for older adults in the United States (Aday, 2003; Gelfand, 2006).

The National Council on Aging (NCOA) definition of a senior center is "a community focal point on aging where older persons as individuals or in groups come together for services and activities which enhance their dignity, support their independence and encourage their involvement in and with the community" (NCOA, 1979, as cited in Gelfand, 2006, p. 145). In 1973 amendments to the OAA, senior centers were defined as facilities that provide a broad range of services, and in 1978 amendments, they were identified as service delivery “focal points” (Wagner, 1995). The 
Administration on Aging (AOA) defines a focal point as: "a facility established to encourage maximum collocation and coordination of services for older individuals” (Administration on Aging, 2006). A senior center may offer a number of different services, such as meal programs, transportation services, and arts programs (Turner, 2004). The success of the senior center hinges not only on the range of services provided but also on the voluntary participation of older adults in services, allowing them to maintain independence while connecting with other individuals and to the community (Gelfand, 2006).

In 1985, Louis Lowy ${ }^{4}$ stated, "The uniqueness of the senior center stems from its total concern for older people and for its concern for the total older person” (NilesYokum \& Wagner, 2011, p. 36). The National Institute of Senior Centers (NISC) emphasizes the role of senior centers as places for older adults to come together for services and activities that reflect their experiences and skills, respond to needs and interests, and enhance dignity, independence and involvement in and with the center and community (Niles-Yokum \& Wagner, 2011). Within this role, senior centers apply activity and continuity theories by promoting positive, engaged roles for individuals later in life. As Fitzpatrick and McCabe (2008) argued, future senior centers should include meaningful roles such as volunteerism and opportunities for part-time employment to stay relevant to future retired older adults. Applying selectivity theory, senior center participants select senior centers as parts of their social environments later in life based on the determination that the center programming is desirable or relevant to their lives. 
Senior center research. Senior centers have become an integral component of the long-term care continuum, providing community-based services for older adults and opportunities for socialization, nutrition, recreation, volunteering, information and referral, and health promotion, among others (Pardasani \& Sackman, 2014). Pardasani and Sackman (2014) determined that, based on past research, the typical profile of a senior center participant is a single, or widowed, older woman with a low-to-medium income and few disabilities; men, married couples, and individuals with higher income and education levels tend to be less inclined to participate. Of course, as Wagner (1995) explained, "People who participate in senior center activities are as diverse as the communities in which they reside” (p. 7). Past research on senior centers has provided some demographic information on senior center participants, differences between users and non-users, and also some contradictory information about senior center participation (Wagner, 1995).

In a study conducted of senior centers in 34 communities, Taietz (1976) examined the extent to which characteristics of senior center participants were more consistent with the conception of the senior center as a social agency or as a voluntary organization. Taietz measured community attachment, involvement in formal voluntary associations, income, age identification, and preference for type of organization (i.e., preference regarding ages of other participants). Taietz concluded that the voluntary organization model more appropriately described the senior center, as senior center participants led active lifestyles and maintained strong attachments to their communities. He found no relationship between income and senior center participation. Taietz noted that an essential ingredient of recruitment and outreach included the availability of transportation to 
facilitate senior center participation. He determined, "In the absence of these and other efforts, the senior center as a formal voluntary organization will continue to attract the active, engaged elderly to the neglect of the more alienated elderly with the greatest need (p. 222, para 2)." It was suggested that a variety of senior centers should be developed to serve different needs, lifestyles, and groups (Trela \& Simmons,1971; Taietz, 1976).

Other data collected by NCOA in the 1970s found that senior center participants were relatively young, healthy older adults (Wagner, 1995). On the other hand, a survey of over 400 senior centers conducted by John Krout revealed that 10\% of participants were aged 85 and older and that nearly 60\% were categorized as "frail” (Krout,1990). Another study of eight senior centers found that the average age at one senior center was 85 years, and that the majority of African American participants in the sample attended just one of the senior centers (Krout, 1988).

Women have been disproportionately represented among senior center populations, even when lifespan differences between men and women have been taken into account; however, studies have varied in their reports of senior center participation rates by men and women (Wagner, 1995). Findings about the age of participants are similarly inconsistent (Wagner, 1995), though Krout, Cutler, and Coward (1990) found that participation rates increased until the age 85 , after which participation rates decreased. Race has not been found to factor into the decision about senior center participation (Ralston and Griggs, 1985), although more research is needed in order to understand the role played by race and ethnicity in senior center participation (Wagner, 1995). 
National data examined by Krout et al. (1990) also showed that 20\% of older adults living alone or with a nonrelative attended a senior center compared to $11 \%$ of those living with a spouse, and that the percentage of older adults attending senior center declines as income increases. This research also found that senior center participants tend to have a positive view of their health and report fewer limitations in activities of daily living (ADLs) in comparison to non-senior center participants.

Dal Santo (2009) noted that the most recent national survey of older adults (in 1984, by Krout, Cutler, and Coward) had shown that $14 \%$ of senior center participants had used a senior center in the past year. Characteristics of senior center participants included higher levels of participation by women, lower levels of participation at lower and higher levels of education, and higher levels of participation with higher levels of social interaction. The data also revealed that $20 \%$ of older adults living along or with a nonrelative attended a senior center compared to $11 \%$ of those living with a spouse, and that the percentage of older adults attending senior center declines as income increases. This research also found that senior center participants tend to have a positive view of their health and report fewer limitations in activities of daily living (Krout et al., 1990). Researchers have noted higher levels of senior center participation for rural than for urban older adults (Calsyn \& Winter, 1999; Krout et al., 1990). Another study by Ralston (1991) found that increased participation was correlated to living closer to the senior center and to the importance of the meal to daily food intake.

Walker, Bisbee, Porter, and Flanders (2004) assessed possible predictors of participation at senior centers throughout an eleven-county area in Texas. Quantitative analysis revealed that the most significant predictor of participation in senior center 
activities was participation in faith-based activities outside the senior center. The next most significant predictor for participation in senior center activities was preference for a small group size; participation decreased with increased group size. The next most significant predictor was the awareness of activities and the number of transportation options available.

Benefits of senior centers for older adults have primarily been associated with the socialization opportunities presented by being able to interact with people of similar ages and interests, often gaining friendships, support, a sense of belonging, and shared resources (Hooyman \& Kiyak, 2008).

Research has confirmed that the senior center is an environment in which supportive friendships can easily be formed, especially among older adults living alone. Aday, Kehoe, and Farney (2006) evaluated 274 female senior center participants who lived alone and were considered at greater risk for loneliness, depression and decreased mobility. The study found that new friendships and other center activities had positive mental and physical outcomes. Compared with a group of older women living with their spouses, the women who lived alone participated more frequently in activities and created social networks that expanded beyond the center.

Turner’s (2004) study, which included a survey of 856 participants in 27 senior centers, found that $87 \%$ of respondents reported that they participate in the meal program as much for the opportunity to socialize as for meals received, and over half (56\%) reported that the people with whom they associate at the senior center are usually the only people with whom they interact during the daytime. The vast majority (90\%) of respondents viewed the contacts that they made with people at the senior center as 
important to them. In each senior center program activity in which respondents participated (e.g., physical fitness, health assessments, trips, cards/table games, community volunteer work), at least $84 \%$ of those who participated reported that they found such participation helpful.

Pardasani and Thompson (2012) listed several studies that have demonstrated a positive impact on the health and well-being of their senior center participants, particularly with regard to decreased stress levels, isolation, and depression; positive perceptions of health; heightened perception of general well-being; better psychological well-being; improved diet and nutrition; and increased social support. The "health and wellness" model has been a popular and emerging trend in senior centers; as a result, many studies have evaluated the impact of specific health programs within senior centers (Pardasani \& Thompon, 2012).

Krout, Cutler, and Coward (1990) emphasized that few empirically-based generalizations can be made regarding participants versus non-participants, as few studies have provided a clear, consistent picture of factors influencing participation. Generally, research has not been guided by a conceptual framework; Taietz's conceptual framework of the two models of senior centers is one of a few exceptions, but has not been seen as useful to help inform funding and programming decisions. As Pardasani (2004) said, with the advent of multi-purpose centers, a new model of service has evolved that essentially combines the two conceptual models of senior centers.

Future of senior centers. Currently nearly 11,000 senior centers serve one million older adults every day (NCOA, 2015). Senior centers vary in structure, size, and functioning capabilities. These variations relate to senior centers' origins, as they 
originate in individual communities, are sponsored mostly by volunteer, non-profit, or public organizations, and rely heavily on locally-determined sources (Gelfand, 2006). Some centers serve a single purpose, such as to provide meals, although most are multipurpose, serving as focal points to co-locate and coordinate the greatest possible number of services for older adults; some centers are public entities, whereas others are private or nonprofit entities; some rely more on municipal funding, whereas others receive aging network support under the OAA; some are nationally accredited, although most are not; some charge money for specific services, whereas others do not (Turner, 2004).

The proliferation of senior centers across the U.S. was largely a result of funding through federal legislation, most importantly, Title V of the OAA in 1973, which identified senior centers as a unique and separate program. Title $\mathrm{V}$ provided funding for Area Agencies on Aging (AAAs) to acquire, alter, or renovate centers, while Title III provided development and operational funding. Amendments to the OAA in 1978 consolidated Title V under Title III, so that Title III could "provide for acquisition, alteration, renovation, or construction of facilities for multiple-purpose centers as well as provide for the operations of these centers (Gelfand, 2006, p. 146).” This provided greater opportunities for AAAs to develop and fund senior centers from the initial stages through the fully operational stages (Gelfand, 2006).

Through the OAA, resources are available for senior centers and other community organizations to provide services such as meals, information and referral, health promotion and disease prevention, transportation, and caregiver support, many of which are provided at senior centers. Although the OAA actually expired in 2011, U.S. Congress has begun working on the OAA reauthorization process in 2015, beginning 
with a markup by the Senate earlier in the year (NCOA, 2015a). The provisions of the OAA are carried out by the Administration on Aging (AOA) which, as of 2012, is under the Administration for Community Living (ACL) that was established in the U.S. Department of Health and Human Services (HHS) with the belief that: “All Americans_including people with disabilities and older adults—should be able to live at home with the supports they need, participating in communities that value their contributions” (ACL, 2015, para. 1). The ACL brings together the entities of the AOA, the Administration on Intellectual and Developmental Disabilities, and the HHS Office on Disability. The AOA works closely with state AAAs and other programs to provide planning, coordination, and services for older adults, caregivers, and their families. The AOA's Office of Supportive and Caregiver Services is the mechanism with which AAAs implement home and community based services, including funding and operating senior centers (ACL, 2015).

Threats of closure. Federal budget debates remain contentious, and many recent budget cuts included reductions in discretionary programs such as those of the OAA. More cuts are looming (NCOA, 2015a), and senior centers are feeling the impacts as percapita allocations are hardly capable of sustaining their organizations with their current levels of functioning (Pardasani \& Sackman, 2014).

With their current funding, senior centers that continue to rely on public revenue are not expected to survive to the next decade (Pardasani \& Sackman, 2014, p. 203). Research has noted the aging participant pool - or the "graying” of participants - and stagnant participation rates in senior centers (Caslyn \& Winter, 1999; Pardasani \& Thompson, 2012); it is feared that decreased participation, especially by younger 
participants, will lead to funding decreases, as fiscal allocations are tied to attendance rates (Pardasani \& Sackman, 2014). Some senior centers have been experiencing increased demands, but in the face of financial reductions they will struggle to demonstrate their relevance, contributions, and impact on the lives of participants.

Downturns in participation rates have been attributed to a number of factors. Hooyman and Kiyak (2008) noted a reduction in senior center participation due to: older adults' lack of interest in the center's activities; older adults' desire to be with people other than "old" people; low proportions of men among participants in many centers; poor health among older adults; and inadequate transportation for older adults. A study by Walker et al. (2004) provided similar results; older adults who were not attending senior centers explained their reasons for not attending, mainly that: there was not a center nearby or transportation to get there; other people who attended were too “cliquish” and unwelcoming; they didn’t want to be labeled as senior citizens; and they were too busy with other things.

Demographic factors pose challenges to senior center programming, because quite often aging participants become too frail to participate in the centers, (Cox \& Monk, 1990; Dal Santo, 2009; Hooyman \& Kiyak, 2008; Turner, 2004), and younger older adults are less inclined to participate in senior centers (Hooyman \& Kiyak, 2008). Senior centers have been criticized for not doing more to reach older people who are frail, of color, of low income, or with disabilities. Low-income minority older adults may not have participated in their communities' senior centers due to lack of transportation, lack of knowledge about the centers, and lack of culturally sensitive programs for people of diverse backgrounds (Quadagno, 2011). 
Senior center staff have been examining ways to provide programming to enhance wellness of older adults in their communities and meet the challenges of their changing roles in the network of home and community-based services (Wagner, 1995). Walker et al. (2004) revealed that: older adults wanted more transportation options, specific programs (e.g., music and exercise) and specific food options; many facilities lacked space and parking areas; and directors and managers felt a need for better marketing of programs, especially professional marketing to change the public perception of senior centers as welfare programs. Alt (1998) examined demographic and societal trends and projected that future programming would have increasing focus on caregiver and health support, information and referral, volunteer opportunities, employment and retirement options, and health insurance counseling.

Recent articles have exemplified the negative imagery of senior centers and their seemingly antediluvian natures. For example, in an article “Centers (Don’t Say Senior) Look to Get Hip," senior centers were compared to nursing homes, and a baby boomer project director was quoted saying that "a baby boomer would not be caught dead in a senior center" (Young, 2005, para. 22). A more recent blog post, titled "Why We Need to Get Rid of Senior Centers,” suggested that senior centers should shift their focus to become intergenerational community centers and discard their "stifling, stodgy, old agevibe” (Hannon, 2015, para. 11).

New directions. Despite the many contributions of senior centers, a relatively small amount of research about them has been conducted. In her literature review of senior centers, Dal Santo (2009) noted, "In light of all of the accomplishments senior centers have made in servicing older adults, it was disappointing to uncover such a small 
number of studies [ $\mathrm{n}=40$ ] documenting their important service and the quality of research was disheartening” (p. 10). Research about senior centers has documented the array of programs and activities that exist and the positive association between senior center participation and life satisfaction; little research has been done, however, about boomers' attitudes to help forecast future needs for aging services and resources (Dal Santo, 2009). Only two studies thus far have attempted to look at the leadership profiles and organization philosophies of senior centers, and since 1987, there have been no peerreviewed studies of senior center administrators published in the literature (Pardasani \& Sackman, 2014).

In 1995, a conference convened by the NISC and the NCOA focused on the future challenges of senior centers, and participants agreed that change would be necessary for senior centers to survive and be effective in the future considering issues such as changing demographics and declining financial support for senior centers (Niles-Yokum \& Wagner, 2011). Dr. John Krout stated the following:

This is not your mother's senior center' is a quote that likely describes to a 55- or 60-year-old what the senior center of the 21st century is striving to become. Over the past 30 years or so, senior centers have experienced their own life cycle change as participants (who often served as volunteers) have 'aged in place' (Niles-Yokum \& Wagner, 2011, p. 40).

Innovation seems to be on the rise. For example, in 2010, the Virtual Senior Center was unveiled as an innovative public-private partnership between Microsoft Corporation, New York City and Selfhelp Community Services Inc., demonstrating how technology can be used to revitalize senior centers and create an interactive experience 
for homebound seniors (Microsoft, 2010). As the CEO of Selfhelp Community Services explained, the internet can help homebound seniors stay connected to family, friends, caretakers, social workers and community services, ultimately reducing social isolation and depression.

Pardasani and Thompson (2012) described a study of several senior centers that have been restructuring to remain viable within the market. The "New Models Taskforce” of the NISC applied a multiple-case study to a national survey sample to identify six innovative models that represent new, re-imagined senior centers. The models that were identified included:

- Community center: a center for all ages with a variety of activities;

- Wellness center: health and wellness programming for active older adults (age 50 and over);

- Lifelong learning/arts: programs for active older adults (age 50 and over) who want to continue to learn and grow postretirement;

- Continuum of care/transitions: provides services on a gradual continuum as older adults age;

- Entrepreneurial center: programs for active older adults (age 50 and over) who want to utilize skills and expertise postretirement;

- Café program: non-institutional, non-age-segregated community gathering space.

The owners of these new models in the New Models Taskforce study shied away from the use of the term "senior" to identify their centers. Staff of the centers in this study 
all reported that they wanted to avoid the negative image of senior centers (Pardasani \& Thompson, 2012).

An AARP Louisiana report authored by Lawler (2011) further discussed the models identified in the New Models Taskforce study and provided some recommendations for transforming senior centers into $21^{\text {st }}$ century "wellness centers." The report highlighted the need for senior centers to include programs and facilities that address social, mental, and physical needs of participants, and to be designed to best fit the unique needs of their communities facilitate their communities' specific definitions of wellness.

As a way to advance the quality of senior centers nationwide, the NISC has developed nine standards of excellence for senior center operations, providing senior center staff a guide to improve their centers and position them for the future (see Appendix B). The NISC also offers the only National Senior Center Accreditation in the U.S., which provides official recognition of senior centers that meets the nine standards of excellence. Over 200 senior centers have been accredited. The accreditation status lasts for five years, at which time senior center staff are expected to revisit the accreditation process (NCOA, 2015b).

According to the NISC website, accreditation adds value to a senior center because it: results in national recognition; provides a written strategic plan; assists in determining outcome measurements; heightens awareness of the senior center activities in the community and among funders; improves and enhances the senior center's operations; highlights best practices, and is "endorsed by NCOA, which has more than 50 years of nonprofit experience with advocacy for the elderly” (NCOA, 2015c, para. 1). 
Implications. As this review of literature indicated, efforts are underway for communities and their senior centers to accommodate the aging of their populations. Leaders in places such as Portland, OR are exploring ways to engage and support different groups of older adults who are seeking relationships and environments that allow them to age with health and independence. Senior centers have provided benefits to older Americans for several decades as focal points offering socialization, recreation, services, opportunities, and other resources. Past research has demonstrated positive associations between senior center participation and wellness; questions remain, however, about the future of senior centers, especially those with limited funding and resources.

Relationships between senior centers' governance structures, funding, and their abilities to expand and add new programming have not been explored in past research. Much of the success of senior centers seems to hinge on their ability to provide ample transportation options, programming that is attractive and relevant to diverse groups, and generous marketing of the centers' offerings. The abilities of senior centers to provide such things vary depending on the financial and administrative support to them, however; centers that rely solely on either OAA funding or on donations are often limited in what they can provide compared to centers with stable funding from their governing entities.

The cases selected for this dissertation research varied in many ways, including governance, administration, funding, participant characteristics, community partnerships, transportation options, physical environments, and range of services and programs offered. The study was designed to highlight how these variations influenced the centers' challenges, experiences, and future directions. The information gleaned from reviewing 
literature suggested that each case would have a unique experience; for example, the senior center that had achieved national accreditation was predicted to have few challenges and many positive experiences compared to the other centers, and the senior center that are more reliant on OAA funding were predicted to have more challenges and constraints than the other centers in this study. The unique experiences of the senior centers were revealed through semi-structured interviews and focus groups that explored: the roles of these centers in their communities and in their participants' lives; who uses and who will continue to use the centers; if current and/or future challenges were perceived among the senior centers; and whether the centers seem to be adapting according to changing needs, interests, and circumstances. The following section discusses the research design and methods that were used for this multiple-case study of senior centers in the Portland metropolitan area. 


\section{Chapter Two: Research Design and Methods}

This research was a multiple-case study of urban senior centers located around the Portland metropolitan area. Using qualitative research methods, it was intended to examine the variations, challenges, constraints, strengths and successes of the centers as they attempt to meet the needs of a growing and increasingly diverse older population.

This research had four primary components:

- Exploration of five different centers, using data collected from staff members, senior center participants, observations, newsletters, and other primary site content at each center.

- Within-case analysis of characteristics, operations, and issues of each case to develop conceptual categories.

- Cross-case analysis of differences among categories and how these differences related to challenges, constraints, strengths, and/or successes for centers.

- Development of recommendations for how senior centers might capitalize on these opportunities and for how their communities might provide mechanisms of support to facilitate the continuation and contributions of senior centers in metropolitan areas. 


\section{Research Questions}

The following research questions were asked in order to determine the experiences and potential future directions of urban senior centers:

- What are the variations among urban senior centers?

- How are their differences related to their challenges and/or constraints?

- How are their differences related to their strengths, and what practices have led to their successes?

- How can urban senior centers be adaptive and supported in the future?

\section{Use of a Case Study Design}

This study used case study research as a methodology. As Berg (2007) explained, "The case study method is an extremely useful technique for researching relationships, behaviors, attitudes, motivations, and stressors in organizational settings (p. 296).” The case study provides a deep understanding of phenomena, events, people, or organizations (Berg, 2007, p. 285); it is a comprehensive strategy that involves the logic of design, data collection techniques, and certain approaches to data analysis (Yin, 2002, p. 14).

As a multiple-(or collective) case study, this research involved exploring an issue through multiple cases within a bounded system. Through detailed, in-depth data collection, it included multiple sources of information and produced descriptions and themes of each case. As Yin (2002) suggested, this collective case study design used the logic of replication; procedures were replicated for each case, with the understanding that findings could not be generalized from one case to another because of the different contexts of the cases (Creswell, 2007). 
The case study approach was deemed appropriate for this research, which sought to provide an in-depth understanding and comparison of several clearly identifiable cases. The cases were selected because they were representative of different types of senior centers located in an urban area. They showed different perspectives on an issue: challenges, experiences, and future directions of senior centers serving a metropolitan area. For analysis, the research used the typical format for case study research of providing detailed descriptions of each case and themes within each case, called withincase-analysis, followed by thematic analysis across cases, known as cross-case-analysis. In accordance with the general structure of a case study, details about the issues selected through analysis were followed by the researcher's assertions and conclusions based on the data (Creswell, 2007).

\section{Case Selection and Recruitment}

In order to inform the selection of a diverse cases for a multiple-case study analysis, online information was used to identify over 40 facilities or programs in the Portland metropolitan area that could be considered places designated for older adult programming. This broad definition of a facility as a senior center is consistent with the literature that attributes the term "senior center" to a wide range of diverse organizations (Fitzpatrick \& McCabe, 2008). Most of the facilities or programs in the list had programs operated by the regional Meals on Wheels People (MOW) organization, which was founded in 1969 and serves Multnomah and Washington counties in Oregon and Clark County in Washington. The organization provides delivered meals to homebound older adults as well as group dining at over 35 meal sites in the area, with the vision that 
“no senior shall go hungry or experience social isolation” (Meals on Wheels People, 2015).

For the purpose of this research, the two conceptual models of senior centers developed by Taietz, the social agency model and the voluntary organization model, were used to stratify the sample of senior centers in this study. As previously mentioned, the social agency model represents senior centers that are designed primarily for low-income and socially isolated older adults, whereas the voluntary organization model represents senior centers that are designed primarily for older adults who have more resources, are active in voluntary organizations, and who manifest strong attachments to their communities (Gelfand, 2006). Because information about the participants of the senior centers in this study was not yet known, the sample was stratified based on the type of programming available at the centers. By accessing information available on the websites of most of the centers identified in the region, two cases were selected to represent the social agency model, two others were selected to represent the voluntary organization model, and one was selected as a unique case; it represents a blend of the two models (see Table 1). As pointed out in the literature, because the cases are multi-purpose senior centers, they all depict overlap of the conceptual models (Pardasani, 2004). Nonetheless, they were carefully selected as cases that generally align with the models. The centers that fit the social agency model emphasize nutrition, case management, services, information and assistance as central to their programming; alternatively, the centers that fit the voluntary organization model emphasize recreation, activities, games, classes and socialization. The center that represents a blend of the voluntary organization and social agency models is also unique as it is the Portland metropolitan area's only nationally 
accredited senior center (i.e., it succeeded in meeting nine national standards set by the NISC; [NCOA, 2015b]).

\begin{tabular}{|c|c|c|c|c|c|}
\hline \multicolumn{6}{|c|}{$\begin{array}{l}\text { Table } 1 \\
\text { Selected Cases }\end{array}$} \\
\hline $\begin{array}{l}\text { Center/ } \\
\text { Case }\end{array}$ & Case \#1 & Case \#2 & Case \#3 & Case \#4 & Case \#5 \\
\hline Location & $\begin{array}{l}\text { City in } \\
\text { southwest } \\
\text { Portland } \\
\text { metropolitan } \\
\text { area }\end{array}$ & $\begin{array}{l}\text { City in eastern } \\
\text { Portland } \\
\text { metropolitan } \\
\text { area }\end{array}$ & $\begin{array}{l}\text { Central } \\
\text { Portland }\end{array}$ & $\begin{array}{l}\text { City in west } \\
\text { Portland } \\
\text { metropolitan } \\
\text { area }\end{array}$ & $\begin{array}{l}\text { Downtown } \\
\text { Portland }\end{array}$ \\
\hline $\begin{array}{l}\text { Basis for } \\
\text { selection }\end{array}$ & $\begin{array}{l}\text { Represented } \\
\text { blend of } \\
\text { models; } \\
\text { nationally } \\
\text { accredited }\end{array}$ & $\begin{array}{l}\text { Represented } \\
\text { voluntary } \\
\text { organization } \\
\text { model }\end{array}$ & $\begin{array}{l}\text { Represented } \\
\text { social agency } \\
\text { model }\end{array}$ & $\begin{array}{l}\text { Represented } \\
\text { voluntary } \\
\text { organization } \\
\text { model }\end{array}$ & $\begin{array}{l}\text { Represented } \\
\text { social agency } \\
\text { model }\end{array}$ \\
\hline Type & $\begin{array}{l}\text { Parks \& } \\
\text { Recreation } \\
\text { center (city- } \\
\text { funded); } \\
\text { designated } \\
\text { AAA focal } \\
\text { point; } \\
\text { no "senior" } \\
\text { in name; } \\
\text { MOW } \\
\text { offered }\end{array}$ & $\begin{array}{l}\text { Nonprofit; } \\
\text { located in } \\
\text { county } \\
\text { building (co- } \\
\text { located with } \\
\text { MOW site and } \\
\text { AAA office) }\end{array}$ & $\begin{array}{l}\text { Nonprofit; } \\
\text { designated } \\
\text { AAA focal } \\
\text { point; MOW } \\
\text { satellite site }\end{array}$ & $\begin{array}{l}\text { Parks \& } \\
\text { Recreation } \\
\text { center (city- } \\
\text { funded); } \\
\text { no “senior" } \\
\text { in name; } \\
\text { MOW } \\
\text { offered }\end{array}$ & $\begin{array}{l}\text { Partnership: } \\
\text { MOW and } \\
\text { AAA focal } \\
\text { point satellite } \\
\text { site; no } \\
\text { "senior" in } \\
\text { name }\end{array}$ \\
\hline
\end{tabular}

Two key informants were also recruited for this research through open calls. Key Informant \#1 is a former senior center staff member and is currently employed in aging services in Portland. Key Informant \#2 is a former senior center staff member and is currently employed in a long-term care setting in Portland. 


\section{Data Collection}

Prior to beginning the research, questions for the semi-structured interviews were developed based on challenges for senior centers identified in the literature and on the nine standards of excellence developed by the NISC. In order to understand some of the challenges, strengths, and future directions for senior centers’ operations, the researcher found it useful to ask general questions about each center's (1) purpose, (2) community, (3) governance, (4) administration, (5) program planning, (6), evaluation, (7) fiscal management, (8) records and reports, and (9) facility (NCOA, 2015b). Only one of the cases selected for this study had achieved national accreditation.

This research triangulated data concerning senior centers in the Portland metropolitan area from several perspectives, including (a) the views and expertise of staff members, (b) the views and experiences of senior center participants, and (c) the perspectives of experts who work in the aging services field. Semi-structured interviews and focus groups were both used, as each contributes uniquely to research. Focus groups allowed the researcher to observe interaction on a topic and capture opinions and responses that would not necessarily be the same in separate statements of the interviewees. Interviews, on the other hand, allowed a greater amount of control for the interviewer and a greater amount of information with the extensive time allowed in an interview (Morgan, 1997).

After this study was approved by PSU's Human Subjects Research Review Committee, online information was used to identify administrators and staff members at each case site, and semi-structured interviews were scheduled through open calls and invitations by email or by phone. The key informants, who are personal connections of 
the researcher and established aging services professionals in Portland, were invited to the interviews through invitations by email. Once potential interviewees agreed to participate, they received the interview protocol so they could choose to review the questions in advance. The date, time, and location were agreed upon for the interview. Upon the researcher's arrival, the interviewee was handed two copies of the formed of informed consent; one was signed and given to the researcher, and the other was kept by the interviewee. Two recorders were then turned on to record the interview.

A combination of recruitment through fliers and snowball sampling was used to identify senior center participants. The researcher coordinated with staff at each center to decide upon the date, time, and location for the focus group. This information was communicated to focus participants by staff or with a flier, along with refreshments and a gift card as incentives for participants. At the time the focus group was planned to begin, participants were handed two copies of the informed consent form; one copy was signed and given to the researcher, and the other was kept by the focus group participant. Participants were also asked to complete surveys, which provided the researcher additional information about the participants' demographics, interests, experiences, and expectations. After about 15-20 minutes, two recorders were turned on to record the focus group.

In total, this study included 20 interviewees and 31 focus group participants (Table 2). 


\begin{tabular}{|c|c|c|}
\hline \multicolumn{3}{|c|}{$\begin{array}{l}\text { Table } 2 \\
\text { Research Participants }\end{array}$} \\
\hline & $\begin{array}{l}\text { Interview } \\
\text { Participants }\end{array}$ & $\begin{array}{c}\text { Focus Group } \\
\text { Participants }\end{array}$ \\
\hline Case \#1 & 4 & 6 \\
\hline Case \#2 & 3 & 6 \\
\hline Case \#3 & 3 & 5 \\
\hline Case \#4 & 4 & 4 \\
\hline Case \#5 & 4 & 10 \\
\hline Key Informants & 2 & -- \\
\hline Total & 20 & 31 \\
\hline
\end{tabular}

\section{Data Analysis}

The interviews and focus groups for this study were recorded digitally with two recorders and transcribed using Olympus ${ }^{\circledR}$ DSS Standard Player. The surveys that were distributed to focus group participants were also analyzed, and open-ended responses were integrated into the qualitative data. This study also included archival material and primary site content, such as newsletters, brochures, online content, and some participant data that staff had collected at two of the sites.

The cross-platform program Dedoose ${ }^{\circledR}$ was used for coding and qualitative data analysis. As Charmaz (2006) explained, coding allows researchers to begin to define what is happening in their data and to grapple with what it means. Two phases of coding occurred: first, an initial phase, in which pre-determined categories were used to name segments of the data; second, a focused, selective phase to pinpoint and develop the most salient categories in those segments of data. Interviews and focus groups were coded on a case-by-case basis, followed by the interviews from experts in the aging services field. 
Throughout the coding process, memos were written to help clarify the themes and processes that developed from the codes. These were then explored and compared to other themes within each case. Common themes began to emerge among the cases, which were then analyzed across the cases. This process allowed the researcher to develop assertions and conclusions based on comparing the data with existing research and literature (Creswell, 2007). 


\section{Chapter Three: Findings}

Through exploring and analyzing data about the differences among the cases, and how these differences led to their challenges and strengths, four dominant themes emerged: participation and community engagement; administrative structure and funding; transportation and physical environment; and programming, activities, and services. This chapter presents each theme with case summaries in narrative format followed by summaries of the strengths and challenges identified among the cases. These summaries will also include data collected from the key informants.

\section{Part One: Participation and Community Engagement}

This section describes the participants who typically use the centers, how they use the centers, and how participants have changed over time. It also describes how the senior centers present themselves to and engage community members, and how they utilize and expand community partnerships to encourage participation.

Case \#1. This senior center, located in the southwest part of the Portland metropolitan area, represents a blend of the voluntary organization and social agency models as it offers a broad range of programming. It is a Parks and Recreation center and designated AAA focal point. Any person aged 50 years and older is eligible to participate in activities at this senior center and to receive human services at no cost. Participants can become members at different rates which depend on whether the participants are city residents or non-city residents. The senior center membership allows participants to receive discounts on classes, trips, and special activities, which range in cost from around ten to fifty dollars per session. Every participant must complete paperwork upon arrival (e.g., name, address, contact information). Recently, the center provided participants key 
tags to scan, ideally, every time they access the center. Many participants do not like this change and refuse to scan their key tags, one staff member explained.

According to staff, this center tends to attract participants who are intelligent, engaged, healthy and wealthy. They have "storied careers,” said one staff member. They range in ages from 50 to 100 years, with perhaps an average age in the mid-70s. Staff noted a recent shift to a younger participant base (which was verified by data that staff collected and provided to the researcher). One staff member, however, seemed disappointed in the recent inability to attract new members. She says that the change in membership is mostly associated with the natural attrition of older participants, but that the baby boomers are certainly coming.

Most participants live in close proximity to the center; occasionally participants will arrive from outside the city, depending on the activity. For example, participants who come for lunches usually take the shuttle, which can only be accessed if you live within city boundaries. Of any group of participants at one time, about $20-25 \%$ is from outside the city boundaries.

Participants are mostly Caucasian, though some are Asian, Hispanic, and Middle Eastern. "It's really white here...there's not a lot of diversity," explained one staff member. Generally not a lot of cultural issues get brought to staff's attention, though staff try to offer culturally-specific classes and programs, because many people are interested in and/or have experienced other cultures. The gender balance has been fairly consistent over time: about $70 \%$ of participants are women. Attempts to attract more men have not been very successful, staff explained. One staff member expressed the desire to see more LGBT diversity, pointing out that the center has tried to be inclusive by referring to 
different membership types as "single or double" rather than "single or couple," presumably to be inclusive of those who do not identify as traditional "couples." In some ways, she said, the area is very "60s" in terms of masculine and feminine roles, although there are openly LGBT participants who seem to be very satisfied at the center. Participants also have a range of different abilities. Staff have tried to ensure physical accessibility of the center and, if people volunteer information about having a disability, disorder or disease, staff keep this information in the center's confidential records.

One staff member explained that several participants lost a lot of income - or perceived they lost a lot of income - since the national recession in 2008, and have stopped traveling as much as before. Some programs, such as overnight trips, have become expensive. “Things are getting expensive and money’s getting tighter. If your $401 \mathrm{~K}$ and the market are not doing well, you know, you're going to be a little different in how you spend your money.” Older residents have downsized into smaller homes on one floor or moved out of the city because there is lack of affordable housing development in the area. “I don’t know if we're losing people, but I know people are moving because they can’t find reasonable housing," explained one staff member.

One staff member said that when she first came here, participants were a mixed group of some former stay-at-home moms, retired blue-collar workers, and some retired professionals such as college professors, lawyers or doctors. They came to the center looking for socialization, to keep in touch with friends, go on trips, and volunteer. They had a lot of free time and were still pretty young and healthy; large groups came for lunch because they were not working. Centers had big bazaars to raise money, because the participants made all kinds of crafts to sell. The staff member explained: 
And I think as our first wave of boomers are coming in, and those people, even 70-year-olds, are still working, so they're really not coming in for that kind of thing. They may be utilizing social services or human services in many different ways ... I've seen them if we have evening classes.

Staff discussed a wide range of interests and needs among participants. "The needs of 40-year-old caregivers differ from 70-year old caregivers and from 80-year-old people who exercise and 50-year-olds who do art." One of the challenges is for staff to try to categorize participants and create targeted programming for different groups, while also finding common ground for all the different generations.

Staff described participants who are homebound and aged around 80 years and older; participants who engage in activities and are in their 70s-80s, who come for the meals, companionship, and services; and participants who are younger and more physically fit and tend to view the center as an "adult" center. Some needs and interests cross generational lines, such as the need for caregiving resources. The center supports multi-generational families that may include, for example, participants who work and provide care for their parents, participants whose children have returned to live with them, or participants caring for their grandchildren. In some cases, three or more generations are living in the same household.

Most participants in the congregate meal program include older adults in their 70s-80s and occasionally younger adults with disabilities. As one staff member said, participants who come to the meal become like family: they sit at the same table each of the three weekdays, and worry about someone if (s)he does not show up. Groups sometimes participate in other activities together aside from the meal. 
Staff members speculated that the increases in delivered meals are related to rising incidents of debilitating, chronic conditions associated with older age. They also guessed that meal participants either prefer to stay at home or do not want to feel pressured to contribute to their meals. Some congregate program volunteers, even when asked by staff not to do so, have watched to see if participants "pay" for their meals, one staff member explained. Participants may feel uncomfortable about this, and they know that that if they get their meals delivered, they can contribute whatever they choose without judgment.

According to staff, one of the primary things that especially the younger senior center participants want is to volunteer, and the center's volunteers are an important component of its operations. These volunteers have participated by helping to promote the center and by managing the center's computer technology program, as examples. Volunteers tend to be over the age of fifty. Many of them volunteer throughout the year, though some leave for the winter (i.e., "snowbirds"). Interestingly, many of the older adult volunteers do not participate in the center's other activities, but they seem to want to be involved with the senior center by volunteering. One staff member explained, "We know that they want to volunteer, but they want meaningful volunteer positions." She has had difficulty placing them in volunteer roles at certain times. A lot of tasks are computer-based now, so volunteers need to be computer literate if they want to help with them. "It sounds like it wouldn't be a problem to have a lot of volunteers, but sometimes we haven't done the things we should have in making sure they get assignments right away.” This has led some eager volunteers to become discouraged or to feel like their help is not desired. 
Occasionally, staff explained, youth have come to participate at the center, particularly during the school year. They have volunteered for events and technology classes, and sometimes with parents. Staff members saw these as successful intergenerational activities. They also agreed that the center could not become a fully intergenerational community center. It is restricted by its size, and there is already an existing center in the community that invites a broad population of all ages. The city government had at one time attempted to convert the senior center to a community center in a new building, but this was controversial. Staff explained that the interests of different generations need to be considered; as an example that one staff member mentioned, a child running through the center after swimming lessons may present a falling risk for an older adult using a walker. Staff agreed that creating a community center would require a significant amount of planning and resources, and that current senior center participants value having their own building. It seemed, however, that staff realized the potential benefits of more intergenerational classes and activities either in the building or out in the community.

The national accreditation held by this senior center helped to improve the center's community recognition and engagement. The center had recently had an increase in membership and phone calls from people asking about the center after seeing it advertised in the newspaper. One staff member explained, "Certainly a lot of other good things happened out of that, but I think that was a motivating factor for staff. To be able to say, 'we're accredited now ... Recognize us! You might want to drop by."” The national accreditation brought validation from another source, a national organization, which staff thought the community would appreciate. 
The accreditation process was also a catalyst for remodeling the center. As another staff member explained:

It's like when you invite friends to come over to your house, you tend to straighten up things. Not to say things were a mess, but it just helped us focus on what we really needed to do that everybody should always do, and it made us look at our policies and our procedures and everything and really bring them into alignment.

She pointed out that the accreditation demonstrated that the center brings value and benefit to the older adults and their families, not only in the city, but to the broader area, and could be beneficial if staff decided to pursue grant funding.

The process of applying for senior center accreditation, according to staff, was a lot of work and was fairly stringent: “But that's what standards are for. They're something to aspire to. If you don't have somebody out there, some organization saying 'here's the ideal,' then...you're just average.” One of the factors that made it possible for this center to complete the accreditation process was the ability for staff to take on extra responsibilities, including attending several additional meetings. The center also had the funding from the city that was necessary to complete the process. Perhaps most importantly, the center had several passionate volunteers who served on the accreditation board, and they stayed on afterward to help the center continue to improve and prepare for re-accreditation. "We call them the 'A Team,'” said one staff member. Staff acknowledged that many senior center staff often feel overwhelmed and would not want to take on one more thing. "However, having said that, I would do it again,” one staff member said. "And we are ... because we have to every five years. The accreditation 
injected so much positive energy, ideas ... the community engagement that we were able to enjoy from that has been so worth what we had to do.”

Staff explained that one area the senior center has struggled with is marketing. The national accreditation evaluators wanted to see improvement in this area before the re-accreditation, so staff went to work on creating a marketing plan. The visibility of the center is part of the challenge, as it does not sit in a well-traveled area. The center also had a newsletter that seemed to reflect an older, less active participant base; it was a monthly issue that eventually transitioned to once every two months, until staff determined that they needed to create something to which the boomers would respond. As a result, they developed a new, magazine-like newsletter marketed to the 50-and-older population, with a much more vibrant look. Staff believe that the updated newsletter, along with the website and occasional newspaper articles, will help in terms of improving the visibility of the center and facilitating understanding of the center's purpose. The center also now has an insert in the newspaper that goes out to all city residents, whereas before it was targeting only its current membership base through mailings.

The center was evaluated especially well by the accreditors in terms of partnerships. This senior center has a number of strong partners that help to build its participation base and to provide some of its services. Partners have included healthbased organizations, residential facilities, the farmer's market, the local chamber of commerce, other senior centers in the county, and some nonprofit and/or advocacy organizations. These partnerships have been beneficial in terms of community engagement and have often alleviated staff responsibilities and financial burden when partners have sponsored events. Partners have also provided volunteer opportunities for 
senior center participants. Staff continue to search for opportunities to partner and do outreach activities. A recent fundraiser, one staff member said, led her to realize that the center needed to strengthen its relationship with businesses, and particularly with local hospitals and medical entities, including alternative medicine. She would also like to connect more with other senior centers: "We are all fairly siloed, and aging services are pretty fractured, and segmented, and siloed.” Another staff member said, "We will refer. I don't think we interact much as entities, but we do refer out." She explained that one challenge involves the fact that senior centers are so far apart from each other, geographically. "I think it would be a good partnership but it would require effort on both sides; and I don't know, in the long run, if the benefits would outweigh the effort. But I think it would be helpful."

Despite marketing improvements, many people are still unaware of the center, staff explained. One staff member said that some people just seemed misinformed about the center; they have a perception that the center serves the oldest-old population and primarily older adults who have low incomes. Through surveys conducted at the center, staff have learned that most participants learn about the center through word of mouth, and it usually takes a discrete event or need, such as for borrowing medical equipment, for them to actually come.

Staff also noted that many qualified older people refuse to participate. One staff member admitted:

I have no idea what other people want. We've talked about incentives to join the center...do people want discounts, do they want more services? I don’t know. 
People respond positively to surveys that we give them, and we actually do what they say they want; it hasn’t necessarily resulted in outcomes we want. Staff speculated that some people are just not looking for that kind of social contact, and some have moved out of the area because they could no longer afford to live in the city.

Staff acknowledged that many people will not come to the center because of their denial of aging. At the time of the interviews, one staff member was trying to promote a transitioning program which would allow participants to plan ahead for life changes or crises rather than waiting until they occur in to make decisions. She said that it is natural for people to avoid learning about these things, largely because aging is not celebrated, even in societies where it had traditionally been revered. "If anything, it's a youth culture and aging is something you want to avoid.” Another staff member remarked that when a crisis does happen, people seem to find the center; they knew it existed before, but didn't want to know until they needed it. “I think some of it is human nature; you don’t look for things until you're going to need it. And you just...you know, we struggle with that.”

Even after adding a fitness center and changing some of the publications, the younger age group is still not joining at the rate that was expected. Staff often hear older adults in the community say that the center is for "senior citizens;" they say, "it's not for me.” Many people will come and participate by volunteering, however. One staff member said that many volunteers will not participate in other ways at the center, because their perception is, “I'm not old enough to come here yet...but I'm going to participate and help.” She said that one volunteer had been helping with meals at the center until the age of 100, but he never stayed to use the center's amenities. When asked, 
“How come you don’t stay and have lunch?” he would respond, “Oh, I’m a volunteer; I'm not old enough to come here."

One staff member said that the center's current marketing focuses more on attracting the younger, healthier group of older adults. "I think it’s marketed as a place to come and retire and enjoy your peers,” she explained, admitting that it may sound "elitist," but that it has an appeal to certain people. "In terms of marketing the center, it’s a way to market it." This new way of marketing may be challenging to many of the center's participants who are opposed to change, but, as the staff member said, "You have to just push through. And be open to their comments and complaints but still continue.”

With regard to future participants, staff members seemed aware of the aging of the population and the influx of the boomer generation into the older demographic. They seemed to be looking at ways to reinvent the center and get some of the younger participants in the door. One staff member said, “I don’t know if anyone’s come up with a magic answer; I sometimes wonder if the senior center model is still viable.” Another staff member wondered about boomers' health compared to other generations. For example, she says, they were the first soccer kids and will come in with other issues with their bodies. She presumes that they will live longer, and their lives will be profoundly impacted by that athleticism in their younger years. Staff also seemed aware of increasing numbers of people with dementia.

Another staff member, who is a boomer herself, explained that her peers are still working and active and that expectations will be higher among them than previous generations for what centers will be offering. They may be using services and coming for 
referrals, but they are not going to be coming in for lunch or many of the daytime activities. She believes they may be looking for fitness and volunteer work.

\begin{tabular}{|c|c|}
\hline $\begin{array}{l}\text { Table } 3 \\
\text { Focus group \#1 Survey Responses }\end{array}$ & \\
\hline Total focus group participants & $\mathrm{n}=6$ \\
\hline Average age & 74.5 years \\
\hline Year first started coming to senior center & range: $1990-2010$ \\
\hline Living alone or with others & $50 \%$ live alone \\
\hline Male, female, or other & $50 \%$ male; $50 \%$ female \\
\hline Self-reported health status & $83.3 \%$ healthy; $16.6 \%$ somewhat healthy \\
\hline $\begin{array}{l}\text { Use a mobility device (e.g., cane, } \\
\text { wheelchair) }\end{array}$ & $0 \%$ yes \\
\hline Highest level of education completed & $\begin{array}{l}\text { Bachelors degree: }(n=2) \text {; Masters degree: } \\
(n=3) \text {; Advanced degree: }(n=1)\end{array}$ \\
\hline Self-reported race/ethnicity & 100\% White/Caucasian \\
\hline Primary language spoken in household & 100\% English \\
\hline $\begin{array}{l}\text { Rating of past \& current experiences at } \\
\text { senior center }\end{array}$ & 100\% “Excellent” \\
\hline Frequency of attendance (per year) & $(n=5)$ minimum: 40 times; mean: 97 times \\
\hline $\begin{array}{l}\text { Frequency of attendance of faith-based } \\
\text { organizations outside of center }\end{array}$ & $\begin{array}{l}16.6 \% \text { frequently; } 16.6 \% \text { sometimes; } 50 \% \\
\text { rarely; } 16.6 \% \text { never }\end{array}$ \\
\hline
\end{tabular}

Focus group participants (see Table 3) reflected much of what staff said about the senior center's participants. They appreciated the opportunities for active participation and engagement through the center. One male participant discussed his participation in a 
walking audit led by a local organization that allowed older adult volunteers to evaluate walking conditions in an area and report back to the city on what needed to be improved. He also discussed participating in the center's national accreditation process. "I feel like it's a focal point, so that people who are wanting to help, rather than receive, can come here and volunteer, and get things done that improve the city or help people.” He continued, "It gives you a chance to use your skills, I think. And I think that's what retirees want; they want to help. They're getting younger and healthier, I guess.” He said that what brought him here was the opportunity to volunteer.

Another male participant agreed, saying:

There's a tendency, I think, with this adult center - probably all centers - to see it as a place of taking. There's a very large percentage of people who want to give, in some fashion, whatever it might be. And they want the satisfaction, but they also want to see the effect it has on others. I think it's part of what makes a place like this really important, because it provides ways to give service for your community.

A female participant agreed that the center provides myriad volunteer opportunities: "I'm helping teach a tai chi class at the [building] and it's all-volunteer." One of the challenges that one participant mentioned is that there is not a volunteer coordinator for the center or for the city’s departments. Another said, "Even if it was just listed somewhere...maybe if we had a list of all the volunteer opportunities;”, this led another participant to offer to post the information on her blog. "Not only here, but other places with volunteer opportunities that are out there. I could create a page.” Another focus group participant said that she would like to help with this as well. Interestingly, 
the focus group had become a situation in which participants identified a problem and came to at least a partial solution for addressing it.

Focus group participants seemed in agreement that socialization is a key element and benefit of participating at the center. They discussed how social isolation becomes common for many people as they age, and how this center provides opportunities to socialize. It even has a program that allows participants to visit homebound older adults; "That's another wonderful service at this center. They just sit down and talk with them.” Another participant said, "I think that the ability to have a place to come to is really important. They need to come, is the thing. And some of them have such physical limitations that they would prefer to just stay in their home.”

Focus group participants discussed other reasons, besides physical limitations, that other older adults may not come to the center. One focus group participant suggested that people are working longer now than they traditionally have worked. Others alluded to the denial of aging. Some key quotes included:

- 'We need to think about mostly the ones who are going to be seniors. They're not now; they're still working, they don't think of themselves as someone who would get into that party. But they are, and they will.”

- "If you ask ten people, they’re going to say, “Oh it’s just for old people.”

- "Most people [think], 'Oh, they're 80 and 90 in there.’”

- "It's like, nobody wants to be a senior unless there's a discount, you know?" Issues around marketing were clearly seen as important factors for attracting new participants to the center. As one participant said, "I think it's this whole business of 
'How do you reach that group of people in some fashion? How do you let them know?” Part of it, another participant suggested, is the image of the senior center; he suggested that the center should try to depict younger, active participants in its marketing, "Because you've got to get other people thinking about this place.” Another participant suggested marketing the center as a place for "people who have grandkids.” Participants seemed to agree that the boomer generation would be inclined to use social media, so the center should focus on that as an outlet. They also agreed that individuals don't realize that when they retire, "that's when they're going to get busy," as one participant explained. Another said, “I couldn't lie anymore when my Medicare card came in the mail. And I thought, oh my god, I'm a senior citizen now! Time to start taking advantage; there's so many opportunities for us!”

Focus group participants agreed that the boomers will be increasing their attendance at this center and that the center will need to expand or somehow absorb this influx. The city seems to be in denial, one participant remarked. Another participant emphasized the need to recognize that the community is becoming more diverse. Other participants agreed, noting that there is already some ethnic and cultural diversity in the center, mostly in the meal program, and that diversity seems to be growing out in the community. "The community is changing,” one participant remarked. Others agreed, and one participant said, "That is a reflection of [the community]. Not extremely diverse, but maybe becoming a little more so.”

Case \#2. This senior center, located in the eastern part of the Portland metropolitan area, seemed to represent the voluntary organization model, as it offers only classes, games, and activities. It is a nonprofit organization renting space inside of a 
county building. There are no fees or requirements to participate at this center.

Participants are asked to fill out one sheet of paper with information about their emergency contacts and any medical issues about which the center should know. They are also asked for small donations for the classes, as the center has a nearly all-volunteer staff. Most participants pay to receive the newsletter, which many seem to think is a membership, said one volunteer staff member. Ideally, another staff member said, the center could advertise classes at no charge; some participants truly can only give their time as a donation, but as one staff member explained, the center always needs people who are willing to give both their time and money. Some activities, like sewing, also require participants to bring their own materials, which can be a challenge for some participants.

Staff agreed that, in general, participants are in their 70s and 80s, and that the center attracts people up to 100 years old. One staff member said, "There are people in here that take advantage of the community and group and of getting to know people that are anywhere from 50 to 90 plus.”

One staff person noted that health crises (for example, strokes, heart attack, and other illnesses) often occur at the center, and that the majority of participants live independently. She also noted that many of the city's residents, and many of the center's participants, have low incomes or are on or fixed incomes. There are some more affluent participants, and they usually come for the center's tai chi class. The center attracts some participants from assisted living facilities for special events, such as the weekly dance and special fundraisers, but most classes are attended by people who live independently in the community. 
Some staff members said that the center is diverse, mostly with regard to health, age, socioeconomic status, and ability. Once in a while, some Russian community members will participate. Participants with whom staff primarily interact, however, seem to be of a similar culture with similar values. The center also has very little engagement with the African American community and is not necessarily trying to reach out to or bring in people of different cultures; it will offer assistance, however, if a group or organization wants to reserve a room for an event and needs the center to sponsor the event.

One volunteer staff member discussed gender issues at the center, remarking, "We're just a bunch of old ladies who try to do something with our life and have a purpose in our life.” She said that the center would get about six regular male participants playing pool once or twice a week, and about ten to twelve to attend the weekly dance. Male participants generally are unwilling to help with the center as volunteers, however, even with setting up tables. The staff member suggested that perhaps men don't need the center; maybe they don't need the social activity that women feel they need. Perhaps fewer men are eligible participants because they don’t live as long as women. Some male participants are looking for a female partner at the center, perhaps having lost their wives, explained the staff member. She said men have actually told her, "I’m coming here looking for a woman,” and have not returned if they did not find a female partner.

Another entity in the building offers a weekday Parks and Recreation program that engages older adults with disabilities in doing crafts and activities. The program participants occasionally interact with senior center participants, but some of them have communication impairments that restrict their socialization with others. One staff 
member expressed frustration over the insistence of this program’s leaders on developing the interaction between the senior center participants and older adults with disabilities: “Some of them can’t speak ... [they] require an aide to take them to the bathroom ... I just think this is the wrong place for it ... I don't know many seniors who can adjust to that atmosphere.”

Many of the senior center participants have formed little cliques or groups over the years and generally participate in the same activities every week. For example, the weekly dance group mostly consists of older participants who enjoy dancing to Western music. Meanwhile, some of the younger participants have formed a Sock Hop group, as it has been difficult for them to associate with long-standing traditions such as the weekly Western dance group.

Staff explained that one of the main roles of the center is to provide volunteer opportunities for older people to remain involved in the community. The high level of volunteerism and generosity among participants was clearly a source of pride among staff. One staff member said:

Kind of challenging for me the first year I was here was figuring out who considers themselves a volunteer. Who's actually just taking a class and who is contributing as a volunteer? And so we ended up with - we've probably got 80 people to recognize for volunteer appreciation in the spring.

There is no volunteer coordinator for all of this; the center used to have one but now has a staff member who trains volunteer receptionists and a staff member who trains in the consignment shop. 
According to staff (most of whom are volunteers themselves), a lot is asked of the volunteers. There has been concern about ensuring that the volunteers feel valued and are given interesting, important work that will keep their attention and promote the center at the same time. They are expected to purchase tickets for and attend the center's fundraisers, over which there has been some disagreement; one staff member said that if volunteers didn’t pay for tickets to fundraisers, there would be no fundraisers; they would just be parties.

One staff member said that the volunteers work well together and can disagree without being disagreeable. She also thinks that the future level of participation will depend on the number and quality of the volunteers. Increasingly, more volunteers are asking, “What am I going to get?” For example, the travel department is getting pushback from volunteers who want to get paid to go on the trips as leaders. An ongoing challenge is finding and retaining committed volunteers. In any one week, two or three people who work at the front desk or in the shop are out for medical reasons, and some have passed away. Future programming is very much dependent on volunteers continuing and developing programming. If a new class is to be offered, a volunteer needs to get a base group of four to six people who want to participate. One of the benefits of the allvolunteer staff is that recent funding cuts had no effect on the operation of the senior center, and volunteers were not impacted by wage losses.

One staff member expressed interest in reaching out to the high school in the area, because she knew that some of the high school seniors are required to do outside community work as part of their graduation points or credits. She said, "They might be able to come in and help with some of the things that we have, that we put on.” For 
example, they could move tables and chairs, as they have done before; it's something that is needed. "One time they brought in boys from one of the churches ... if we had a group of people we could go to and say we need this help for this day to do this, it would be great.” Another staff member was interested in seeing more intergenerational activities rather than youth just coming to help with fundraising events. She mentioned that one of the things most important to older adults is for people to know their story while they're still here. An intergenerational activity could involve younger people interviewing senior center participants, and the center could record the interviews as part of the history of the senior center.

This senior center has no advertising budget, though it has a newsletter, a website, and occasionally distributes flyers, appears on cable access, and submits information in article format to local newspapers. As a primarily volunteer-run center, marketing is one of the areas on which staff are not able to spend a lot of time. The newsletter is free to people who come in to the building, but participants must pay an annual fee to have it mailed to them, so it doesn't reach many people beyond those who already come to the center. “It’s stayed pretty steady at about 200,” said one staff member. "We had a bulk mailing ... we mailed out 1,000 , and were having it printed somewhere ... it was costing a fortune, so we had to make a decision; and that's when we came up with the subscription.”

Senior center participants who make quilts also help advertise the center by selling them or auctioning them at events, such as the car club show. The website was still fairly new for the center, and the plan for its future maintenance was still undetermined. A lot of participants, staff explained, are attracted to the center by word of 
mouth or because a neighbor already comes. The collocation of the center with different services has been beneficial for getting people who walk through the building to come in and learn about the center. The center also recruits people who visit the consignment shop, which is staffed by senior center volunteers.

This senior center's staff consider the MOW and aging services organizations their partners, as they share the same building. The senior center has been successful in engaging long-term care facilities as partners because they want information about their facilities to be made available to senior center participants. The facilities often reach out to the center to partner on events and projects, which they do as part of their own promotion and which also helps to boost the center's participation numbers. They sponsor, for example, food for the fundraising events. The center does not sell advertising space in its newsletter, but it will include stories about participants living at one of the facilities or future projects on which the senior center is partnering with the facilities.

The senior center will also sponsor certain partners through events, such as classes from outside organizations, the Bridge group, or AARP tax aide. “And that's always a very busy time. And they can’t take donations; they can give us a donation, and we do get donations from people who come in and get that," one staff member explained. Other partners include churches, which will provide volunteers for events, and the Chamber of Commerce, although one staff member said that this partnership had fallen off over the past year. Staff said there could definitely be more involvement of the senior center in the community. "I don't think that the community in general sees us as community-involved. Not as much as we ought to be.” Another staff member said, 
“There are lots of ways in which we could be more integrated; that would probably require that community liaison person; [a new] position.”

Staff also acknowledged a lack of awareness of other senior centers, as illustrated through the following quotes: “I don't really know to answer the question of how this senior center is similar to others. I only know that there are senior centers who are sponsored by Parks and Recreation”; “With the other senior centers...I don't really know about them”; “To my knowledge, we have never been involved in any networking with any other senior center. Or any other facility”; “You know, I really can’t speak to that because I haven’t visited other senior centers, and I haven’t really had that much feedback from them.”

No staff members were aware of the national accreditation process. While reading the national accreditation standards, one staff member laughed: “'Staffed by qualified people. Paid and unpaid, capable of implementing its programming.' Well, that's a big statement right there!” Another explained that the center does meet some of the standards:

We keep good records and reports, we promote as much as we can within what we have. We do all of this, but a stand-alone entity? I don’t think we could qualify. I don’t think there’s anything wrong with it, but I just don’t think we are in a position where we could qualify to be there. Especially if it costs money. Another staff member agreed that the center could potentially meet nine standards, but she wasn't sure what the advantage would be for all of the work that is needed. “I didn’t know there was any such program available or what the benefit would be of doing that." 
Overall, staff agreed that the center is a pleasant place to come and that the participants get along well. The staff did not seem to have any ideas about things to add or do to encourage more people to come. "What we have seems to be doing it," one staff member said.

\begin{tabular}{|c|c|}
\hline $\begin{array}{l}\text { Table } 4 \\
\text { Focus group \#2 Survey Responses }\end{array}$ & \\
\hline Total focus group participants & $\mathrm{n}=6$ \\
\hline Average age & 73.8 years \\
\hline Year first started coming to senior center & range: 2002-2013 \\
\hline Living alone or with others & $66.6 \%$ live alone \\
\hline Male, female, or other & $100 \%$ female \\
\hline Self-reported health status & $\begin{array}{l}33.3 \% \text { healthy; } 50 \% \text { somewhat healthy; } \\
16.6 \% \text { unhealthy }\end{array}$ \\
\hline $\begin{array}{l}\text { Use a mobility device (e.g., cane, } \\
\text { wheelchair) }\end{array}$ & $33.3 \%$ yes \\
\hline Highest level of education completed & $\begin{array}{l}\text { High school diploma or GED: }(n=3) \text {; Some } \\
\text { college: }(n=3)\end{array}$ \\
\hline Self-reported race/ethnicity & 100\% White/Caucasian \\
\hline Primary language spoken in household & 100\% English \\
\hline $\begin{array}{l}\text { Rating of past \& current experiences at } \\
\text { senior center }\end{array}$ & 83.3\% “Excellent”; 16.6\% “Good” \\
\hline Frequency of attendance (per year) & $(\mathrm{n}=5)$ minimum: 12 times; mean: 37.5 times \\
\hline $\begin{array}{l}\text { Frequency of attendance of faith-based } \\
\text { organizations outside of center }\end{array}$ & $33.3 \%$ frequently; $66.6 \%$ rarely \\
\hline
\end{tabular}


The focus group participants (see Table 4) noted that as the boomer generation grows, centers will need more support to meet the needs of the older generation. One participant said, "I think that more programs are available that people could take advantage of if they knew about them, and it's probably going to get better and better, because there's more and more of us old people!” Another participant responded, “And we need the services!” They discussed how important it is for those who come here to continue to have access to the center, and that once people in the new generation of older adults find out about the center, they will start to show up. Another also surmised, "If they can afford it, I imagine a lot of them will be doing a lot of RVing... once they retire, that's a big thing."

A common theme that arose from participants' interests was the socialization aspect, as their interests have allowed them to make new friends at the center. As one participant said:

Once you've been here and made friends and connections, you can call somebody if you're at home and you're down, or you need maybe help with something, which you wouldn’t have otherwise. Because sometimes your family isn’t there to support you.

Most of the participants said that they came to the center to meet people, and some of them because they just moved to town or lost a spouse. One participant explained:

They're just trying to keep the doors open for what they have. And that's a shame. Because there's so many people, from death in the family to just getting older and wanting to be around friends, to whatever reason - [they are] new in town and 
don't know where to go - would love to be in a place like this! I can’t imagine not coming here or to another one someday. Because there are so many things you can do and people your age that understand, 'Hey, I had trouble sleeping last night; how about you?'

Another said, "We highly look forward to this day ... Everybody knows - never call me Thursday. It’s important for your health.”

One of the focus group participants said that she enjoys the occasional interactions with children when they come through the building. Regarding intergenerational programming, she said, "We've had older children come and play cards with us. But they're on a one-time basis, usually.” The others explained that although the senior center does not have an age requirement, all of the participants are going through several of the same things: "And we may want to discuss them and that may be very disgusting to younger kids.” They emphasized that they enjoy having a place where they can joke, play, and interact with other people with whom they share similar characteristics. "I think if you had different generations, that wouldn’t - they’d think, 'What a bunch of loonies!’”

Focus group participants also pointed out that there is little ethnic diversity, although there is some over at the meal site. Although at this center, one participant explained, “Everyone’s in a different economic stage in their life, and some people can’t afford it. We say, come anyway; we don't care! The main thing is to be here and be with us.” Another said, "The nice thing about this is, everything that's here, you can give a donation. You're not required to pay anything for the activities offered for the seniors. So it is affordable, if they can get here.” 
Marketing, according to focus group participants, could definitely be improved. One participant said, “I don’t think I've ever received anything from the senior center in my mail saying 'this is what we have to offer the seniors,' so I think that if they were able...it's probably the expense of doing it.” Another said that the senior center would probably have a better turnout all the time if it was better communicated or publicized. "I know for a fact that that's the reason they haven't: because they don't have the funding!"

Case \#3. This senior center, located in central Portland, seemed to represent the social agency model. It is a nonprofit organization and designated AAA focal point. This center has no requirements for participants to come into the center for meals or services, though participants are supposed to be aged 55 or older. There is an annual $\$ 20.00$ registration fee to become a member of the center, which includes access to all classes, programs, activities, and a mail subscription to the monthly newsletter. Donations are generally requested for classes, although Parks and Recreation classes that are offered at the center require their own fees.

Participant characteristics are widely varied at this senior center. The average age can be difficult to determine, according to staff, as there seems to be a wide range of ages. One staff member described the average age as "predominantly 60s and 70s, maybe, just because it tends to be easier for those folks to be mobile; maybe they have [fewer] restrictions on transportation.” Participants are predominantly Caucasian and around 65-70\% female. Most of them are independent, though participants' activity levels fall along a broad spectrum from frail to active. Many participants arrive alone; those who come with caregivers are in the minority. Most participants at the center tend to have lower incomes, according to staff. The center was initially established to serve a 
low-income population and still mainly attracts people from this demographic. If there had been a trend over the last few years, said one staff member, it was an influx of a younger age group, many of whom have disabilities and few resources. A lot of participants have been displaced from work much earlier than they had planned, and their ages (i.e., below 65 years) may not qualify them to collect Social Security. The center recently expanded its services to another area of Portland where staff are hoping to reach a more diverse, mostly low-income, population.

The location of the center is conducive to participants arriving by various modes of transportation from different parts of the city, which is increasingly important, staff noted, as older adults have faced difficulties staying in the area. The center tries to assist local residents by connecting them with home services, such as laundry assistance, so that they can continue to age in place. One staff member said, "I see us as a welcoming center. People are greeted right away; we'll all step up to let them know what's going on here. There's always a newsletter available so they find something that appeals to them.” Staff said that there is some diversity in culture and ethnicity at the center, but they are always looking at ways to make it more diverse. The center's community partnerships and foreign language classes, for example, provide opportunities for outreach and increasing diversity, and the center has been expanding and engaging the African American, Vietnamese, and Latino communities in the area.

One staff member said that when she looks at photographs from the 1970s and 1980s, participants were, on average, older - probably an average of 75-80 years of age. Traditional roles could be observed; for example, women would organize potlucks and put on fashion shows while men played pool. The center was originally developed as a 
drop-in day center for older adults in the neighborhood to come in, perhaps get a donut and a cup of coffee, socialize a little bit, and then move on. Now they often come for longer periods of time and for a variety of resources, including health and wellness. There is a lunch crowd that staff can depend on coming twice a week when lunch is served. Some participants just come in to socialize; the majority of participants come for a specific activity, and they come early and linger after that. Although most participants are retired, some of them are still working or looking for employment.

The socialization component at this center seems to be one of the primary benefits from participants, as demonstrated by these quotes from staff:

- 'I've noticed that the socialization among some of the regulars is really, very interesting.”

- “They'll have a cup of coffee. But they talk to people. I'm noticing that people have begun to talk to each other, and share an activity. It's getting out of isolation, which seniors seem to suffer from a lot. I've worked in the senior activities, and people in apartment buildings didn’t even know their neighbors because nobody came out of the apartments. And this is an opportunity to do that."

- “People look out for each other here. They notice if somebody hasn’t come on a certain day, or they notice if there's a person who's been absent for a while, or if a person has come and is having some difficulty in some fashion. They look out for each other and will say something to the staff or the case workers. So it's that kind of support system for people who come. They don't need to 
be alone, in whatever disability or whatever is happening to them. They just want to relate; so it’s the socializing."

While participants discontinue use of the center over time, primarily due to health issues, new participants are always joining the center such as those who just moved to the area. As one staff member explained, the participation always seems to be "replenished." “There’s definitely ongoing interest from new folks,” she stated.

Volunteerism has thrived at this center over the years. One staff member explained that there are always new participants stepping in to volunteer. A number of volunteers view their volunteerism as "work" and even come in on their "off-days" to socialize. Some have even volunteered in hopes that a paid position would open up at the center for which they can apply. They have helped serve lunches, teach classes, advocate for the center, and sit on the advisory committee, among other things.

There is some intergenerational programming at the center. For example, preschool children will occasionally come over to sing for participants, and youth volunteers help with classes, events, and the meal program. One staff member expressed concern about the city's focus on intergenerational programs and community centers, which does not include older adult-specific programming: "For our seniors that come to the center, many of them come here because they want to be surrounded by peers. And they're not comfortable going into a community center setting."

As the senior center has expanded to other parts of Portland, it is reaching new participants. One staff member explained, "We really are important to those who use us, and to those who might need us in the future. Everybody's going to get older. So it's just a matter of how we evolve and adapt to meet those changes." Staff expect to see more 
disabilities and dementia among participants and want to be able to address all types of changing needs. The center's advisory committee is composed of participants who volunteer and use the center on a regular basis. The contract actually requires the center to either have this committee or to have listening sessions, so the center has both. Staff feel it is an important group with whom to connect, as the members of the group have their "finger on the pulse" of the interests of older adults in the community. There is not currently a large presence of younger members on the advisory committee, which staff would like to see.

One staff member was familiar with the NCOA national accreditation, and said that the senior center had considered applying in the past. "It is standardization and best practices, and that's the way that many other things are going, so I could see it being a great feather in our cap," she explained. "It’s just a matter of prioritizing and time; we've been able to get this far without it, but it would be something for us to aim for.” She felt that the center probably met the nine standards already, and that the board could use the accreditation process to re-visit the center's past strategic plans and develop a strategic plan for the next five to ten years.

Another staff member said that she was aware of an accreditation process for information and assistance, though she was not aware of the senior center national accreditation. She felt that other centers would need it more, as this center is connected to a strong network as a result of its contract. "That has connected us more and really given us some of what that kind of accreditation would provide. If we were just on our own [like] other little centers ... it would benefit a stand-alone site like that.” Another staff member simply explained that money is a barrier, and the costs may outweigh the 
benefits. Because the center's reputation is already well-established, that sort of assessment, she believed, is probably not worthwhile.

Although the senior center has recognition in the community, staff seemed to agree that most people are unaware of the center’s scope of services and its impact. "I’d like to have it be where everybody just knows about what we do,” one staff member said. The new satellite site, meanwhile, may take time to raise awareness among the community, especially because it does not have the main site's familiar name.

Staff invest a significant amount of time and resources putting together a multiple-page newsletter each month, which is mailed out it to over 2,000 homes, apartment buildings, and businesses, as well as posted online. Case managers also bring the senior center newsletter to homebound participants during their visits. The senior center has an online presence through social media and its recently-updated website. It also advertises through articles in local newspapers, community events (e.g., health fairs, fundraisers), or through the county’s aging and disability resources network. "We're listed on the [county's] site but you have to dig around for it; it's not just right there,” one staff member explained. “It feels like the number’s right there, the way I get calls sometimes. But no, you have to scroll through several different names until you get to the senior district center list." Staff agreed that they would need more time and resources to increase the marketing efforts for this senior center.

One staff member explained that having the term "senior center” is often helpful to people who are looking for this particular center, because it is a traditional term. On the other hand, staff realize that the word "senior” is, for many people, a deterrent or has a negative image associated with it. "And so all around the country there are a lot of 
senior centers that are finding euphemisms and new ways to say what they are without really saying it,” one staff member explained. “And that's something that we're always looking at. Does that keep people from being involved?” Another said, “People do still have this image of a senior center, that you walk in and it's just Bingo and oxygen tanks. We have discussions about sex after 50 and dating; I mean, we're pretty progressive!” Another reason that older adults may not participate in the center's programs is that they may have communication impairments, disabilities, or diseases as dementia, which often create challenges for engaging. As one staff member described, “Then you start seeing that maybe you can’t even play Pinochle; people who used to be able to play Pinochle now get anxious about it because they can no longer do it.”

Older adults may also simply have different interests and not be attracted to the programming at the center. The boomers, in particular, seem to want to do different things, staff agreed. One staff member provided an example:

Someone was looking for a singing group, and we had the [Tunesters], but the [Tunesters] have a particular style of music; it’s older music, and I had an individual say, 'I want to sing some place, but I don’t want to be singing that old music!' So I think we have to pay attention to that.

One staff member, who is a boomer, said that her generation is most interested in travel, fitness, and volunteer opportunities. "It’s still a challenge to attract baby boomers, because we are a particular kind of generation, and we were always a little bit rebellious. We are taking care of ourselves better physically.” Staff have talked extensively about making the senior center appealing to the boomers; while they want to appeal and be 
ready to accommodate the younger generation, however, the core of the center's mission is still focused on the generation that is older.

The staff hold listening sessions to gain input on what works well at the center and what can be done better to support participants. They have occasionally seen some new people at these sessions who were unfamiliar with the senior center. Surveys have been sent out asking participants about how they use the center, what they would like to see, and how they can be better supported. “And the feedback ranges,” explained one staff member:

Everything from 'keep up the great work! Everything’s perfect!' to 'this center needs updating; it's not attractive-looking, and I don't want to be here, and there's no parking,' or 'I don't want to be here because there’s no one else who looks like me here, and I want to come to a center that is more reflective of my community.' So just really broad, and we use that when we plan for the coming years.

Staff discussed this senior center's highly-valued partnerships. One staff member discussed the center’s recent anniversary celebration, explaining, "I think that was a good example of how much we value partners and we're valued as partners. I think we're good partners. We really commit to a partnership and support our partners in any way we can.” She said that she would like to see more strategic partnerships moving forward to advance initiatives and build political support to better serve surrounding communities:

I'd also like to see us reach out to more organizations that are serving communities of color, and finding ways that we can partner. We struggle somewhat to serve the Latino population, so looking at how we do that - is it through the churches, is it through organizations? It makes no sense to start from 
scratch; I think it’s always better to find organizations that are already serving but could possibly benefit from partnering with us, because it's bringing in a whole new group and new resources.

This staff member also said that she would like to connect more nationally with other senior centers to see what they are doing, share resources, understand the policies affecting them, and work collaboratively to maintain the success of senior centers.

The senior center's current partners include a variety of health-based organizations, transportation agencies, other senior services, and some nonprofit and advocacy organizations. Staff partner with a job placement program, which supports participants in their job training and skills for them to find employment. The staff also participate in a number of resource fairs and community events, which is helpful for promoting the center's programs and services. "We definitely rely on those connections in order to be able to offer more to seniors,” one staff member said. Future partnering possibilities include co-locating with other services. The MOW satellite meal site, which is currently located within the center, has been a positive example of this type of arrangement. 


\begin{tabular}{|c|c|}
\hline $\begin{array}{l}\text { Table } 5 \\
\text { Focus group \#3 Survey Responses }\end{array}$ & \\
\hline Total Focus Group Participants & $\mathrm{n}=5$ \\
\hline Average age & 77.4 years \\
\hline Year first started coming to senior center & range: 2002-2012 \\
\hline Living alone or with others & $80 \%$ live alone \\
\hline Male, female, or other & $20 \%$ male, $80 \%$ female \\
\hline Self-reported health status & $100 \%$ healthy \\
\hline $\begin{array}{l}\text { Use a mobility device (e.g., cane, } \\
\text { wheelchair) }\end{array}$ & $40 \%$ yes \\
\hline Highest level of education completed & $\begin{array}{l}\text { High school or GED: }(n=1) \text {; some college: } \\
(n=1) \text {; Bachelors degree: }(n=3)\end{array}$ \\
\hline Self-reported race/ethnicity & 100\% White/Caucasian \\
\hline Primary language spoken in household & 100\% English \\
\hline $\begin{array}{l}\text { Rating of past \& current experiences at } \\
\text { senior center }\end{array}$ & 80\% “Excellent”; 20\%“Good” \\
\hline Frequency of attendance (per year) & minimum: 30 times; mean: 133.2 times \\
\hline $\begin{array}{l}\text { Frequency of attendance of faith-based } \\
\text { organizations outside of center }\end{array}$ & $20 \%$ frequently; $20 \%$ rarely; $60 \%$ never \\
\hline
\end{tabular}

Focus group participants (see Table 5) regarded the senior center highly, agreeing that it is "one of the best in the area." One participant said that she hears from other participants that the reason they come here, other than other centers, is because it is so friendly and inviting. 
A majority of the focus group regularly volunteered at the center. One shared, "I came in and said I wanted to volunteer, and this felt like home to me.” Another said, "I started volunteering here at the center in 2002, and I've done it all; I've done the desk, the gift shop, the thrift store; I'm here, easily, four days a week.” Jokingly, another participant exclaimed, “There’s some of us that people think live here!” Many of the center's participants volunteer as a way of giving back to the center. One focus group participant explained that she had received help with construction on her home, as well as legal aid, and was not asked for anything in return. Another said, "I thought it was a very busy, warm, welcoming center. And so when I retired, about a year or two ago, I thought I'd come here and volunteer. I just feel very comfortable here.” Another has volunteered since first coming to help in the MOW kitchen. "I also participate in one or two of the classes. And I also have been an advocate out in the public; [it's] pretty much a voluntary situation."

One focus group participant said she had been at the center before to play cards, and she just knew it was a nice place to come. "There were so many services here. There's a service here for just about everybody. And if they don't have the service, they try to find the service that they're in need for.” One of the focus group participants acknowledged that it’s sometimes difficult to schedule intergenerational activities, but when they occur, "It’s wonderful.”

Another participant said, "Socialization among some of the regulars is really very interesting." Participants answered affirmatively when asked if participants spend a lot of time at the center when they are not at home. Participants look out for each other and will say something to the staff if something seems awry: "So it's that kind of support system 
for people who come.” Participants agreed that the center is for people across the income spectrum:

You could be middle class, upper, and still be lonely, be isolated, and need this kind of activity and socialization. But people don’t view a senior center that way. They view it because they're either in a low-rent housing situation, or they're living on Social Security ... it's got a stigma, and you have to get out of that mindset.

Participants suggested that people also stigmatize the center based on its name: “They look upon a senior center as being 'old'; and they may be in our category, but they say 'Oops, if I start going there, then I'm 'old.’” Focus group participants said that the baby boomers, in particular, are in denial. “They don’t even think about that, because that's not in their radar screen. We'll think about it later.” One participant mentioned that some of the apartments that were being constructed near the center may include tenants who are boomers. She said, “I see that as a possibility of saying, 'Hey, look, we're here! Come on over! Participate! Be a part of this.'”

In order to attract the baby boomer population, focus group participants suggested changing the name from senior center to, perhaps, “social center.” They also acknowledged a need to add programming that would attract a younger group: "We need to look at that as saying 'Okay, guys, you're entering our realm now. Now how can you help? Because you're going to be here for a while!'” Marketing, they said, needs to be improved; "You really need to make a big splash to catch people's attention; when we did our [anniversary event], we really publicized, and we got good turnout,” said one participant. She said that attracting donors and supporters on an ongoing basis is critical. 
“There should be - I don’t know, I can’t explain it, but I have a sense of...just getting out there, and bursting through that barrier of silence, of unawareness!”

Case \#4. This senior center, located in the western part of the Portland metropolitan area, seemed to represent the voluntary organization model. It is a Parks and Recreation center with a heavy focus on recreation for older adults in the district. While there are no fees to come into this center, classes require different fees, ranging from under ten dollars to several hundred dollars. For health classes, staff require participants to have medical clearance and to provide their health history. As part of a Parks and Recreation District, this center's participants who live within the boundaries of the district pay through their property taxes. People outside of those boundaries are assessed a fee so that the prices are higher (they pay about $\$ 100.00$ more for a class). As one staff member explained, "It’s an in-district, out-of-district separation there." This fee structure can be cost-prohibitive, although older adults can still participate in the non-fee-based activities at the center (e.g., games, MOW lunch). One staff member said that if Out-ofDistrict (OD) policy was different, the center would have more people from surrounding areas: "We have a better program, but there are other programs out there."

One staff person said, "I would say the biggest challenge that I hear is the class pricing is going up. And up and up. So that's the biggest challenge that I hear, because they're on limited budgets." A consultant visited the center recently and told staff members that they needed to improve the center's cost recovery; as a result, the center's prices increased. Despite costs, however, the center has been having huge success, nearly filling its classes. Staff also provide scholarships, which are approximately $\$ 200.00$ for a year, for in-district users. 
Staff described the participants, and the center, as an active, positive, and fun place. One staff member explained that participants come because they want to keep moving; they greet each other in an upbeat way, and if they are not smiling when they walk in, they are most certainly smiling when they leave. People are happy to be there and may spend their entire day there. It's a part of their daily activities, their "home away from home.”

One staff member classified the participants at the center by age group (55-65, 6675, 76-85, and 86-95 years), acknowledging that programming reaches across all generations because people have diverse abilities at every age. Other staff members described the average age as maybe 65-75 years; some participants are closer to 55, as the center advertises that it is for people who are " 55 or better," and there are some people in their 90s. "We have a 94-year-old that is here playing pool every day, one of the most positive people you'd ever meet in your life,” said one staff member.

Another staff member described three groups at this senior center:

We have the 'go-gos': people that are out here, take a class, go out here, come in the fitness room. We have the 'slow-gos': they're still going, you know - maybe they do one class or just come for lunch. And then we have the 'no-gos': those are the people that just come in and sit on their butt all day and play cards. They get up once and they go to lunch. They sit.

Working with older people is no different than working with any other age group, one staff member explained. They just become even more of the way they have been their whole lives: “That's another statement I’ve used my whole career. People say, 'isn’t it hard to work with old people?' And I say, 'Why is it hard? It’s the way they’ve always 
been, only more-so."” Participants at this center have generally been social prior to coming to the center have been looking for social outlets. "I have this program where we go to lunch or dinner. It's kind of spendy, and these girls are all over 80 and lost their husbands. They're - like - ready to party! Because they haven't all of their lives,” this staff person explained. She has also spoken with people who want to bring a parent to the center, and they often tell her that the parent is fighting it "tooth and nail." She recommends to them that they visit the center together to see if it is a good fit. The center welcomes newcomers with a tour, an overview of the classes, and registration for people who have never joined the center.

Participants come to the senior center primarily from within the district for classes and from all over the metropolitan area for non-fee-based activities. According to staff, they often come to the center initially to try something new or to get in shape, but the social aspect becomes very important. They often have just moved to the area and find this center when they start to explore the community for activities, services, and socialization. Eventually, they get to form "family-like" relationships and use the center as a meeting place. They are concerned about each other; for example, if somebody doesn't show up to class, they want staff to try to contact them. "There are people who have driven by a dozen times and never come in. But once we get them in, they're usually returnees.”

There is some diversity at the center such as, for example, some LGBT participants. A Korean group of participants and a Spanish-speaking group of participants each come to the center for lunch. They don't usually communicate with others outside their group, but some will take classes during which they tend to interact more with other 
participants. Traditionally the district has been culturally homogenous compared to other cities, one staff member explained, and there are no culturally-specific community centers to which the center has been able to advertise itself. There are many different spoken languages in the district but not many interpreters. Some participants at the senior center have disabilities, and occasionally people bring caregivers with them.

One staff member said that the center has about 75 active volunteers who are all older adults and that many of them have been volunteering for several years. Staff explained that volunteers typically help with events, leading classes, or as part of the advisory board.

One staff member said that the district is looking for ways to increase intergenerational programming, and has tried to add classes at this center for people of all ages. Some of the center's events are intergenerational (for example, junior high school students and Girl Scouts come in during the holidays), and sometimes grandchildren come to visit. The center does not have ongoing intergenerational classes or programming, however. It does offer sports programming at local schools after hours, which has not worked out as well as staff would like. One staff member explained: "Because of the budget cuts with the school districts, the costs involved with lighting [are problematic]. And that's not prime time for seniors interested in engaging in fitness; their prime time is when they're [students are] in school!” She said it is important to have dedicated spaces for both.

Senior center staff, in general, seemed more opposed to than in support of adding intergenerational programming. One staff member explained: “I’ve heard some seniors say, 'I don’t want that...it’s going to change what we do here.' Another said: 
We are serving the senior population. And that I feel very strongly about, that we don't lose that balance between, 'Okay, we have to bring in this much money,' and what we're trying to do. A long time ago, they made the commitment that they did want to serve that population; I don’t want us to lose focus of that.

This staff member believes this center should remain a recreation center for older adults only. "We've got the disability program at night; if they want to grow that, grow that," she said. "But it's so safe here. People are very safe, and if you start mixing that, with kids running up and down the hall, it doesn't work.” She acknowledged the positive aspects of intergenerational programming and that it could be included in a different center but not this one. This is the only senior center in the district, while all other facilities are multi-generational. For truly intergenerational programming, there need to be staff members who understand older adult programming as well as youth programming and how to balance those two things. "So when they're designing the facility, that thought process has to be something to consider.”

The center has been attracting more participants over the last several years, many of whom are baby boomers who seem more aware of their health and proactive about preserving it compared to previous participants. One staff member explained that she had been talking about the boomer generation a decade ago and had wondered how to get boomers interested in the center. "If you build it, they will come. Depending on your classes, what you're offering; get the word out. They just have to all stop working; it's still a slow start.” Many of the older boomers who have been turning 65 are still working, so they have tried a few things on evenings and weekends. Another staff member said, "I think it's much more active here than it used to be; much more active.” 
Staff said they are always trying to figure out what they can improve and add to the center to make it appealing to a broad spectrum of older participants. Staff had not recently surveyed participants, though they are always soliciting feedback and comments. They also engage and learn perspectives of the volunteers who comprise the advisory board.

One staff member was aware of the NCOA's standardization and accreditation process for senior centers, though she did not seem interested in it for this center. She said that the process is important for centers going after grant funding, which this center does not need. Perhaps staff would be interested in the future, however, she explained. Another staff member said that the center does not have a strategic plan, with which the accreditation can help, but that the center is doing well without it. "I measure growth in each area; obviously I take statistics on which populations we have attending. So I know who’s coming. I think we're doing a pretty decent job.” She does not believe staff would have time to go through the process of accreditation, and besides, she also believes that the center does not need the recognition or funding like other centers probably need. She agreed that she did not know how accreditation would benefit this center, specifically. A third staff member also agreed that the senior center is doing well without the accreditation. She said she will go to conferences and find out what other centers are doing to see if this center is missing anything, but as she explained, "We're still looking at ours as a model.”

The district, which has a communications department, was in the process of hiring someone for marketing. Staff at the senior center were enthusiastic about the need for this. The center currently has a page on the district website, though it is not appealing, 
especially for older adults, or easy to navigate. The center has a social media presence and newsletters that get mailed out electronically with the activities guide. Physical copies of the activities guide are available to participants for $\$ 5.00$. The center's new mobile fitness vehicle could be another advertising possibility. Word of mouth seems to be a large part of how participants learn about the center.

The center has improved in its ability to attract participants particularly, according to staff, because of the quality of its programming and instructors. Community members are often pleasantly surprised to learn about what is offered at the center. Some people, one staff member explained, are coming in and looking at the center for their parents, and realize, “Oh my gosh; this is for me!” She said they think of it as the traditional senior center and are surprised by what it offers. 'It’s like, ‘Oh, it’s a senior center. There won’t be anything for me there.' But once they come in and visit - bring their parents in - they go, 'Oh, I could take that with you!’”

Staff mentioned several reasons that qualified older adults may not be participating in this center. One staff member explained, “Older adults have a lot of choices right now, just like you do. Some people are busy once they retire. They're busy in their churches or their social clubs, garden clubs, etc. They just haven’t had time.” Another suggested that transportation is a problem, largely because existing options may be inconvenient. Sometimes, staff explained, people are just not social; others mentioned that the prices may be a barrier. Another simply said, “I don’t know why people aren’t coming except that they just don’t want to.”

A main reason for not participating in the center, staff speculated, could be that they just don't understand what kind of center it is. If they hear the term "senior center," 
they don't have a clear understanding of what is happening at this particular center. This senior center does not, actually, even have the word "senior" in its name; one staff member pointed out that this creates a challenge, because people do not recognize it as a place for older adults. "So it's getting the word out, or adding or changing the name a little bit to have a positive spin for the older population.” When asked what possible name the center could use, she struggled to determine an answer; "It's kind of hard to come up with a name...you know, you don’t want to say “aging”; what can you come up with that has a positive spin?”

Staff seemed to agree that the term "senior center" is stigmatized and problematic. "We use seniors in quotes, just because," one staff member said. Another said, “I feel it’s a grand kind of knowledge that senior centers aren't respected on the same level as allage centers. I think they think it’s just basket weaving and coddling old people.” The center used to have the word "leisure" in its title and changed this in an attempt to rebrand and stay modern. "I think, in our respect, it’s more of a community center. I mean, yeah, it's 55 and over, but the diversity of things that we offer is much more, I think, than most senior centers that you'll go into," one staff member explained. Another said:

For some people, it will always be a senior center. It’s just the nature of the beast. If they refuse to come into the building, then we can't change that. Once they come in, though...I don't know if you feel it when you walk in, but it's pretty vibrant. People are active. It doesn’t feel like anyone's walking around in their walkers; people are moving and grooving and doing what they want to do. So it's a lot different than what you have in your minds when you think of a senior 
center. So killing those stereotypes and that ageism is what I hope we will get to in the future.

This senior center has some key partnerships that have added to its overall success. For example, the center partners with other entities in Parks and Recreation to share ideas, trends, and anything to improve their programs. Staff have also connected with some other local senior centers, churches, and retirement communities to build the center's participation and community presence. One of the senior center's advisory board members sits on the city’s advisory board, serving as a liaison. Most partnerships with community organizations help staff connect senior center participants with social services and supports that they might need. One staff member said, "I think it's a good relationship that way. People know they can come here and find out about things they want to find out about. Or get help if they need help.”

Staff could not think of additional partnerships that would be beneficial to the center. "I think networking and finding what works and what doesn’t work...I think the networking is beneficial,” one staff member said. "For us, it’s not required, because we have incredible funding. But it always helps. So for people who are willing to sponsor an event, it’s always helpful. It always adds a little extra.” 


\begin{tabular}{|c|c|}
\hline $\begin{array}{l}\text { Table } 6 \\
\text { Focus group \#4 Survey Responses }\end{array}$ & \\
\hline Total focus group participants & $\mathrm{n}=4$ \\
\hline Average age & 76.25 years \\
\hline Year first started coming to senior center & range: 2002-2012 \\
\hline Living alone or with others & $25 \%$ live alone \\
\hline Male, female, or other & $50 \%$ male; $50 \%$ female \\
\hline Self-reported health status & 75\% healthy; 25\% somewhat healthy \\
\hline $\begin{array}{l}\text { Use a mobility device (e.g., cane, } \\
\text { wheelchair) }\end{array}$ & $25 \%$ yes \\
\hline Highest level of education completed & $\begin{array}{l}\text { High school or GED: }(n=1) \text {; Associates } \\
\text { degree: }(n=1) \text {; Bachelors degree: }(n=1) \text {; } \\
\text { Masters degree: }(n=1)\end{array}$ \\
\hline Self-reported race/ethnicity & 100\% White/Caucasian \\
\hline Primary language spoken in household & 100\% English \\
\hline $\begin{array}{l}\text { Rating of past \& current experiences at } \\
\text { senior center }\end{array}$ & 50\% “Excellent”; 50\% “Good” \\
\hline Frequency of attendance (per year) & minimum: 50 times; mean: 121.4 times \\
\hline $\begin{array}{l}\text { Frequency of attendance of faith-based } \\
\text { organizations outside of center }\end{array}$ & $50 \%$ frequently; $50 \%$ never \\
\hline
\end{tabular}

Focus group participants (see Table 6) had a few different reasons for initially participating at this senior center. One participant said she had just moved from out-ofstate, so the first thing she did was try to find a church and a senior center: "Both places are very excellent. It has helped me meet new people and to have all kinds of things to do 
and a variety of things to do and new people to meet. I've really, really enjoyed the center.”

Another participant said that he and his wife had volunteered to help serve meals through Meals on Wheels (MOW) all around town but had never considered going to a senior center. He said he thought, “I don’t know if I even really want to go there; it’s kind of...no, I’m not interested.” But then, he says, he was "blown away” when he came by: “It had lots of services that I really enjoy, like they're tailor-made for me. I enjoy the social interaction and I enjoy the services they provide. And so it's become like a home away from home for me.” Another focus group participant arrived with her husband, and they started volunteering. This led them to taking classes and participating in other activities at the senior center. Another participant first came for the physical fitness and now mostly comes for MOW.

Socialization seemed to be the most important theme for focus group participants. They discussed the benefits of meeting and interacting with other participants. One said, “I enjoy the social interaction, and I enjoy the services they provide." Another theme that arose during the discussion was the variety of programming offered at this center. One person said, "Whatever you want to do, [there are] all kinds of things to do and a variety of things to do, and new people to meet.” Another said, “I was surprised at the variety of things that they have here.”

One focus group participant, who has previous experience in gerontology, said that she came to the center as a way to apply her expertise and as a social outlet: "A way to keep my foot in the work domain, but also a way to entertain and interact with new 
friends.” Other participants said that the center provides numerous opportunities for volunteering and giving back, which they really appreciate.

Focus group participants were enthusiastic, compared to staff, about the amount of diversity among participants at the center and about the interactions they have had with the other cultural groups. They also noted the large number of male participants at this center. One focus group participant said that older adults with disabilities come to the center on certain evenings, admitting, "I find it disorienting, all the chaos. That's why I say - and some people I think would - if there was a lot of that, especially during peak hours, a lot of people would stop coming."

One focus group participant said:

I really like seeing the kids outside. We don't interact directly with the kids, but seeing them parade across all the time feels good. Just having them near like that; some mixing; if they were running around inside with people with walkers and things, that would be totally inappropriate. But this is good.

With regard to people who don't come to this senior center, one focus group participant said, “This type of thing isn't for everybody. Some people aren't interested in coming to a place like this. I have a friend who doesn't like to be with a lot of people and crowds.” Another participant said, "They don’t want to be with the old people.” Accessibility and expense were also mentioned. Focus group participants agreed that many of the classes are too expensive for many people, from both in- and out-of-district, who may be interested in taking them. One participant expressed frustration because she previously lived one block from the district boundary and had to pay the out-of-district fees. 
Two of the focus group participants said that they prefer this center over any other center because it is so nice; one said that, because of how well the center is funded, it attracts a different population compared to other centers: "They get no funding; [so it’s] a different population there.”

Case \#5. This senior center, located in downtown Portland, seemed to represent the social agency model. It is a partnership of a MOW meal site and of a social services organization, and draws participants who are generally interested in accessing one of the two organizations. To access the social services at the center, participants need to be registered clients. "When people first decide they want to be a part of this little community here, they'll come in and register and they fill out paperwork," explained a staff person. Staff record participants' meals for reporting to the county, and also keep information on participants for future assistance or emergencies.

The social services are generally available to anyone, for a variety of reasons. For example, if a person requires assistance to pay the electric bill, the agency may be able to take care of it. MOW is intended for people aged 60 and over; it has exceptions, however:

[We have] Medicaid patients who are under 60. We have clients in their 40s who are getting the meals. The youngest client I've ever had was 28 . He had just gotten out of the hospital. He was living at the [Name] Building downtown, and they have a re-cupe program there where they can live in the [Name], and they check up on them as they're recuperating from surgery. And this kid - it was great to get to serve him.

The social service clients are, on average, around 70 years of age, and up into their 80s and90s. Because social services staff are not present at the center full time, they 
each see only some of the participants who come in for services, and they spend very little time interacting with people who are only MOW participants.

One staff member explained that this center has a large responsibility as one of the largest MOW centers in the metropolitan area and as the only one that operates all seven days of the week:

There's a smaller, more condensed demographic in downtown Portland, and there's a large variation in downtown Portland, because we have such extremes with everything - with the income, poverty, demographics of men and women even. Gender is huge here. There are more men in downtown Portland than there are women, so that alone makes us very unique.

Staff emphasized the uniquely large male presence at this center, with participants being about $85 \%$ male, and an all-female staff. Some staff mentioned that participants can have mental illnesses such as Post Traumatic Stress Disorder, and staff expressed that working in this environment can be somewhat challenging. "The only time we expel someone is if they use foul language a lot,” one staff member explained; "Or there was one guy who was passing out pornographic stuff and harassing women, that kind of thing." Other incidents, such as participants drinking cough syrup or liquor with their meals, were mentioned as well.

One staff member said that she believes the center was originally intended for middle-class retirees, though staff do not see that group coming to this type of place. Increasingly, this center's participants are transient, homeless, or have very low incomes. A point of contention among staff relates to the center's purpose and identity. One staff member said she would like the center to be a more open, inviting place, explaining that 
every participant has different needs and expectations, and whether they are coming for the meal, services or classes, the majority of them just want to see a smiling face and staff who are friendly and hospitable. Other staff had a different point of view. One stated: We're a senior center; we serve lunch. And we're not here to supply a place for homeless people to drop down their stuff and plant themselves all day, and just sleep. There were people coming in and sleeping, for hours and hours, and we just put a stop to that.

This center has its "regulars" who really love this place; it’s hard to get them to go home, according to staff. They select their own place to sit and always return to that one place; they claim it. Many participants live close enough to walk to the center; some even live on the same block. Others arrive by public transportation or by getting dropped off; they rarely drive themselves. A small number of participants live far from the center and tend to come primarily for social reasons; they prefer it to other senior centers in the areas, or perhaps they used to live in this center's neighborhood, and they enjoy visiting with the participants whom they know.

Staff acknowledged the high level of diversity at the center. One staff member said that she has known participants with all different educational levels, backgrounds, and professions. Another said that nearly 15\% of participants are non-white (e.g., Asian, Cuban, Russian, Hispanic, Native American). The center used to have a satellite site with a Native American rehabilitation organization, but that dissolved for reasons unknown to the staff member.

Volunteers and interns have been essential to the operations of the MOW organization, particularly at this center. One staff member said that she has been so 
fortunate, because she doesn’t even really have to recruit. “People just walk in off the street and go, 'I'd really like to volunteer here.' And I can tell just by looking at them, 'Perfect.' And know exactly where to put them.” Part of this, she speculated, is because volunteerism in Portland is very popular. “It's like, if you're not volunteering, you're just not trendy enough. You're not hip enough.” The organization attracts volunteers of all ages and backgrounds, from college students, to corporate employees, to service clubs. The center generally has eight volunteer job positions. The main challenge, explained one staff member, is that volunteers tend to leave after three to six months, so staff sometimes rely on people who have been sentenced to community service to fill certain positions. The staff member explained that, despite the benefits of volunteers, hiring additional staff would be most beneficial to the center.

Staff have seen an increase in younger (boomer) participants, and they have noted the different interests, needs, and desires associated with this group. For many of them, one staff member explained, “Their whole livelihood has changed dramatically; they’ve lost everything. So they're looking for more of a handout.” She said that these people, who are "falling between the cracks," need many of the services offered by this center: We see a lot of people with drinking problems and drug problems who have lived high-end lifestyles and suddenly find themselves - either due to mental disabilities or addiction issues - their lives have spiraled down, and they're in this situation. It’s like they're totally bewildered and lost.

Some of these people, who had been accustomed to higher-end lifestyles, are too proud to use the services provided at the center. A staff member described one MOW 
participant saying, “She wouldn’t take MOW because she considered it a charity and was too proud to take it. But she was going through this thing where she needed the help.”

The MOW organization is looking ahead and trying to find innovative ways to meet the needs of older adults. It may, for example, start serving dinner, or handing out pre-packaged foods that people can take home and heat up themselves, explained one staff member. "With the boomers aging, it’s just going to keep...it's going to be booming for sure! Already we’ve had lines outside into the street.” She also sees long lines of people waiting for services at other organizations that are specifically intended for the homeless population.

Staff at this center were not aware of the NCOA standardization and accreditation process for senior centers. One staff member explained that this center follows the strict guidelines and procedures of its contract, maintaining high and consistent quality, but she didn’t know about accreditation. Another simply said, “I’m not really up to speed on it,” but felt that for this center, it would be a challenge.

At the time of this research, staff said that this senior center is nearly full to capacity. Staff do their best to introduce new participants to the center, but they also try to direct participants to other organizations, especially if they are more appropriate for the participants’ needs. Staff also to try to get MOW participants to access services through the center’s social services organization. "It's spreading the word. And sometimes you get a lot of those folks that are just one-time shots in here.”

The social services organization has a monthly newsletter that is mailed out physically and electronically. Mostly, the center is marketed through outreach to different apartment buildings and resident service coordinators in the surrounding neighborhood. 
Half of the battle, staff explained, is the initial introduction and trying to get new participants scheduled for appointments. A staff member also explained that, for certain services:

It is just that fear of making the first step out to go someplace where they might not know anyone; you just get in a rut, and it's hard for a person to get out of the house once they've hit that point. Or they socialize within their own building. Many of the surrounding apartment buildings have their own programming, so a resident may not feel they need to leave unless they need the meal program here: “Or if they need to use the computer, but many of the buildings have computers available to their residents as well, so they don't necessarily need to come down here to use a computer.”

Staff hold presentations at resident meetings and post flyers on bulletin boards inside apartment buildings about their services (e.g., senior law appointments). "We'll even have folks who come in and say, 'my neighbor told me that you could help me with this,'” one staff member explained. "We get folks in a lot of different ways; word of mouth is definitely one; we'll have them pull something off the bulletin board, bring it in, and say, 'can I get a copy of this for myself?’”

One staff member said that the image she wants this center to project is that it is a safe place where people are treated with respect and dignity; “They wouldn’t have gotten it from their family or others." She wants the center to offer good customer service even for people who just come in to drink coffee. She struggles with how to distinguish it as a senior center rather than a day center, explaining, "If you're 60 years old you have the 
right to be here. This is your place; this is your center. Some of those people will bring in their stuff because they have nowhere else to put it.”

Staff seemed to agree that people with higher incomes will not be coming to the center. They have come for certain activities offered at the center through Parks and Recreation, such as yoga, aerobics, and Qigong, but they generally do not come to socialize. Staff acknowledged that many people will probably not come to the center because they don't want to be around a lot of the current participants who have not recently bathed or who may exhibit unusual behavior. "You never know if you're sitting next to someone who's just going to go off on you all of a sudden and start yelling at you, which happens."

One staff member said she would like participants to take ownership of the center and to really engage in other activities besides just the meals, puzzles and books, but that many of these activities have been "epic failures." Her vision for the center, she said, is to “create and build client participation through client ownership and providing welcoming interaction, and to create positive environments.”

The shifts in management at the center have created challenges with regard to community outreach and building new, sustaining partnerships. Staff had been able to refer to other organizations, mostly through the center's social services component. The center sometimes partners with organizations for transportation or fundraising opportunities, for example. “There’s definitely room for growth. You can only connect with somebody on a short period of time,” one staff member said. “Just doing one little event, you only have like four emails back and forth, versus a year, when you're dependent on that person and there's some trust involved.” This staff member said that 
the senior center will be focusing on growing partnerships with a variety of businesses, churches, community organizations, and other agencies.

\begin{tabular}{|c|c|}
\hline $\begin{array}{l}\text { Table } 7 \\
\text { Focus group \#5 Survey Responses }\end{array}$ & \\
\hline Total focus group participants & $\mathrm{n}=10$ \\
\hline Average age & 69.9 years \\
\hline Year first started coming to senior center & range: 2003-2014 \\
\hline Living alone or with others & $100 \%$ live alone \\
\hline Male, female, or other & $70 \%$ male; $20 \%$ female; $10 \%$ other \\
\hline Self-reported health status & $\begin{array}{l}50 \% \text { healthy; } 10 \% \text { somewhat healthy; } \\
30 \% \text { somewhat unhealthy; } 10 \% \text { refused to } \\
\text { answer }\end{array}$ \\
\hline $\begin{array}{l}\text { Use a mobility device (e.g., cane, } \\
\text { wheelchair) }\end{array}$ & $20 \%$ yes \\
\hline Highest level of education completed & $\begin{array}{l}\text { Some high school or less: }(n=1) \text {; High } \\
\text { school or GED: }(n=1) \text {; Some college: } \\
(n=2) \text {; Trade or vocational school: }(n=2) ; \\
\text { Bachelors degree: ( } n=2) \text {; Masters degree: } \\
(n=1) \text { (“two years toward Ph.D”); no } \\
\text { response ( } n=1)\end{array}$ \\
\hline Self-reported race/ethnicity & 100\% White/Caucasian \\
\hline Primary language spoken in household & 100\% English \\
\hline $\begin{array}{l}\text { Rating of past \& current experiences at } \\
\text { senior center }\end{array}$ & 50\% “Excellent”; 50\% “Good” \\
\hline Frequency of attendance (per year) & minimum: 75 times; mean: 254 times \\
\hline $\begin{array}{l}\text { Frequency of attendance of faith-based } \\
\text { organizations outside of center }\end{array}$ & $22 \%$ frequently; $44 \%$ rarely; 33\% never \\
\hline
\end{tabular}


During the focus group session, participants (see Table 7) made several comments that illustrated the affinity they feel toward the center and the socialization it affords. What follows are samples of participants’ responses:

- "It's just a sense of belonging that makes me feel good. After I got robbed a couple times I slept on park benches in the pouring rain; I was really outraged because there are supposed to be laws protecting aging and disabled people.”

- "There are people here that care about other people."

- "Who bad-mouthed our place? Is someone saying nasty things about the center?”

- "I feel like I’m with family when I’m here.”

- "And the people treat each other with respect, male and female, once you understand you're in the same boat. It's really nice and really mellow, male and female; they're super nice people. Nobody gets out alive.”

- “We can’t complain one bit!”

Some participants had been coming to this center when it was a meal site at a different location. Others explained that they were homeless or in transition to finding housing. Some simply expressed their feelings about getting older:

- "My perspective at 67 is a lot different than it was at 62 . There are things I want to finish, whereas before there were things I had that I wanted to start.”

- "We [boomers] were spoiled rotten. We took a large - in a certain sense - we took the largest prosperity in the history of man and we turned it into the 
Beatles, and Don Henley and the Eagles, a little bit of Rock and Roll, a little bit of poetry."

- "If you work for minimum wage your entire life, it’s kind of like retirement. It's your turn; you're supposed to be able to get to do what you want to do.” When asked about the diversity at the senior center, one focus group participant responded, “A lot of diversity.” Another said: "But it isn’t diversity so much in the programs as in the different kinds of folks that come here. No one makes a big deal about it, really, which is good.” Another said: "There's not a lot of invidious comparison here.” One participant emphasized that, judging from the people he sees every day:

This is not a representative core; it's just a small sample. You need many different aspects - positive and negative. There are so many different people here that act in remarkable ways, if you catch them at the right time. You might learn more coming here anonymously. Sometimes you learn more when you don't ask a question than if you do, if you just come and hang, or pop in.

Participants agreed that this senior center has drawn more participants who have mental illness, including dementia, as well as more participants who are homeless and from other parts of town. One participant said that staff handle the overcrowding very well; when he arrives, everyone is already seated.

When asked about their thoughts on reasons that other older adults may not come to the center, participants suggested that they may not feel comfortable or trust government organizations. "Some people might be self-conscious about not being able to afford a meal,” one participant offered. Another said, "Maybe they're not old enough. If 
you're under 60 , you need to pay $\$ 6.00$ for a meal. They’re more strict about people who are under 60 than over 60.”

Strengths. As one of the staff members remarked in an interview, centers are unique based on their location and on the communities that they serve. "Centers are reflective of the community they serve," she explained. "If you've seen one senior center, you've seen one senior center." Some of the strengths related to participation that emerged from this research included:

- Offering services for diverse participants. All of the cases offer some programming and services at no cost and seem to attract participants with different levels of income. Some cases have extremes among their participants (for example, Cases \#3 and \#5 attract some participants who are homeless; Case \#4 attracts some participants who willingly pay several hundred dollars a class). Key Informant \#2 explained the value of providing some services, stressing that this is important for serving $100 \%$ of the older population:

Not just the high-income or the low-income, but all income levels - 100\% of the population ... That's great if you have a center that has capacity for members to pay a membership, but what are they doing to subsidize the low-income groups that don't have the resources; or what is the center doing to connect people who need to get to food stamps or case management services, while also taking a group to the opera? I think there are challenges to find that balance; how do you serve everyone?

Some cases offered evening classes, which are beneficial to participants who are still working. Some cases offered caregiving services, which are 
increasingly important to care providers and recipients. Case \#3 had been able to increase its diversity through community partnerships and foreign language classes; meanwhile, Case \#5 was diverse with regard to the gender, age, background, incomes, and education levels of participants.

- Strong social connections among participants. All of the centers attracted participants who benefit from strong social connections. Staff used terms such as "family-like relationships"; "gathering with people that share similar characteristics”; and “ownership of the center.” Although intergenerational programming, which was somewhat rare, was seen as beneficial, staff members and participants were adamant that centers need to exist as places where older adults can gather without the presence of other age groups.

- Staff interaction with participants. The various techniques used by staff to interact with participants, such as advisory groups, surveys, and listening sessions, were expressed as strengths by staff. They provide open, two-way channels of communication that allow older adults to influence the senior center according to their needs and desires and staff to shape the center and its programming in a way that better meets those needs and desires.

- Available volunteer opportunities. Volunteer opportunities were seen as vital to all cases, and were increasingly in demand. These opportunities helped connect participants to other programming at the center and provided them additional ways to be involved in the center. 
Some of the strengths related to community engagement that emerged from this research included:

- Strong partnerships. Strong partnerships had helped all cases in this study with attracting participants, connecting and referring participants to partners, leveraging resources, reducing costs, alleviating responsibilities, building political support, and sharing ideas. The cases in this study had partnered with a variety of health-based organizations, transportation agencies, other senior centers in the county, of resource fairs and community events, and some nonprofit and/or advocacy organizations Case \#3 has also partnered with a job placement program, which supported participants in their job training and skills for them to find employment.

- Community presence of the senior centers. Staff at all of the cases in this study seemed to think that community residents are at least aware of the senior centers. All of the centers had an online presence, and some used social media. They all had publications that provide information about the senior centers. Several staff members and participants agreed that new participants are attracted to the center by word of mouth.

- National accreditation. One of the unique strengths with regard to community presence was the achievement of national accreditation, which was a characteristic for Case \#1. The accreditation helped the senior center improve its community recognition and engagement; it was a catalyst for remodeling the center; it helped staff focus on policies and procedures, and 
bring them into alignment; it increased the likelihood that the center could be awarded grant funding; and it injected positive energy and ideas into the organization. One of the important strengths that allowed the center to engage in this process was the group of passionate volunteers who served on the accreditation board. Staff at the other senior centers in this study had not applied for national accreditation, though some staff members were aware of it. Staff members at Cases \#3 and \#4 seemed to think that their respective centers could meet the NCOA's national standards for accreditation, but that the benefits would probably not outweigh the costs.

Key Informant \#1 discussed national accreditation, noting that the standards are important, but that accreditation is promotional in nature. "And while people of younger ages and demographics tend to feel that accreditations promote and attract them, people of older populations sometimes don’t feel that way about accreditations.” Key Informant \#2 agreed that accreditation is often too much work for senior center staff to take on; however, she added, "I do think that it's a positive thing in the sense that there is an accreditation for something for older adults. Because oftentimes this is a population that is forgotten about.”

Challenges. Some of the challenges related to participation that emerged from this research included:

- Lack of diversity. All cases, except for Case \#5, had challenges with a lack of cultural and ethnic diversity. LGBT diversity was hardly addressed by staff, though two staff members mentioned that they wanted to engage that 
community more. Male participation was seen as disproportionately low at all centers except for Case \#5. Case \#4 staff mentioned the cultural homogeneity of the center, and by extension, the city, compared to other areas. Key Informant \#1 pointed out that Parks and Recreation facilities have more challenges with increasing diversity, largely because of their fees present a financial barrier to many older adults, especially those who have low incomes and are historically disadvantaged.

- Sustainability of volunteers. Utilizing volunteers appropriately was another common challenge. Staff at some centers, especially Case \#2, alluded to the challenges associated with relying too much on volunteers and the associated problem of lack of continuity. Other staff expressed challenges with finding appropriate, fulfilling, engaging volunteer roles for senior center participants. Volunteer coordinators were seen as valued and important roles for senior centers.

- Barriers to participation. Staff at senior centers in this study alluded to concerns over declining numbers in congregate meal programs, primarily among Cases \#1, \#3, and \#4 in particular (\#2 had no program; \#5 was always at capacity, every day of the week). Staff speculated about reasons why older adults who could participate in their senior centers were not doing so. These reasons included (a) lack of awareness; (b) non-participants are not inherently social; (c) non-participants have health issues that prevent them from participating; (d) non-participants face transportation or accessibility barriers; (e) non-participants have had to move out of the community; (f) non- 
participants are unable to afford fees for some activities and/or feel uncomfortable using non-fee-based services; (g) non-participants live in retirement communities or facilities that offer programming; (h) nonparticipants don't identify with, or feel uncomfortable around, current participants at the senior center.

Most staff members acknowledged that they are aware of the coming wave of boomers. Staff at Cases \#2 and \#3 seemed to think that boomers will not be coming to their senior centers. Staff at Cases \#1 and \#4 have been seeing an influx of boomers already and have adapted much of their programming to appeal to them. Staff at Case \#5, meanwhile, expect to see baby boomers who have lost everything and are experiencing poverty and perhaps mental illness.

- Increasing poverty, illness, and/or disability among participants. Staff members at every case discussed the increasing demands on senior centers to provide services that are affordable and geared toward health improvement or assistance with chronic health conditions and disabilities. Key Informant \#1 mentioned the challenge for some senior centers of not being able to provide care or assistance; she provided the example of a person with dementia coming to the center alone: "This is a senior center - independent living, daytime center - and we can't be responsible if this person walks out of the building.” Participants who come to senior centers are typically independent, because senior center staff cannot accommodate people who need ADL assistance. 
Some of the challenges related to community engagement that emerged from this research included:

- Marketing. Marketing was seen as a challenge especially among staff at Cases \#2, which has no marketing budget. Most staff seemed to think participants come to centers by word of mouth. Key Informant \#2 described the issues as such:

I think that's more based on a challenge of nonprofits. Because there [often] isn't a marketing budget, or there isn't an [Information Technology] department to have social media, or a [Public Relations] department to do press releases on all the cool things that are happening at the center. So it's based on an industry's weaknesses; they just don't have the bandwidth or resources to advertise and promote.

As a result, social media was often limited and difficult to maintain for the centers.

- Silos. One staff member remarked, "In terms of umbrellas, there's marketing entities and professionals who work in the aging field, but there really isn't anything that I've found that unites senior centers.” All staff acknowledged the need to connect with other senior centers. Staff at cases \#2 and \#5, in particular, mentioned the lack of sustaining partners in general.

- The term "senior center." Several staff members addressed the use of the word "senior" for their centers. It was seen as stigmatizing and often a deterrent to use of the center. 
Staff from Cases \#1 and \#4 said that omitting the word has probably been helpful for drawing some of their participants to the centers (Case \#5 also does not use the word "senior" in its name, though this was not addressed among staff). This omission has been a trend for senior centers; as Pardasani and Thompson (2012) pointed out, the new models in their study shied away from using the term "senior” to identify their centers. Key Informant \#2 pointed out, “People don’t identify themselves as a senior. Even our clients, who are like 85, will say 'This is for people who are older.'” On the other hand, a staff member at Case \#3 explained that using the name "senior center" is often helpful for people trying to find this type of center. It is a traditional term that people often search out, as some of the focus group participants had.

\section{Part Two: Administrative Structure and Funding}

As discussed in the review of existing research, senior centers can be set up with different administrative structures and funding streams, which can lead to different strengths and challenges for the organizations. The cases in this study represented a variety of administrative structures and funding streams of urban senior centers. Data collected from staff illustrated some of the challenges and strengths related to these differences. Data related to the administrative structures and funding streams of the senior centers were not collected from focus groups.

Case \#1. This center, located within a city in the southwest part of the Portland metropolitan area, serves as the city's focal point for social services and has a contract with the county's AAA. The center is a program of the city's Parks and Recreation Department, which includes other entities such as the golf course, tennis facility, and 
public art, which have been "rolled up into Parks and Recreation for budget reasons, but also for chain of command reasons," according to a staff member. This senior center's funding comes from a combination of different sources, primarily membership fees, donations, and city funding.

One of the strengths associated with the Parks and Recreation model, one staff member mentioned, is that centers under these departments tend to have more guaranteed funding, although the amount of funding varies according to the political and economic climate. At the time of the interview, the city manager position had just been vacated, and one staff member said that the new interim manager was much more invested in issues pertaining to older adults. The interim city manager was also supportive of the senior center creating its own strategic plan, unlike the previous manager. The staff member explained, “That's one of the reasons we became accredited, because becoming accredited forces the issue of a strategic plan.”

One staff member compared senior centers that are governed by cities with those that operate solely as nonprofit organizations; "I think there are strengths for both, but in terms of being able to be nimble and change directions, I think a nonprofit runs easier than one that's part of local government," she said, noting that the reins of the city had been tightened on this center. She continued, "I was not familiar with shifts that occur with elections of City Council; I'm just used to a more sedate setting. I had never worked anywhere where senior services was a political football. And then I came here, and not always are senior services so highly regarded, so far as they would be subject to threats of cuts." This city, she felt, has a relatively volatile political climate compared to other cities in the region. 
Multiple staff members said that they attempt to be transparent to the community about what is happening with the center as a public program, and how changes might impact employees and participants. Many participants and supporters have rallied and confronted city and state government officials when they have perceived threats to the senior center, and this strategy, in the past, has protected the center from proposed budget cuts and other threats. For example, the city government had looked into moving the senior center into a newly-purchased building, co-locating it with other departmental programs. This was a very unpopular idea among the senior center's participants and supporters, and it was eventually dropped due to lack of support.

Some money through the county's AAA funds aging services (e.g., congregate meals). "That money becomes mixed; some of this money is mixed up with other funds, too. For example, funds that the governor has, and transportation money that the county gets from the group nonprofit called Ride Connection,” explained one staff member. ${ }^{5}$ "That money goes to the county, and so we're like a subcontractor to them, because we get the money from Ride Connection which actually comes through the county; it’s not really clear.”

Funding is seen as an ongoing challenge for this center. All senior centers across the county experienced meal cuts after the recent sequester, one staff member explained; fortunately, this city agreed to replace the money in the budget that was cut during that time. Still, she said, the congregate meal program loses money every year. Staff

\footnotetext{
${ }^{5}$ Ride Connection "is a non-profit and works with community partners to provide and coordinate transportation options primarily for older adults and people with disabilities. Ride Connection and its network of partners serve individuals in Clackamas, Multnomah, and Washington counties with customerfocused, safe, reliable transportation options.” (Ride Connection, 2015)
} 
emphasized that they often feel that the center operates at the whim of the government, and that its programs and budgets can diminish or become eliminated at any time. One staff member explained that, several years ago, the county's case managers became state workers due to county funding shortages. The county has maintained some of its services, but overall, county services had been dramatically trimmed down. Another staff member explained that a city position at the senior center had just been eliminated, so she had suddenly become responsible for $25 \%$ of that former position; “And it’s not something I really feel that comfortable with," she said.

Financial challenges were expressed by several staff members, as follows: "I think the economic [challenge] and realities of the bad economy have been kind of a threat on and off the whole time”; "I don’t think the budget thing will ever go away. I think it will always be there because of who we are and what we do"; "I don't think any of us, in reality, see this economy as suddenly going into a boom time in the foreseeable future - so we're really having to do more with less. There's a new normal”; "We go with the economic times, and with the will of the City Council, and hope that people do see us as a vital part of the community." Convincing community members that the senior center is a valuable resource to the community seems to have been challenging, at times, as many residents are more inclined to support facilities built for young families. Interestingly, one staff member said, "When you actually say Meals on Wheels, then everyone says ‘Oh, I wouldn’t want that to go away!’ But some of the other pieces too that they don’t really recognize, maybe.”

It seemed clear, overall, that the center staff felt a need for increased and sustained support from the city and its residents. The senior center's advisory board raises 
funds for the center and makes recommendations to the City Council, though the center could potentially benefit from having representation at a higher level of government as well. One staff member explained:

It would be great to have more collaboration on a higher level - more connectivity, more power, and perhaps that would be legislative. That's one area where I know we don’t do a lot, is that we don't keep up on the current legislation affecting seniors; in terms of legislative power of the centers, we have no voice. The senior center is managed by a small number of union-represented staff members who often make decisions by consensus. One staff member explained: "You don't look at chain of command; you don’t worry about whose job it is. Everybody just does what they do and we don't think twice about it. And that's really how things happen sometimes. You don’t worry about stepping on toes; you just get the job done.” Creativity and new ideas are encouraged, and communication is often dealt with through face-to-face interaction. As one staff member explained, "It's the best way to manage, and kindness and compassion go further than discipline and corrective plans.” The senior center closes for two weeks every year for a deep clean and any renovation or construction that needs done. During that time, staff participate in team-building activities that are intended to boost staff morale.

After years of a relatively stable, unchanging situation, the senior center had recently entered a state of flux, with the unexpected loss of one staff member and otherwise gradual staff turnover. One staff member explained that this has created challenges but also opportunities for changing some of the programming and operations from the status quo. "It was a little disjointed for various reasons," she explained, "But I 
think certainly the status quo, in terms of senior centers, is a death wish.” Another staff member said, "It takes a while for everybody to gel; we're in that process, trying to figure all this out.” Personal agendas and issues can sometimes confound things, as can bureaucracy, but staff members seem to work well together in spite of that. "I think we're all on the same page; we all enjoy this population, we all like working with these folks. That's why we're here."

Case \#2. This center, located in a city in the eastern part of the Portland metropolitan area, functions primarily as a place for activities and socialization. It is part of a county building that houses a combination of public, private, and nonprofit entities. As part of the rental agreement, which includes a discount on the center's rent, the center furnishes the volunteers at the building's reception desk who provide information about the building's services to visitors. The senior center also operates the building's consignment shop, through which older adults can sell their crafts. Because the center shares the building, staff often have to coordinate with staff from the building's other entities about use of the rooms.

This center depends entirely on donations, and a \$2.00 class fee per session that is requested but not required. All staff members are volunteers, except for one. One staff member explained, “Other than the discount on our rent, we don’t get any grants or any kind of money from the city or the county." One upside to the way the center is funded is that it is not subject to budget cuts and layoffs. Funding is, however, on ongoing challenge. Staff explained that the center's board of directors - which consists of 14 volunteers - has not been very reliable or successful in finding new funding sources. One staff member said, "I think more dynamic fundraising-type folks on the board who have 
that focus would be the way to go. Business leader types! That might be a nice balance to what's going on.”

Staff have not been successful in applying for grant funding or garnering support from government officials. One staff member explained that she had met with one official who notoriously had little interest in older adult issues. When he refused to follow up after their visit, she attended a public meeting with a speech she had prepared. "I said that our grandparents and parents built this city, and yet we're like second-class citizens.” This did not go over well with the officials in attendance, apparently. In past years, the senior center had a lot of political and financial support from the city's government, but now, “The interest isn't here,” the staff member explained. “They don't attend anything here. They've been invited; I've made sure that they got our newsletters when they went out on a monthly basis.”

The center has four annual fundraisers to provide the majority of its funding. These have traditionally been successful, though staff explained that they rely heavily on mostly the same volunteers and business sponsors for every event, so it would be difficult to plan more events than what currently exist. Staff have also found it challenging to offer free admission to volunteers, because so many event attendees have been volunteers at the center, so the events would not generate much revenue through ticket sales.

Other income for the center includes its newsletter that most participants receive at a cost of $\$ 12.00$ per year, donations from the Bridge group, and money generated from quilts made at the center. Staff had sent out letters in autumn to major corporations in the area requesting donations, but they received nothing in return. They occasionally receive larger donations from family members of former or current participants, and some local 
businesses will sponsor the center for its events. One staff member explained, "We do have a savings; we haven't touched that. So our goal is to maintain our expenses as we go along, and so far we've been able to do that." Staff agreed that the center would benefit by having a volunteer who could apply for grant funding and help manage the center's finances.

Costs, besides paying rent, include paying the wages of one staff member, which has been a significant cost for the center. The center used to have four paid staff members before it was forced to go all-volunteer in order to survive. This senior center was then managed by an all-volunteer "working board of directors.” Eventually, the volunteer staff became burned out. “And there was no continuity,” one staff member explained. Volunteer staff members could only commit to being at the center for one or two days a week. "I'd come in and I'd have no idea what the person did on Monday. I came in on Wednesday. We tried different ways of trying to communicate, and it wasn't working.” At this point, staff went through a part-time, or temporary, agency, and found a paid staff member to oversee the operations of the center. "She’s our continuity," one volunteer staff member explained. "Without her, it would be pretty chaotic."

Ten reception volunteer staff members currently work one of two shifts, either morning or afternoon, and six staff members manage the consignment shop. Another 35 or 40 volunteers contribute by working in the sewing room or by helping with the travel department (through which trips for participants are organized and planned), which is run primarily by one volunteer staff member. Staff explained that the center has even more volunteers if those who have volunteered once are counted; "But the ones who really do 
the work, we're all ex-workers, all very strong women. We have very few men who want to do anything. That's a challenge.”

This senior center faces various challenges related to its administrative structure. Communication among staff has been another ongoing challenge. "Keeping the information channels open, making sure that everybody that needs to know information does, like coordinating reception,” explained one staff member. She continued, alluding to the challenge of continuity at the senior center: "And then [name of volunteer], on the travel desk, one of these days is going to retire. I think that's a big challenge. It's like, who’s going to keep the programs running?” Staff have often had difficulty finding volunteers to fill in at the consignment shop, for example.

As a nonprofit organization, staff described the management of the center as follows: "You are free to come up with all kinds of ideas, but then you have to implement every part of the project that you come up with or that you get funding for.” One staff member said that she feels like the staff here are a good group, and can disagree without being disagreeable; “We work it out.” Another said, “There have been a few personality clashes; that's everywhere you work, it's that way. But for the most part, the people that are here want to be here. From that standpoint I think it runs pretty smooth.”

Staff agreed that if they didn't have the costs associated with maintaining the center, they would offer everything for free. One staff member said, "We're strictly out there hustling all the time.” Another explained:

We wouldn’t have to always be begging people for a donation for what they do; always taking into consideration, 'how much money do we have to make off this?' Just do it for fun. I don't know if other senior centers have that ability or 
not. We have heard, through the grapevine, that some cities finance the whole thing, actually pay for the personnel. I don't know if it’s true or not; it’s just what I heard. But unfortunately, we don’t.

Case \#3. This center in central Portland is one of nine senior centers contracted with the county division that serves as the AAA. The basis of the contract is to support older adults in their desire to remain living independently in their community, explained one staff member. Contracts are assigned to organizations that respond to requests for proposals, and this contract originated as the OAA was developing senior centers through AAAs all around the country. The staff member pointed out the uniqueness of this center as a contractor, because it focuses specifically on older adults, whereas other contractors serve the full age spectrum. "Because of that [older adult] focus, we're often called upon to partner with other organizations to advocate, to speak, to be representing senior services." Staff seemed to agree that the strong organizational network associated with the county contract is a benefit to the center, as it helps the center fulfill the contract by connecting staff with new clientele and by allowing staff to refer participants out to other organizations.

The senior center's operations and planning are dictated primarily by the aging social services network, and they evolve according to changes within the contract. For example, one staff member explained that a recent restructuring of the contract led to the center opening a branch in a new location. Also, all senior district centers were to now have their information and assistance services accredited, so staff had begun this process. Another change in the contract relates to the county's directive that case managers incorporate health and wellness into their plans and assessments. Case managers now 
spend time with homebound participants going over wellness classes that are available, or they may, for example, bring participants fresh produce from the farmer's market.

The center's board of directors meets several times a year, and is composed of a diverse mix of center staff, people in the work force, retirees, and community leaders. They discuss the contract, overall health of the center, and the center's future directions. A few years ago, the board had examined the possibility of co-locating the center with another organization in a new building with attached housing. "After a lot of discussion, it just wasn’t something that the board could embrace at this time; they just felt like we have stability where we're at,” explained the staff member. She said that, whereas other organization boards tend to micromanage or focus on continually raising money for the organization, this board serves by helping the center meet the needs of its contract in a fiscally responsible way and by offering to use members' connections, when appropriate, to support the center. Major changes are often met with a lot of hesitation and reluctance from the board. After substantial discussion and focus, some changes do move forward, although they must remain within the context of the mission of the center's contract.

The bulk of this center's funding is for social services that fulfill the center's contract with the county. As a nonprofit organization, the center relies heavily on donations as well. One staff member explained, "We put in a lot of our own revenue to be able to offer more." She added, "I think having our own location also gives us a great advantage. Some of the other centers that are co-located or sharing just don't have the same kind of flexibility that we do.” 
OAA funding to the center had been threatened earlier in the year, so staff had to advocate for the city and county to replace what was getting cut. One staff member explained:

It's just that part never gets easier. There's an increased need, and yet looking back at the funding that we used to receive for - like our in-home services - [that] has dwindled, which is just crazy; when I first started, there was never such a thing as having a waitlist for people who needed services.

Other staff acknowledged that decreased funding for social services has been occurring for several years now, and the reduction of the contract continues to be a looming challenge as demands for services are rising. When funders propose cutting back or eliminating services, staff shift their focus toward advocacy to attempt to stabilize funding.

The center's size and budget allow for a very limited number of staff members who have little time to contribute to fundraising. While most times staff are working just to stay afloat, the center's manager does pursue grants on a regular basis, which, when received, have been very helpful. For example, the center was awarded a transportation assistance grant with which staff were able to provide free bus passes for participants.

One staff member said the day-to-day management of the center requires some resilience. "I'd really like to get to a point where we're not reactive and we could be more proactive in planning, and increase funding so we wouldn't be in this situation all the time,” one staff member explained. Another said: “Greater needs, less funding. Space restrictions. Yeah, that sums it up! [Laughs]” 
The senior center’s small staff includes part-time information and assistance specialists who oversee the social services, such as transportation and housing support, and case managers work individually with senior center participants. Working underneath the center's manager is a coordinator who is the first point of contact for most participants. "And so a lot of pressure can be put on - from the public - on those positions," one staff member explained, referring to the center manager and coordinator. She continued:

When you look at the funding and the output, a lot of what's happening here is what's happening out in the community. It's the support for seniors in their homes, but the public doesn’t necessarily see that. So that can be a challenge. The staff working space consists of several small, enclosed offices. One staff member said that she feels a bit separated. The privacy, however, offers some benefits: "I get so many calls and walk-ins that it would be hard to - you just couldn't do it in that type of environment where we're all together; and then also just constantly hearing everybody's conversations, it’s a little distracting.”

One staff member explained that as staff turnover occurs, it is important to keep up with training, especially because staff members often need to step in and fill certain roles when needed. "We've had, in the last few years, a lot of database changes and technical changes that the staff have had to adapt to and learn,” she said. Training has been an ongoing challenge, especially when some staff members leave throughout the day to conduct home visits. "But there are trainings; we have monthly staff meetings. We haven't done a retreat, but at some point I could see that,” she said. Staff members seemed to agree that with a larger staff, they would have more time and flexibility to 
focus on other areas, such as development, public relations and outreach, and the creation of a strategic plan. Staff acknowledged the variations in how senior centers are administered. One staff member said, "It would be nice if something emerged [from this research] saying, 'If you really want to do things right and efficient, it should look like this!'

When the center holds events, staff are fully involved and acknowledged for the large scope of work that they have been doing. Staff members seemed satisfied with the way that they work together. One staff member expressed what she has learned over the years with regard to working as part of a staff: “Take care of the job, take care of yourself, and take care of each other.” She explained:

To talk about being a team, you have to effectively be a team, and to be a team you need to need the person also on a personal level. Take care of each other; that's what I'm saying. And don't be in your own little bubble, especially for personal stuff, not because you want to intrude - but hey, we spend so much time together here! And it’s very important to give feedback, positive and negative; very important in terms of community.

Case \#4. In the early 1950s, residents of this senior center's city approved an initiative to establish a park district as a result of a recognized need for recreational facilities and planned open space. The senior center is currently an entity of this special Parks and Recreation District along with a variety of other programs and other recreation centers. Residents who live within the district help fund these entities through property taxes. 
One staff member explained that staff try to match the interests and expectations of participants with those of the center's funders. The focus on health and wellness fits the mission of the Parks and Recreation District; however, one staff member said that the center is very different from the Recreation model. "We're not just a Rec [sic], and 'how many classes can you get filled?' We are serving the community; we're serving the senior population.” According to one of the staff members, the district will occasionally move staff around from center to center, presumably to increase staff knowledge and understanding of other entities. "They do that kind of arbitrarily. We went through the big thing where we were down by three people, and they took one of our programmers and sent her off to another facility. [The timing] was not ideal,” she explained. Another staff mentioned that the senior center has tried to offer programming in other Parks and Recreation facilities, which has not gone over well; “We've tried to see if they would allow that, and they don't allow us in there. So that's where the competition - like for budgets and things - that's where you can kind of step on toes.”

The department sets boundaries around what individual programs and centers can do; for example, it would not allow the senior center to add a swimming pool, which one staff member said she would want to do given enough funding. "I still have the mental want and desire; you can always improve it," she said. She explained that, for the most part, center staff are able to try new things and allow participants to shape the center as they want it to be. “As long as the supervisor can say, 'We're okay financially, we're okay to try this, we'll give it this much time and then see what happens.'” She said that a lot of the senior center's programming was started this way and has turned out well. "And of course our patrons - it's their center," she continued. "They will do what they want to 
do. And you don't mess with seniors! [Laughs] So in other words, they have a very, very - almost an innate ownership of this place.” She said the advisory board is like the "stopgap," in that they often inform city on what is happening at the center so that staff members can focus on their work.

The senior center is funded primarily by property taxes and fees. The center has its own budget, which is practically guaranteed an annual incremental increase as property taxes rise. The center was also a recipient of a large injection of funding as a result of a recent bond measure. Several years ago, just before the recession, voters within the district approved a bond to develop natural areas and improve park facilities throughout the district. This allowed the center to expand and add its now-popular fitness center.

When asked “Has the center faced challenges?” one staff member responded, "Not like others," explaining that this center does not have financial challenges like other senior centers. "We have amazing community support. We have amazing funding. Because of being a special district, we don't have to compete for funding with the city, we don't have to compete for non-profit funds; we just are great.” Another staff member said, "We are an example. I mainly think that because of our funding, we're able to do a lot more than senior centers around the Portland area.” She explained that the center has been through five remodels while expanding its budget twofold over the past several years.

The center also has a fundraiser every year, which staff explained is a large, successful event that draws a lot of participants and funding. Every recreation center in the district has an advisory group of community residents that can fundraise and help to 
decide how that money raised is to be used. This center's advisory group, composed of a group of volunteers from the senior center, competes with the other district advisory groups to raise the most money. At the end of the year, staff take the advisory group out for a celebration lunch and announce the total funds raised for each center in the district.

One staff member said that the fundraiser has led leaders from the district to question, “Do taxpayers need to be funding this [center]?” She explained:

It’s like, 'You're not getting it.' They [the advisory group participants] don’t do it for the money; they do it as socialization. They develop friendships that will last them the rest of their lives. I hear from people constantly, 'This place has saved my life.' Where do you get to hear that on a job?

One staff member attributed the general ambience and success of the senior center to its management over the years. Some of the positions have changed or evolved, but many staff members have been at the center for a long period of time. "People get to know each other, and know the patrons. It's very 'family.'” When staff members have vacated their positions, other staff members have filled in to maintain the senior center's operations. One staff member explained that staff may be "scrambling" at first, but eventually the center returns to "even keel." Staff have gotten through these rough periods with teamwork and with a sense of humor, to maintain sanity, as the staff member explained.

Staff members produce a shift report after every shift, which has helped with dayto-day continuity in managing the center. Staff also meet every week and constantly interact via email or face-to-face. "We have close quarters here," one staff member explained. "Staff work really well together, and we cross-reference special events." 
Some staff members have a history at the center that allows them to apply their institutional memory while addressing certain issues.

Staff seemed to agree that they all work toward the same goal and have few conflicts. One staff member said, "We have the best staff anywhere!” As she and another staff member explained, most of the staff members are certified in working with older adults and chronic conditions. “They're here because they choose to be, not because we pay them a lot. And so that makes a big difference," one staff member explained. "We have people with gerontology, we have people with very specialized training; it’s amazing. They just share the wealth and knowledge, and it's great.” The other staff member, when talking about this unique feature among the staff, said:

That's the difference, too; I feel that if you want to come to a center and exercise and feel comfortable, there are certified teachers, there are people with the same thing you're suffering. There's the understanding of that. If you go to one of our other centers and work out, do boot camp with a 30-year old, it's going to feel a lot different than it does here.

Case \#5. This center in downtown Portland is one of nine senior centers contracted with the county division that serves as the AAA. The senior center fulfills its contract through a partnership between two organizations: MOW and a social services organization for people of low-incomes and of all ages. The center's space consists of one of the MOW's meal sites, and of the social services organization's branch office. One staff member discussed the oversight of the senior center, and its accountability to the AAA: 
They check up on us all the time. They check our temperature, the food temperatures, they check our refrigerators. They check our kitchens to make sure everything is clean. We are definitely grilled by [the AAA] - regularly. MOW and the social services organization partner to fulfill the AAA's contract, which the staff member said has stringent rules. "I think our [MOW] centers do a really good job of keeping the quality high and consistent.”

The MOW staff work with the resources available to them at this site to try to feed nearly 150 participants a day. One staff member said the center has done quite well in its ability to serve the community and secure funding. "We're kind of the household word, and MOW is a legacy now. People whose parents and grandparents drove or delivered meals, they get involved now." She explained that the organization has an annual fundraiser luncheon, which is usually successful, and that she personally encounters people who want to donate to the organization on a regular basis. About $70 \%$ of the center's fundraising the previous year was generated through donations to the coin canisters placed at various checkout stands in grocery stores throughout Portland. It has other small events as well, such as a cell phone recycling drive. The staff member said: We're not really begging! Not at all. People see the need, they see what we're doing; it’s not perfect by any means, but they really know how to economize and yet also fulfill the needs. And it's a very delicate balancing act; I'm just so amazed every day at how they cook 5,000 meals a day for Portland. And get those meals distributed out.

Another staff member said that the funding for the staff at this site is not enough, however, as they are making only a small percentage of the salaries made by staff at the 
corporate office. In a perfect world, she would like to see the staff paid higher wages and to have more staff members, as this site relies on a large number of interns and volunteers to handle the workload.

The center’s social services staff said they consider their organization a gatekeeper to the AAA, to which they have the responsibility of referring clients for case management. The organization, which is a nonprofit, is funded primarily by the OAA and by donations. One staff member described the need for more funding for those working with older adults: “The need is more than we can fulfill,” she said. Funding goes up and down, she explained; when it is low, everyone in aging services feels it.

This site is a branch office for the organization, so staff members at this office occasionally communicate with staff at the larger, main office. On some occasions, the main office will send over an intern or volunteer if this office is short-staffed, particularly when it is hosting an event such as "senior law day." One staff member explained, "We go to meetings over there, we're certainly in touch; we're certainly not totally separate, but we don't get to interact that much other than by phone, because there's just that physical distance.”

Staff from this office usually only go to the main office to pick up donations or a food box, the other staff member explained, because there's a food pantry there. The main office also includes a reception area, classrooms, a thrift shop, and a small kitchen much like its own center, as opposed to a small office like the one in this senior center. “That's another reason we make trips down there, is to offload stuff that gets donated here that needs to be out of our space,” explained one staff member. 
At this office, if both staff members are unable to work, they will put a sign on the door indicating that the office is closed. Most of the time, however, one of them is able to be in the office. The social services staff members do not interact much with the other center staff or go to other areas of the senior center. One staff member explained:

Usually it's just too crowded. But we'll walk around and say 'hi' to people and put a face to the person, so that when they walk in here, maybe they aren't quite so reticent about actually coming in and talking to us.

This senior center had gone through numerous recent management challenges. Over the course of the past year, four different individuals held the center manager position. One staff member explained that the first of the four managers retired, and those following had just not been a good fit and hadn't really understood the needs of this center's participants. The other staff member described one of the former managers: "He works out every day; super vital, super positive attitude; I was so glad when he got the job. He didn’t last two months; he couldn’t take it,” adding that he started having health issues due to stress. She said that the last center manager before this current one had a really difficult time as well; "If you had interviewed her, she would not have given you a good story.”

One staff member, who has been at the center for several years, explained that the manager position is highly demanding, stressful, and tedious, and that the person in that position needs to be resilient and strong, which are seemingly characteristics of the current manager. Some of the stress associated with managing the center relates to making decisions about how to interact with and support some of the senior center participants, many of whom have mental illnesses. "I don’t mean to sound sexually 
discriminating, but I almost feel like a male presence is needed here. Because we're 85\% male at this center, and it's run by all women.” Senior center participants have been forcibly removed in the past, staff explained. The center is usually full to capacity, and that it would be helpful to visit some of the other centers in the Portland area to better understand where to direct some of the center's participants, especially those looking for a place to sleep. With such a small staff, the center manager has a large responsibility, often needing to step in to fill roles associated with both of the center's organizations. "Working in this center is like being in the middle of a sitcom or a reality show," said one staff member. "Some of the things people say and do; it’s just so unbelievably ridiculous and funny.”

Strengths. Some of the strengths related to administration that emerged from this research included:

- Strong community support. Data from several of the cases, particularly Cases \#1, \#3, and \#4, demonstrated that senior centers that have strong foundations of supporters and advocates are able to contest threats to the centers, such as cuts to public funding streams or proposals to transform the centers into community centers. One unique characteristic of the senior centers that comprise Cases \#1, \#3, and \#4 is that they are organized in such a way that their centers each have their own advisory boards. Advisory boards, as staff from Case \#4 said, can be very helpful to the staff for operating and maintaining the center. Case \#2 does not have an advisory board; its governing board, staff, and participant base are all composed of volunteers. As a result, it has struggled in its ability to create an effective governing structure. 
Meanwhile, Case \#5, which operates as a partnership of two organizational branches, does not itself have an advisory board.

- Freedom and flexibility in management. Freedom and flexibility in management were also strengths that emerged from the data collected from staff members. Staff often want to develop aspects of their senior centers, as demonstrated by Case \#1 and the creation of a strategic plan. Staff at Case \#1 were also able to adjust to cuts of other staff members, which can be disruptive to organizations. Staff from Case \#4 seemed to feel that they have a high level of freedom to expand programming compared to staff from other cases, although they also were required to adapt according to the city's policies. Flexibility in management seemed to be a strength for Case \#2, which is the only senior center that did not have a governing body to whom staff report. This unique feature allows staff to make decisions based on what works best for them, rather than what is dictated from a higher level and without threats of budget cuts and layoffs from another entity.

Centers that have enough staff are in much better positions to have flexibility and freedom to grow, as Key Informant \#2 confirmed: “That would be the thing, is to increase the staffing so they could do more innovative thinking or intergenerational activities, or - whatever that community is demanding.” She also said, “If it’s not innovative, or isn’t a creative or evolving workplace environment, how do you attract good talent as an employer?” 
- Positive staff environment. A positive staff environment was associated with a number of qualities that were mentioned among staff, including teamwork, cross-training, common dedication to the work, similar interests in success of the center; and getting along well. A unique strength of Case \#1 was the twoweek closure that helped the center to refresh and the staff to build morale and re-connect. This was especially important because the center experienced somewhat of a staffing crisis, and the positive environment created by the management facilitated resilience among staff during this time of crisis. A unique strength of Case \#4 was the certification among staff members. This seemed to help them work cohesively and effectively as a team.

Strengths related to funding that emerged from this research included:

- Guaranteed public funding. Guaranteed funding from the city was a strength for Cases \#1 and \#4, as the senior centers are both entities under their cities’ Parks and Recreation Departments. Case \#4 in particular, because it is part of a special district, does not have to compete for funding and has a high level of stable funding. As one staff member from Case \#4 said, "I mainly think that because of our funding, we're able to do a lot more than senior centers around the Portland area.” A reliable stream of funding seems to be a critical factor of how well a center can operate and adapt to its changing conditions. As staff at the senior centers that rely on AAA contracts explained, they are concerned about the sustainability of their funding sources and the variability of funds from year to year. 
- Successful fundraising. All of the cases, to some extent, had successes in obtaining financial support from the community through fundraisers, grants, or donations. Case \#2 has limited funding, but its four annual fundraisers are consistently successful. Staff from Cases \#4 and \#5 also reported that their respective centers each have one successful annual fundraiser. Senior centers with AAA contracts benefited greatly from the added revenue through donations, as it helped them to offer a wide variety of programming beyond social services. Senior centers that partnered with MOW also benefited from donations to this organization; because of MOW's name recognition, it has generated a substantial amount of individual donations as part of its revenue.

Challenges. Some of the challenges related to administration that emerged from this research included:

- Increased demand on services. Cases \#1, \#3, and \#5 provide social services through contracts with their respective AAAs. As a result, they face challenges associated with the increasing demand for services, because they serve a growing population of older adults as well as younger adults with disabilities who qualify for these services.

- Political and public pressure. Staff from all Cases, except for Case \#2, described experiencing political pressure either from either city government officials, as their senior centers are city programs, or from county government officials, as their senior centers are contracted with AAAs. Some of the senior centers have shifted their foci to organizing and advocacy in order to address 
threats posed by government agencies. Lack of public support has also been a challenge; as staff from Case \#3 mentioned, they want to be more transparent to community members who may not understand the full scope and reach of the senior center. This lack of understanding in the community can lead to diminished support, as there is not a recognized need for the senior center and its programs.

- Lack of control. Staff in all cases expressed a perceived lack of control over the futures of the senior centers, much of which was associated with budget and service cuts from governing entities. Case \#2 is unique in that it is totally reliant on volunteers, which leads to uncertainty about the center's future. As the center is housed within part of a municipal building, Case \#2 staff have limited control over the use of the building's space, and security is often a concern.

- Limited staff. Data from all cases revealed a challenge with limited staff, although to a lesser extent for Case \#4, which has enough funding to hire more staff if needed. A challenge that is unique to Case \#4 was fitting into the Recreation model which, as staff said, focuses on filling classes and generating revenue. Being part of this model has also resulted in the movement of staff to other recreation centers and competition with other Parks and Recreation departments that also provide adult programming.

- Lack of overlap between organizations. A challenge that is unique to Case \#5 is that the two organizations that comprise the senior center have little 
overlap. The center manager is challenged to coordinate and manage the two organizations, which is especially difficult as the social services staff have scant communication with their main office due to physical distance.

Challenges related to funding that emerged from this research included:

- Cutbacks in government funding. Staff at all case sites, except for Case \#2, expressed concerns with cuts in government funding, at the city, county, and national levels.

- Need for more external funding sources. None of the senior centers in this study have their own staff members who are dedicated to fundraising or writing grant proposals.

- Reliance on donations. A challenge unique to Case \#2as a standalone nonprofit includes total reliance on donations, which means every cost, including one staff member's salary, is a burden. This center is not supported at all by funding from the government or from businesses. Board members don't participate or fundraise as much as staff would like them to. Reliance on volunteers for their time and donations presents challenges of continuity as well.

A quote from Key Informant \#1 illustrated how dire the funding challenge can be: The money is so short in the centers; they kind of have to do these things to get a little extra money, like they do night rentals. There's just not a lot of funding out there; there just isn't. 
Key Informant \#2 also reflected on the funding of senior centers, when asked about the kinds of challenges senior centers face:

Sustainability. How are they going to continue to fund, and what does that mean? Will they be competing for funds outside federal funds to expand programs? Also, just their constituent base...is that going to continue on? Is your customer base going to want the product that you're offering? I think they face sustainability [challenges] in their funding models and in their constituent or client base; what are they going to demand from them or want from them?

\section{Part Three: Transportation and Physical Environment}

Research and literature about senior centers have often highlighted the importance of providing transportation options to bring participants to and from senior centers. Older adults show a strong preference for communities that support walking and provide public transportation (DeGood, 2011); according to a 2010 report of survey research conducted by AARP, $70 \%$ of adults aged 65 and older reported that living near places where they want to go, such as grocery stores, doctor's offices, the library and social or religious organizations, was extremely or very important (Keenan, 2010).

Since the second half of the $20^{\text {th }}$ century, older adults increasingly have been experiencing transportation challenges associated with the building of suburban developments that require frequent, long-distance trips by automobile. Automobiles have become crucial components of daily life, as they are often requirements for gaining access to necessary resources as opposed to a luxury (DeGood, 2011).

Without affordable transportation options, older adults experience isolation, reduced quality of life, and potential financial burden (DeGood, 2011). Recent studies 
have revealed that: older adults who no longer drive make fewer trips to see their doctors, to shop or eat out, or to visit friends and family, compared to drivers of the same age (Bailey, 2004); after driving cessation, older adults require access to transportation alternatives for an average of six to ten years (Foley, Heimovitz, Guralnik, \& Brock, 2002); and 85 percent of older adults were either extremely concerned or very concerned about the affordability of fuel for their automobiles, leading many to look toward other forms of transportation or to reduce their transportation (Skufca, 2008).

The creation of accessible, barrier-free spaces is also important when planning for older adults. As explained in the Action Plan for an Age-Friendly Portland (Age-Friendly Portland Advisory Council, 2013), best practices for designing and constructing social spaces pay particular attention to details such as type of flooring, lighting, amenities, and way-finding signage (p. 13).

Research on senior centers has often noted issues around lack of adequate space, accessibility, and needs for upgrades, among other needs. This section explores how participants of the senior centers in this study get to their respective centers, what types of transportation services are offered by the centers, and the overall challenges and strengths associated with transportation for senior center participants according to data collected at each case site. It also provides a physical description of the centers, and what staff see as some of their challenges, strengths, and potential changes to the physical environment to better meet the needs of their participants.

Case \#1. Most participants at this center live within the city’s boundaries which, according to the City-Data forum, include an area the size of about ten square miles 
(City-Data Forum, 2015). The center does not sit on a main street, but in the back of a residential area with its back to a wooded park.

Transportation for participants. Many participants, especially those who come for the congregate meal, rely on the center's shuttle service to get to and from the center. Participants must live within city limits in order to use the shuttle which is indirectly funded by Ride Connection. One of the center's staff members operates the shuttle with pick-up and drop-off service from participants' homes three days a week, including the return trip, for a suggested donation of $\$ 1.00$ per trip. The shuttle is accessible to participants with mobility issues. The staff use the shuttle for trips as well, including those to the grocery store and daytime outings with limited walking. Staff also coordinate volunteers who drive participants for errands such as doctor appointments.

Aside from those who use the shuttle to come to the center, many participants drive, use TriMet LIFT (TriMet's shared-ride paratransit service for registered clients) or Ride Connection's services. Some use participants use TriMet’s public transportation, but there is no nearby light rail (i.e., MAX) stop and there are only four bus line options within miles. The closest bus stop from the center is approximately .35 miles away (TriMet, 2015).

When asked about transportation issues for participants, one staff member said, "Just look at the topography; this is a terrible place to try to age! But a lot of people do, and there are transportation needs. One of our TriMet lines got cut. I don't have a solution." She continued, "We're very limited on how we bring people in using the shuttles, but I would expand on the shuttle service.” Staff agreed that bringing participants to the center, and elsewhere that they need to go in the city, remains a 
challenge. Transportation for older adults in this area had been recognized as a huge need by City Council.

Senior center building or space. This center's building, built in the 1970s and owned by the city, is largely composed of wood; it is almost cabin-like, with two stories, a large reception area, and several small offices. One staff member explained that the center had recently received some state funding for building improvements; "We focused on the lower level which had unfinished concrete walls and kind of some issues. So we were able to upgrade carpet, and surfaces, and paint, and furnishings. So that helped some.” Because of its enclosing surroundings, the center really cannot be expanded. Besides, said the staff member, "The square footage that we have is the maximum square footage we can have for the number of parking spaces, which is regulated." Staff have focused on re-purposing rooms and making them multi-use spaces. For example, the computer room was transformed so that its tables and computers can be taken down each day to make room for fitness equipment. "The feedback we got was very emotional," explained one staff member. "A lot of pushback on that; they [computer users] liked having that convenience, so we had to make what was, at the time, a very unpopular decision. Fortunately, the response from the fitness room has been positive.”

The building has an elevator and, despite the somewhat steep pitch of the staircase, does not have many accessibility issues. A staff member explained that the indoor spaces are designed with neutral, comfortable colors and lighting.

The city government's plan at one time to move this center into a different building would have been quite resource-intensive, one staff member explained. "That 
would've meant millions and millions of dollars to redo that building. It just isn't set up for seniors at all.”

Staff agreed that, in the future, the center would benefit from more space, perhaps even an additional building, and should include some outdoor space for participants to enjoy (e.g., during meals, respite time). "It'd be nice to have warm spaces that felt comfortable for people. And I think we do a good job with what we have,” one staff member explained. Overall, it seemed that more space and transportation options would strengthen this senior center and contribute to its general success.

Focus group. Of this focus group's participants (n=6), 100\% of respondents reported use of a personal vehicle to travel to and from the center, and $100 \%$ of respondents reported that the one-way trip takes ten minutes. During the focus group session, participants seemed to agree that the center is not walkable for many residents in the area, but that the shuttle service is an option for everyone, even for those who have low incomes. "If you can’t afford anything, you don’t pay anything,” one participant explained. Focus group participants also alluded to the fact that the center is underfunded, and that people with physical limitations often stay at home because of the difficulty of getting to the center. One participant said, "The other service that's provided here - for some people who are truly unable to get out of their homes - is that people volunteer to just go and visit with them. And that's another wonderful service at this center.”

Focus group participants also expressed a desire for more space at the senior center or outside the senior center for additional older adult programming. One participant wrote on his evaluation: "Expand activities to form a second center and obtain 
more funding (convince Council to care about seniors as much as streets).” It was evident that the city has competing priorities with regard to providing space for community activities for older adults.

Case \#2. This center is located in a city in the eastern part of the Portland metropolitan area. It is in a municipal building at a transportation hub through which eight TriMet bus lines, LIFT, and the MAX (light rail) run. Participants are drawn from a large area around the center.

Transportation for participants. According to TriMet.org, much of the surrounding residential area is located at least a half mile from any transit stops. Senior center participants, staff explained, arrive primarily from within the city, though many of them come from further away. They generally use personal vehicles, TriMet, or Ride Connection. One staff member recalled a former male participant, who was in his 80s, who used to ride his bike to the center regardless of the weather. The only challenges that staff mentioned were for people who do not drive and may not live near a transit line that connects them to the senior center.

Senior center building or space. This center is unique in that it pays rent to be housed within a large, municipal building right next to a transit hub. The center sits at one end of the modern-looking building with a large window opening to the hallway by which visitors are typically coming or going to services. The front office opens to a hallway that is adorned with quilts, which branches off into several medium-sized, officelike rooms. The center was previously in its own building and co-located with MOW, which paid rent to the senior center. Staff agreed that it would not make sense for the center to have its own building, currently. It would be costly for the center, as it would 
have to pay for maintenance, utilities, security, and insurance, among other costs. One staff member said, “I just don’t know if we could get a better place if we even had our own building.”

Staff also seemed in agreement that the space is adequate for the center's needs. The center has access to many of the rooms at this building, which are coordinated by another organization. "I would say we probably have $80 \%$ of the usage of the rooms because we have more activities than everybody else. They might have meetings, but we have all of our different classes," one staff member explained. Only on occasion are none of the rooms available for the senior center to use. This building is accessible and on a non-smoking campus. The center often receives inquiries to rent a room, and this can be done without a charge, unless the room is rented after-hours or on weekends, when security would be needed. In that case, the cost for security is passed on to the renter. One staff member explained that "basically someone on our board needs to sponsor any outside event that comes in and needs to be present for that event.”

Participants seem to appreciate the convenience of the center's collocation with other services that they need, such as MOW and aging services. One staff member said that there are advantages to being in a county building with other services for older adults: "We get people just coming through who stop to check things out in addition to the people who are already taking classes on a regular basis.” Another staff member agreed:

We have a lot of people that come in and, of course, because of the way parking is, they come in through and hit our reception desk before they ever hit the main desk. Our newsletters that we have out - with all of our classes listed - we hand 
those out all the time to people when they're coming through, and they ask about various things that are available to them. I think we've probably had people join us because they didn’t realize [we] were here.

The senior center is typically staffed with at least one person in the back office and one in the reception area, especially for security purposes. Visitors come into the building for a variety of reasons, including drug rehabilitation programs, and one staff member said that there has been a fair amount of theft in the building. Every two months, various staff from the building's entities meet to discuss security. As one staff member explained, “We have to be really, really careful; that's just one of the realities of being in this kind of building.”

Focus group. Of this focus group's participants (n=6), 100\% of respondents reported use of a personal vehicle to travel to and from the center; one respondent also reported occasional use of the light rail. The average reported time for the one-way trip to the center was about 16 minutes.

Focus group participants described transportation to and from the center as somewhat problematic. Two participants agreed that Ride Connection does not meet the needs for everyone. One participant said that she leads a study group every morning and that the Ride Connection shuttle could only pick her up during that time, whereas another said that she lives just outside of the pickup zone. "That’s another great organization, Ride Connection; except that the problem is that they have to have more volunteers to be able to do something like that!” When asked about those who live within walking distance of the senior center, one focus group participant explained, "They're not seniors; they're younger.” Another participant explained that the difficulties associated with 
driving at night for older adults can be barriers for attending any of the evening activities or events. Overall, transportation was seen as a reason that potential participants may not use the center. The center's building, on the other hand, was viewed as accessible for all people, and focus group participants had no complaints about its current structure in comparison to a stand-alone building.

One focus group participant requested that this study include information about the need for senior centers to be better supported financially:

Somehow they need to figure out, as this older generation is getting older, we're going to need more help for transportation to get to these places and to be able to come for the activities. Because there are a lot of things that people would like to come to, and they just can't get here. This center is surviving because all of us are supporting it in one way or another, from having dollar sales to raise money to having these short little trips where we make a few dollars. So I think it’s very important that somebody starts thinking about this, or you're going to have a lot more people staying at home and a lot sadder.

Case \#3. This center is centrally located in the city of Portland between downtown and the vast eastern part of the city. Participants arrive from a large area around the center.

Transportation for participants. This center attracts participants who arrive and leave by various modes of transportation. Many participants are independent and come alone, by walking, TriMet, or personal vehicle. Some participants use Ride Connection or TriMet LIFT, and a few arrive with their caregivers. They come from all over the metropolitan area; some of them come from areas where they are close to another senior 
center but they come to this center for a particular activity. One staff member explained, "It is somewhat of a hub, it's centrally located in terms of buses and the MAX, so that's helpful.”

Several individuals who are homeless or younger come to the center seeking assistance, largely because it is close to downtown and accessible by transit. One staff member said, "For the most part, they're independent folks who want to maintain their independence and are coming here to socialize with friends, or to volunteer or participate in the wide variety of offerings.”

The center offers trips, and according to staff, there's always a lot of interest in having more trips. The center does not have its own vehicle, however, so it relies on volunteer drivers. The center also partners with a local organization that provides specialized activities and outings for older adults, particularly those who are homebound.

Staff were able to secure a transportation assistance grant through Ride Connection, which provided free bus passes to participants for a limited duration. One staff member explained that she had to keep reminding people who received the bus passes that they would expire at the end of the year, as they would get very accustomed to having them. "But it was so nice to be able to offer something," she said. Staff said they would like to see more transportation assistance or perhaps even a shuttle bus to transport neighborhood residents.

One challenge for this center is the lack of available parking spaces. The center does not have its own parking lot, and visitors often think that the center owns the lot behind its building (and consequently may receive parking citations for parking there). Staff said they could see this becoming more of a problem - especially, as one staff 
member said, if a proposed micro-apartment complex, which would not include tenant parking, is developed nearby. Another staff member explained:

In our area, which is more central, there's actually been a decrease in the number of older adults that have been able to stay in this area. And there's a lot of different thoughts on that, but one is that the homes that are in this area don't really lend themselves to aging in place. They tend to have a lot of stairs, but also just the lack of affordable apartments.

Senior center building or space. This center owns its building, which sits at the convergence of several major streets in central Portland. It had just expanded to include a branch in another area of Portland to increase its presence and reach to potential participants. A sandwich board in front of the center's entrance indicates to passersby when "senior dining" is occurring. Staff explained that since the 1970s, the center has served its community as a place to visit, take a class, or come for a particular service or activity. One staff member said that participants used to come for a short time and leave, whereas now they often come to spend most of their days: "We're constantly moving tables and chairs and looking at this space that we have and rearranging it to try to meet all of the needs, so sometimes there's just not a really great space for people just to lounge.” Staff agreed that with more space, the center could be more innovative and offer much more programming. "That's always kind of a question; what can we really do here?” said one staff member. Staff have been creative with the space in the past, out of necessity; as one member explained, her office became a turkey-carving station when the center held its annual Thanksgiving luncheon the previous year. "It would be wonderful to have a larger space with more breakout rooms and offices.” 
The center has had different groups visit to look at redesigning the space. "It's not a modern-looking design,” one staff member said. The center's leaves the impression of an antiquated high school or church, with a dated exterior, mix of carpet and tiling, and a wooden, creaky stage. “And at the end of the day, I think it’s still a small space. So we could put in a lot of money to make it look nicer; it’s just kind of what it is," explained one staff member. As the building is aging, it has a number of structural issues that staff are trying to address. Accessibility has been an issue; the center has no parking lot and no automatic doors, and the ramp in the back area has a fairly steep incline. The building has had incremental improvements over time, however: "It looked more like a nursing home before, because of the color and everything. And now, the color and the atmosphere has vitality,” one staff member said.

Conversations among staff have touched on the idea of launching a capital campaign to purchase a new building and move the center. Many issues would be involved with this, such as the significant investment of time and work that likely would include hiring another staff person. "If we had more staff, even if we were poised for growth space-wise here, we don't have the office space. So we have to think really innovatively.” Participants and staff also feel strong attachments to this building. Another staff member said that the location is important, so ideally, the center would expand into another building nearby.

Another staff member said that she would love for the center to be co-located with other services, perhaps even with housing attached, and to share staff among the entities. I think being co-located with a meal site has a lot of advantages, and if we had enough space, kind of in my ideal world, we would be in a really modern-looking 
building that had plenty of parking and had all these services that were available for an individual when they walk in the front door. And so, that's just - how do we get there?

On the other hand, another staff member pointed out that co-locating with other entities does not offer the same flexibility for the senior center as does owning the building.

Focus Group. This focus group's participants ( $\mathrm{n}=5$ ) represented a variety of transportation mode users. 20\% reported using TriMet, 20\% reported walking, 20\% reported riding as a passenger in cars of friends, and $40 \%$ reported driving a personal vehicle to travel to and from the center. The length of the one-way trip varied from five minutes to 30 minutes (mean $=20$ minutes).

Focus group participants agreed that it is easy to get to the center, but that parking is problematic. A lot of participants use TriMet, including TriMet LIFT. Many use Ride Connection, which had been serving this location for a couple years and which two focus participants described as a "great organization.” Some walk from surrounding areas. "We would like to have our own van; it's on our wish list, and somebody to drive it so we could organize our own trips and not rely upon the rest of the city.” The center had a van previously, participants explained, but the trips were prohibitively expensive for participants. Also, people would call and cancel the day before a trip, so trips would have to be canceled altogether because they could not generate enough money to cover costs.

The building probably could be improved, explained focus group participants. “Or else another building would have a better layout of space; I'm not an architect, I don't have any ideas. It's just a feeling.” Another participant said, "If we had more space, we 
could have more activities, because we're cramped for space.” Another agreed that there would be many ways to enhance the building, but even though the center owns the building, there are certain restrictions because of the age of the building and what the zoning permits. "But we're fortunate with the space we have," she said. "It's just wild when we go to change classes every hour. Chairs go up, chairs go down! Tables go up, tables go down! So it does present its challenges, I guess."

Case \#4. This center is located in a suburban area of a city in the western part of the Portland metropolitan area. It draws participants primarily from within the district, though some people arrive from out-of-district and pay higher fees.

Transportation for participants. The majority of participants drive, staff said; "You can take a look at the parking lot. It's always full.” The center partners with the surrounding churches and has access to their parking lots. "Without their parking lots we couldn’t survive.”

Many participants use public transportation, as there is a bus stop right out front. Participants often switch to a different mode of transportation so that they can still come to the center when they start to lose their independence. Many use TriMet LIFT, Red Cross (another volunteer-based community transportation service organization), and Ride Connection. Although it does not have a shuttle, the center has a bus that it uses for day trips that are scheduled multiple times a month. Some volunteers at the center also take participants on these trips, though trips are not administered by the center for liability reasons. The center has another vehicle, a van, which belongs to the center as part of a new mobile fitness program. Although one staff member said, “We don’t have a 
challenge with transportation to get here," another disagreed and said, “Transportation can be a problem.”

Senior center building or space. This center is a large, municipal building in a suburban area adjacent to a church and a school. The funding from the district's recent bond included an expansion and upgrades to the center, which were completed four years after the bond was approved. "We've been very lucky," one staff member explained. The building is outfitted with new carpeting, freshly-painted walls, plenty of windows and light, and modern artwork lining the interior.

In fact, the remodel phase was the only challenge mentioned in any of the interviews regarding the center's building and physical space. "The whole front of the building was taken out. Every day we had a different path that we had to go through, so it was constantly changing," a staff member explained. "And that was challenging. Just to make sure everyone was safe and not in an area where they shouldn't be. It was about one-and-a-half to two years before all of that was finished."

When staff members were asked if they would change or improve any aspects of the building, one member said that staff would like to offer some programming in other recreation centers, but this has created conflict in the past. She said they could consider a satellite site, which would be complicated. Another staff member said she would like to make the center bigger, eventually. "So yeah...it's been discussed; there could be a new facility in the works...so we'll see.”

Focus group. Of this focus group's participants $(\mathrm{n}=4), 100 \%$ of respondents reported use of a personal vehicle to travel to and from the center, though one respondent occasionally uses TriMet LIFT, and another occasionally uses a recumbent bicycle. 
Respondents reported that the one-way trip to the senior center takes from eight to 15 minutes (mean $=10.5$ minutes).

Focus group participants had varying opinions regarding transportation.

Participants who do not have financial or mobility restrictions issues seemed to have few issues getting to and from the center either by walking, biking, public transportation, shuttle (owned by the Parks district), or private vehicle. Those with mobility issues who arrived by car noted the lack of parking spaces close to the building for people with disabilities. Participants with mobility issues who arrive using TriMet LIFT, Red Cross, and Ride Connection explained that these modes are inflexible with participants’ schedules. They also expressed frustration with the district vans, which cannot always accommodate a person's wheelchair; as one participant remarked, she could not attend a trip to the beach because there was no room for her scooter in the van.

One focus group participant described accessibility issues for some people who want to participate at the senior center. "One of our friends is very large and in a power chair, and has no money. So accessibility can be an issue for some; she lives half a mile away at most, but she can’t get here.” Another participant had some difficulties with physically reaching some reading materials in the senior center's lobby, as they were placed too high for a person in a wheelchair. On the other hand, she said, "One thing I really love here that a lot of other places do not have is the automatic door opener. Not a lot of other people have it; you'd think the ADA ${ }^{6}$ never happened.”

\footnotetext{
${ }^{6}$ Americans with Disabilities Act
} 
Case \#5. This center is located in downtown Portland, in the crosshairs of several transit lines. Participants are drawn from all over the metropolitan area, though most come from downtown.

Transportation for participants. It was clear from the interviews that nobody drives to this center; many participants walk, and the public transportation access seems to fill most of their needs. "Unless they're so close that public transportation doesn't make sense and they have a mobility issue,” one of the social services staff members explained. She said that parking downtown is difficult for participants, as well as for staff; the social service organization's vehicle is usually parked in a lot, and staff try to avoid moving it whenever possible.

Staff said that a few participants come from a long distance, perhaps because they like this center better than the ones that they live nearby or they used to live downtown and they like coming to the center to see familiar faces. Many of the participants at the center are transient or homeless.

Staff have observed a strong interest in trips that get out of town, such as to the Columbia River Gorge. "Those tend to be the more popular trips, really, because they are getting them out. Unfortunately, that is one place that we were hit somewhat with the budget cuts and with the increasing gas prices and stuff.” The center's social services organization, which uses the vehicle from its parent site, arranges trips to the grocery store for the center participants once a month and monthly outings. “And that's something we're really working on trying to change: increase to more than one trip besides our one shopping trip,” one staff member explained. "Even when we duplicate a trip [with another site], which we try not to do - but say Sauvie Island - you'll find that 
people will go on both of them.” The center used to offer two or three trips a month in addition to the grocery shopping trip; "it has tapered down quite a bit, but we're hoping it will go the other direction.”

Senior center building or space. This center is in a rented space that belongs to an apartment building in downtown Portland. It used to be a MOW site within a different organization altogether, and when this apartment building was being constructed, staff were offered the opportunity to rent out the space attached to its building. As a result, the senior center designed its entire space, with which staff seemed very pleased. It is fresh and modern-looking, with three large, interconnected rooms, multiple offices, up-to-date facilities, plenty of furniture, and murals painted on the walls.

Like staff at other centers, staff members explained that they would like more space in the center, particularly in the social services area. "It's not very conducive to having more than one person, because if we're having confidential conversations, we can’t get anyone else into the office,” one staff member explained. “And sometimes a call will come in that we have to take, and then we have to ask someone to actually leave the office.” The dining area, while fairly large, is usually completely filled at lunch time and would be able to accommodate more participants with additional space.

Focus Group. Of this focus group’s participants ( $\mathrm{n}=10)$, nine respondents reported use of either public transportation (55\%) or walking (55\%) to travel to and from the center. Respondents reported that a one-way trip takes from three minutes to 60 minutes (mean $=24$ minutes).

During the focus group session, participants expressed satisfaction with accessibility to the center using public transportation: “It’s wonderful; I don’t have to 
drive on a freeway. Very free,” one participant explained. “TriMet is a great asset for seniors. It really makes a difference.” One participant said that he could walk seven blocks to come to the senior center, but he takes the streetcar, because it is so convenient.

Focus group participants were appreciative that the center is open on weekends, offering weekend meals. The building, they seems to agree, is sufficient for their needs: "It’s pretty good"; "Plenty of rooms to hide in"; "You always know where you're at" (the rooms are color-coded); "I think we'll be all right until an earthquake hits.” One participant said:

I mean, just the presence of this place - it is just a tremendous place in terms of having a place to be. Everything else is window dressing; I mean, you've got the meal, you've got a place to be and get out of the rain. The basics are covered. As far as other things - it's difficult to name; there are certain things that people just can't do for you anyway. You've got to do them for yourself. No one's going to transform my life into a paradise, so getting the basics covered is very important. So whether the walls are green or yellow, or whether the chair is pink or orange, doesn't matter.

Another said:

We have problems a bit, actually, with cleanliness here. That's not the staff's problem; that's our problem. And then there are other things in these urban settings that are extremely harmful to seniors and other people, such as bed bugs. They do have them in this area; this is downtown Portland, an urban center. It's really a difficult problem, and more education should be given to people about it. 
Strengths. Some of the strengths related to transportation that emerged from this research included:

- Variety of transportation options. Generally, people do not walk further than $1 / 4$ mile to reach a bus stop and $1 / 2$ mile to reach a train station (Litman, 2015). All of the cases in this study have public transportation options within $1 / 4$ to $1 / 2$ mile, with the exception of Case \#1. Walking is an option for Cases \#3 and \#5, both of which seem to draw participants from within the dense urban area. Participants cannot generally walk to the centers in Cases \#1, \#2, or \#4. Cases \#1 and \#4 have shuttle options, which are important alternatives for participants who cannot drive.

A center-owned shuttle - which can provide transport to and from the center or day trips - was seen as a highly-valued resource. Case \#4 had a unique strength, which was a mobile fitness program that included a van with fitness equipment to provide fitness to low-income residents. Driving is less problematic for older adults who participate in centers in Cases \#1, \#2, \#4; participants in Cases \#3 and \#5, which are located in denser urban areas, have more difficulty driving. Parking is not really an option, but it may also be because the participants have lower incomes and higher rates of disabilities. In case \#4, the parking lot is often too full (because so many participants drive). Cases \#1 and \#2 have some more varied options, it seems.

- Partnerships with organizations. Organizations such as Ride Connection are options for participants at all centers. They are clearly a resource for providing both trips and funding for the centers. Partnerships with churches, as in Case 
\#4, can provide ways to address parking limitations. Transportation assistance provided through grants, for example, is one of the more valuable types of assistance that can be provided to participants, as demonstrated with Case \#3.

- Volunteer drivers. Volunteers who can assist with transportation needs are key resources to transportation for older adults. Staff at Case \#1 coordinated with volunteers who drive and visit homebound participants which, as focus group participants mentioned, is a valuable service.

Some of the strengths related to the building and physical space that emerged from this research included:

- Accessibility. Accessibility was seen as a strength for all centers except for Cases \#1 and \#3, which have older buildings compared to the buildings in the other cases. Staff at Case \#1 mentioned the steep incline in stairways in the center, but otherwise the building itself was accessible; the area surrounding the building, however, was seen as having accessibility challenges. Staff and participants at Case \#3 discussed several challenges with the senior center’s building, and the need for either significant upgrades, additions, or for moving to a different building altogether.

- Flexibility. Staff and participants at most cases mentioned the availability of several rooms and the ability to be creative with the space. Some senior centers are even able to rent out rooms, which is a revenue generator for Case \#3. Re-purposing rooms enhances flexibility in use of senior center buildings, as was demonstrated by Case \#1. 
- Proximity to other amenities. Most staff were pleased with the locations of the senior centers. Participants in Cases \#3 and \#5 were able to walk to other urban amenities, participants in Case \#1 had access to natural areas, participants in Case \#2 had access to other services in the building (and a transportation hub), and participants in Case \#4 had access to natural areas, churches, and schools.

- Funding for building improvements/additions. Funding for building improvements had uniquely helped Cases \#1 and \#4. Meanwhile, Case \#1 opened a satellite location, which is something to which many senior centers aspire. A unique strength of Case \#5 was the ability to design the space from the beginning of tenancy, so the layout and features of the senior center are comfortable and attractive to participants and don't need to be improved.

Challenges. Some of the challenges related to transportation that emerged from this research included:

- Lack of transportation options. Lack of transportation options was an issue for Case \#1, in particular, and most participants drive to this senior center as a result. Lack of parking options limited driving for participants in Cases \#3 and \#5, meanwhile. The restrictions on shuttle service or trips were challenges to participants in Cases \#2, \#3, and \#5, which don’t have their own van available for these purposes. Focus group participants also mentioned the lack of reliability and flexibility associated with volunteer-operated services such as Ride Connection. Key Informant \#1 verified, “There are very few 
transportation options if you don't drive, and you don't take the bus.” She also explained that access to medical transportation through TriMet can be very complicated, and is restricted to a limited number of qualified individuals living on Medicaid.

Key Informant \#2 said: "Some people can get there on their own; they have a vehicle or can access it [the center] by family or transit. But they're trying to get folks to the center for care clinic or case management or meals.” As this quote illustrates, it is important that senior centers are designed to provide transportation options for participants who are experiencing illness or disabilities that may prevent them from driving to access services they need.

Some of the challenges related to the building and physical space that emerged from this research included:

- Lack of space. Lack of space was seen as an issue among staff and participants at all cases except for Case \#2 and \#4, although staff at Case \#4 would "like to see" more space to add to its large offering of activities. All cases, except for Case \#4, are not likely able to expand their space.

- Challenges associated with aging in place for nearby residents.

Affordability of living and accessibility of the physical environment in the area surrounding the senior center in Case \#1 was seen by staff as a challenge. Staff of the senior center in Case \#3 were also concerned about the ability of participants to remain in the neighborhood due to rising costs of housing in the area. 


\section{Part Four: Programming, Activities, and Services}

As discussed in the literature review, multipurpose senior centers are designed to offer a variety of programming. The cases in this study differed in what they offered, as they represented either the voluntary organization model, social agency model, or a blend of the two models. The following section provides an overview of some of the strengths and challenges that were revealed among staff and participants with regard to current and future programming, activities, and services at the senior centers.

Case \#1. This senior center’s mission was described by staff members as a place of innovation and cutting-edge practices; a focal point; a place for opportunities, services, and support; a place to help people stay in their home longer when they become ill or frail; the "highlight of their week"; and a reason to get dressed and go out. One staff member explained, “I think, first and foremost, it is that human services piece: that we're supporting the community in helping people stay independent and making sure that everybody has a meal and has the basics.” Another said:

I think the mission is to help people in the community to have the best quality of life they can have as they age, and whether that means for them being able to stay in their home longer when they become ill or frail, maybe we can kind of assist them to stay at home for a longer period and not have to go move into assisted living.

This senior center provides some core social services to community members. As a focal point, it must adhere to the policies of the county and offer meals (three to five times a week), information and referral, community outreach (e.g., Medicare assistance), client assessment (e.g., home visits), transportation, social services, legal counseling, 
health promotion activities, and recreation and social programs (Clackamas County Social Services, 2013).

Staff from senior centers throughout the county who provide information and referral meet every month, which allows staff at this center to compare their services with those at other centers. One staff member explained:

Because we have this contract with the county; we just talk about cases, and sometimes we talk about things that are required that we should be doing. There are just slight differences that way; somebody else in our county may offer different transportation options. We have a grocery shopping program that goes out once a week, whereas some of them may have more of an individualized one. It just all kind of depends on the community they're serving. So there are some differences, but there are certainly some similarities.

She explained that some services at the center have been eliminated because they are offered elsewhere; for example, the center used to provide flu shots but stopped because there are so many places that provide them now in the community. Other services, such as providing health information, have been terminated because people are accessing them through the internet instead, although some prefer to receive them in person so that they can interact and ask questions. Many people in this community, she added, are also fairly healthy and see their doctors regularly, so they don't need the services.

The need for increased caregiver support has certainly been a concern among staff. Several years ago, the center received a private grant to develop a day respite program for caregivers of people with dementia, and it is currently one of the few places 
in the metropolitan area that offers a day respite program. The center also added a new family caregivers’ support group, as staff realized that there are many people who benefit from sharing their experiences of caring for others who have a broad range of health, mental, and emotional difficulties. One staff member explained that there has been interest around expanding the outdoor area to allow more space for participants to walk around and enjoy the center's surroundings.

Staff also discussed the need for more in-home services. The county used to have a registry program through which people could provide in-home services for around $\$ 15.00$ an hour, one staff member explained. It no longer exists, however:

There's nothing like that. I can only refer now to private agencies. And I have people come in all the time who want to do caregiving, and they just give me their card and their background and [ask] that I just refer them out, and I explain that I can't do that and I don't even have any place to send them anymore.

The senior center does have a medical escort program and a grocery shopping program for homebound participants, but those services are scheduled according to staff availability rather than what works best for participants' schedules. Private in-home care services can be unaffordable for many older adults, staff explained, at up to around $\$ 22.00$ an hour for a minimum of three or four hours. If the center had its own registry program for in-home services, it could help match people who are willing to provide caregiving at a low cost and with flexible hours. The liability issues, however, could be complicated, as the staff member said.

The center also has run into issues around offering services that compete with existing services, either through the public or private sector. One staff member explained: 
For a while there was a discussion that what we did at the center was competing with businesses and that churches, and that volunteers could do as well as what we were doing. There were arguments that we were really not good conservators of the public dollar, and that it could be done cheaper and better and that other centers in the area were doing it better.

The county pays annual dues as a member of the MOW organization, so the senior center uses "Meals on Wheels" in the name, which is widely recognizable to the public. Staff have also spoken with several people who don't realize that the city has a meal program available; “A lot of people in this community didn’t think that people needed MOW. But we serve a lot of meals," explained one staff member. "They think it has something to do with being low-income, and that the only way you need to go to the center or access human services is if you're considered low-income.” Many community residents do not realize that a large part of the MOW's vision is addressing social isolation. They may also not realize that there are many older residents in the city who are facing financial insecurity.

The center has its own kitchen staff to prepare, package, and deliver meals (with the help of volunteers), and all food is prepared according to the guidelines of the county. The MOW at this center includes a home delivery meal program and a congregate program, which are based out of the same kitchen. The congregate program is larger than programs at many other centers and is costly compared to those that have pre-prepared food brought from the central MOW kitchen.

Some staff seemed unsure if the congregate meal program will continue for many more years. One staff member asked, rhetorically: 
Do baby boomers need congregate meals? Without it, will we then see people go back to social isolation? I don't know. People, to me, are getting socially isolated because of our texting. And there are certainly more restaurants where you can go for a meal; I think that's probably the most interesting place to see - if that will be the big change.

According to staff, other centers have also seen their congregate meals shrink, and they have theorized that this has something to do with the accessibility of packaged meals or online grocery delivery services:

The congregate meals are an older group; that group of people used to, before my time, fill that room. And now it’s down to 25 to 30 people on a Monday, Wednesday, Friday, unless we're having a holiday lunch or something. And even for those, we don't have the turnout that we used to have.

Staff said that while congregate meals at the center have been declining, homedelivered meals are "off the charts." The previous year, the center experienced a $40 \%$ increased demand for MOW delivery, from about 70 meals to about 111 per day. The center only has the capacity to deliver three days a week, but participants can have as many frozen meals as they want.

Staff noted the decreased contributions to meals as well as federal budget cuts. As one staff person noted:

Not as many people contribute toward their meals. In order for the program to be sustainable, it will have to rely on fundraising, as county funding has also diminished. All the centers in [the county] experienced meal cuts. Our cut was 
about $\$ 6,000.00$. We really only get reimbursed $\$ .80$ per meal, and now it’s down to $\$ .52$ per meal.

For the MOW program to be sustainable, staff acknowledged the need to keep changing and gauging what should be done next. The meal site is not like another restaurant in the community; people do not walk by and wander in, as the center does not have street visibility, so staff need to be innovative in order to attract new participants to the meal program. The center may develop something different, like perhaps a bistro service, one staff member suggested:

Congregate meals - we're talking about a donation basis for people 60 and over if you're under 60 you have to pay $\$ 5.00$. So in a bistro setting, I don’t know; would it be like a congregate meal thing? Would we do it that same way? With regard to activities, one staff member explained, “We’ve become so much more visible to the public; with the activities we offer, we've raised the bar on ourselves.” Community members seem to have raised their expectations of the center, challenging staff to think outside the box to redevelop or reinvent the center. "We created our own little monster there. But it's been challenging in a good way; that piece has been fun.”

Staff provide a variety of opportunities for older adults in the community to participate, learn, socialize, travel, and engage. Interests vary across the age spectrum, staff explained. Participants enjoy discussion groups, memory enhancing activities, and other educational programming. As travel becomes too expensive and a hassle for some older adults, the center's day trips provide a chance for participants to get out for short, frequent travel opportunities. 
This senior center has a technology center, which is unique compared to many other senior centers. It has been volunteer-operated for about 12 years, and volunteers have adapted their techniques to serve different needs by offering a range of classes (from introductory Windows and computer basics, to Twitter and Skype). Classes are individualized, even offered as one-on-one tutoring sessions. As one staff member explained, the center has evolved from a time when people were still retiring at 65 and had not had much computer experience:

That's where our program started; it started with people that never had the basics. Some had retired and they knew something about computers, but they were maybe specific to their job, so they didn't have a broader use of it. And now we're at a point where the baby boomers that are coming in pretty much know computers. Some of them still are - I'm surprised sometimes when some come in and say they really don't know that much of the basics.

The technology center, therefore, is constantly changing to meet the needs of new generations.

The fitness center, staff agreed, is another one of the senior center's most popular features; it is "trending really high," and the classes are a big draw for new participants. Staff said that many participants want functional fitness assessments; they want to know what classes are best for them and what level they should take. Staff members were planning to update all of their fitness class descriptions so that people can understand if something will be too rigorous for them or will not be challenging or engaging enough. Staff solicit participant feedback through evaluations and have observed positive outcomes for participants. One staff member said, "We had a guy in Tai Chi Better 
Balance who went from being in a mobility scooter to being able to walk. That's my favorite thing that happened I think in the entire time I've been here.” The tai chi class is very popular and effective as a falls-prevention program, and staff would like to see it expanded to other facilities throughout the community. They also want to grow the fitness center and believe that baby boomers will be especially attracted to fitness classes, especially if the classes are health outcome-oriented and led by highly qualified professionals.

Participants enjoy playing games at the senior center, although staff got rid of Bingo a couple years back because they didn't like the negative associations with Bingo. A few people asked for it back; however, it only gets about seven participants, explained one staff member. Bridge, meanwhile, is the most popular game, with multiple groups of participants. The Bridge groups are highly structured and organized, with facilitators managing the games. "When we have a group that is more democratic, then the numbers are not as strong,” one staff member explained. Mahjong also attracts a wide range of participants, as does Pinochle, which was launched when a group of participants at the congregate meal site decided to start a weekly, ongoing class.

For future programming, one staff member explained:

I think it's adjusting; it's learning, keeping your eyes and ears open and going to conferences you can go to. At the same time, not forgetting that you will always have an older population that needs attention, and needs a very different kind of attention; and it's the attention that's always needed because of the frailty that comes with aging. 
Other staff members agreed that the human services piece will need to grow, but at the same time, they want to continue attracting new generations of older adults:

Our direction seems to be going forward in a way that we're trying to reach out to those baby boomers, and/or that sandwiched generation ${ }^{7}$ that we're hearing about, and trying to find programs that will appeal to them.

The staff have attended webinars and conferences to understand how they can meet the coming wave of users. They also acknowledged that there is an existing older population that needs attention as they reach the oldest-old age bracket, as advanced age is associated with frailty. They have also seen healthy, vibrant, vigorous participants become debilitated as a result of a sudden health event. One staff membered conjectured that unless the center brings in highly qualified health professionals, boomers would not come to receive information or services.

At the time of the interviews, staff were in the process of pursuing a grant that would allow them to collect data among their participants via focus groups. Staff agreed that this center will be looking to other programs to see how they are engaging the boomers, as they want to continue to provide a broad array of both programs and services. Another staff member said she would like to use the check-in system to track what participants are doing and recommend other activities; "Like Amazon does! You bought this, now we can recommend this; but I'm just trying to keep going at this point.” She is also concerned about what Parks and Recreation will offer, and if there will be overlap because that department has an adult section.

\footnotetext{
${ }^{7}$ Middle-aged people who have both dependent children and aging parents (Quadagno, 2011).
} 
In general, the center has made gradual changes in programming, and staff agreed that the center will be changing in the future as the boomer generation reaches retirement age. Staff said they are often gauging what they should be doing next, often looking to other programs to see what might be the "next big thing."

Focus group. On the focus group surveys, participants responded that the primary reasons for attending this center include: friends, support for the center, activities, exercise room, location, MOW, volunteerism, and participation. Of the activities in which focus group participants engage, responses included: classes, lectures, lunch, the writing group, the drug take-back program, meetings, senior center accreditation, strength training, tai chi, Bridge, and the advisory group. Of the programming that focus group participants said they would like to see, the foot clinic, which was apparently offered previously, was very popular. Other things that participants would like to see included: "Expand activities to form a second center and obtain more funding (convince Council to care about seniors as much as streets),” and “Please don’t eliminate exercise and social programs or lunches offered at center.” Focus group participants also commented that the center staff are fantastic, the center is "improving all the time," and that participants "love and support this place.”

During the focus group session, participants agreed that the range of programming offered at this center makes it uniquely attractive compared to other senior centers. One participant said, "I've discovered there are all kinds of fun and interesting classes, and I started seeing people in here that I knew [laughter]; so it’s fun!” Several participants said that they were initially interested in one service or activity and then discovered a variety of other amenities at the center that they wanted to access. Two participants mentioned 
that they were encouraged to get involved with the senior center because their former spouses, who passed away, had been involved. Another participant said that volunteering at the center was a way for her to give back, as her father had received a lot of MOW meals, and that she has recently also started taking classes.

Participants agreed that prices at the senior center are reasonable. “I think that's important, to keep the prices down, because you're dealing with people at an age when a lot of them are on fixed incomes,” said one participant. “And so I think that's one of the benefits of an adult center is that, if they can keep the prices down for things, it gets people out of their homes and keeps them more active.”

Focus group participants said they enjoy having the technology center and using new products that seem to be coming out all the time. They were also very appreciative of the fitness center, because outside gyms can be unaffordable for adults on fixed incomes and don't offer the personal attention provided at this fitness center. "No sense of community; and that's what you have here,” said one participant. Another participant, speaking about outside gyms, added, “And they’re all size twos [laughter].”

One participant suggested that the city should look at other spaces, such as those belonging to the school district, to expand activities for older adults. "I think they're going to have a hard time; this City Council is very oblivious, I think: 'Oh there’s plenty of room.'” He would like to see the center grow and services expand, but said that this center is pretty much at capacity in its present building. Focus group participants seemed very knowledgeable and concerned about local politics, discussing issues around the lack of funding and the competition for funding among schools, other Parks facilities, and the senior center. One participant said: 
The local governments have been hit by this recession. And their tax base has gone down, so they're looking at places to cut. And the first thing you do in a triage system is look at the ones that you can cut the easiest, and this is one of them!

Case \#2. Staff described the mission of the center as providing activities, volunteer opportunities, and social interaction for seniors in the area, to keep them actively involved in the community. The center does not provide services, mostly because it is part of a building where those services are available. As one staff member said, "It's strictly social; it’s to feel good.” Another said, "Being active, I think, keeps people younger. We provide that at this senior center. There are so many activities available; if you look at the activity sheet we have, you'll see that there's something going on all the time.”

Older adults are encouraged to come in, meet people, share ideas, learn new things, and enjoy themselves. "I think our mission is to provide a place for seniors to not have to be alone and to spend time and meet new friends.” The volunteer staff members see themselves as providing a place for people, but otherwise are very hands-off: "We try to identify the kind of people who need that kind of help and get them involved, but we don't interfere. As long as everybody is safe, we don’t micromanage."

Unlike the other cases in this study, this center does not have a meal component as part of its programming. In its previous location, the entire building belonged to the senior center, and the MOW site was part of it and paid rent to the center. Now that both the MOW site and the senior center are separate parts of a shared building, there is only some crossover between the participants of each entity. One staff member explained, 
“The main ones who come for meals, they don't have the money to be in some of the other activities. Because if you're going to sew, you have to have a machine; that type of thing." Sometimes participants will take a class in the morning, and then have lunch at MOW afterward. One staff member said that some people think that the MOW and the senior center are all the same thing; “They'll call the senior center number and say, 'Let them know that I don’t need a meal today [laughs].”

The center has been working to increase its interaction with MOW or to at least create a more harmonious co-existence. "There was kind of a friction when we first moved in here: 'This is my area, this is my area, this is my area.' And over the 10 to 11 years, it’s evolved to a much better, cooperative [relationship].” One incident that occurred recently was that a volunteer at the front desk of the senior center told all of the new volunteers that they had access to free lunches at MOW. All of a sudden, MOW was providing more meals and not getting any donations for them. This was eventually resolved. The director of the MOW site in the building had actually just become one of the senior center's board members, so the senior center began promoting the MOW activities and special events. The MOW and some of the other services also capture a greater amount of diversity among participants; many of the people who come to access these services walk by the senior center, so it is possible that the center could attract a more diverse community as well.

The senior center has pool tables and organizes various games such as Bridge, Bingo, Bunco, Mahjong, and Hand and Foot. It also has organized activities such as exercise classes, dance nights, card making, painting, ceramics, quilting, and sewing. Because a lot of older adults tend to avoid driving after dark, staff try to schedule 
activities during the day. Some participants attend an art class, often as experienced artists. There is also a large class of women who participate in sewing and quilting. Sewing room volunteers offer quilting machine services for people who want to finish their quilts at reasonable prices. One volunteer had offered to buy a new quilting machine for the center, which made possible the creation of several quilts that generated funds for the center, as well as other handmade items that have been donated to various charities. Staff (most of whom are volunteers themselves) depend on other volunteers to develop new programming and to offer new classes. If a base group of four to six people want to participate, then usually it will be scheduled. At one time, for example, someone came in and offered to host a Spanish language class. Unfortunately, explained one staff member, the class did not generate enough interest to continue. Staff had recently received a request for a qigong class but did not know of anyone qualified to teach it.

New programming can be a lot of work and a bit slow to develop, especially without more funding. One staff member said, "I would like to see more communityinvolved workshops that are of general interest to seniors. We don't have the captive audience of a resident place, where you could bring in a speaker for everybody at lunch time.” The center has partnered with MOW for lunch-time presentations, because it does not otherwise have a captive audience that is at the center for single period of time, aside from the fundraiser or the large group of Bridge players.

The center coordinates day trips and longer trips, which staff seemed to think that participants enjoy, as part of its programming. It does not really have a technology component. One staff member explained that the building has a computer room, but it belongs to a different entity. “And they’ve had some issues with viruses and problems 
they've been having, and then they needed to have somebody monitor every day; so it's only open on Fridays for a class that they teach.” Most people, it seems, go to the library or elsewhere in the community to use computers. Staff said that they have heard requests, however, from people who want to take a basic computer class or learn to use a laptop. Groups that play card games, such as Bridge and Hand and Foot, are also fixtures of the senior center.

Participants at this senior center enjoy the fitness opportunities, according to staff. The tai chi class offered at the center is one of its most popular classes. As one staff member explained, “The center has a really strong cadre of teachers who are certified through the Arthritis Foundation to teach a particular form. And I'd say a third of our class income comes from tai chi.” The class is offered several times a week and usually fills the room. This has been popular just over the last couple of years. "We had maybe two or three classes a week, and they’ve gone up; they'll start in the morning, and then they'll have a class in the afternoon; so they're doubling up on the days that they have them.”

Regarding future participation at the center, one staff member said:

I just think that there is so much here to offer; if you can't find something here that's of interest to you, there's something wrong, because there's just so many people here that do so many different things and are happy to be here.

Another staff member said that new participation depends largely on the volunteers who are leading activities and groups:

When we moved here, we had this beautiful quilting room. There was a gentleman who called himself the leader, and we might have three people at the 
most; and they never came back because he did not have the personality. And then [Name] came in, and we probably have 30 people who come in and out of the sewing room.

Staff agreed that older adults may not be coming to the senior center if they are living in facilities and participate in activities there. The city has several assisted living facilities within its boundaries, and they often provide classes, social programs, field trips, and other activities. One staff member said that some activities directors at these facilities sometimes view senior centers as their competitors:

Before that [the prevalence of assisted living facilities], there was much more need for a senior center; that was their center. I live in a retirement center, and I have tried to encourage different [people] to come here, but the ones who are interested don't have transportation; they're not driving anymore, and then it’s a hassle of how are we going to get them here. So we've lost a lot of people who probably would come otherwise.

She said that even with free admission offered to them, they are reluctant to try to come to senior center events.

One staff member said she does not expect to see new retirees participating at this senior center. Some of the younger generations are reluctant to participate in traditional activities that attract an older demographic. Staff agreed that the boomers, those currently reaching retirement age, have a whole different lifestyle than the previous generation. One staff member explained that older generations grew up with the philosophy of "what can you do for somebody else” rather than "what can you get from somebody else.” The latter philosophy seems to be that of the boomers, she explained, perhaps because the 
boomer generation has had so many activities available to it that the previous generation didn't have. For example, eating out is not considered special to them, so the center is lucky to get 100 people to come to one of its dining events.

Focus group. On the focus group surveys, participants responded that the primary reasons for attending this center included: exercise (line dancing), friends and family, cards, to interact, to be involved, to help, and to laugh. One participant wrote, "Needed to make friends with ladies; us women need 'girl time' even at an older age.” Of the activities in which focus group participants engage, responses included: cards, line dancing, tai chi, trips, meals, special events, enjoy other people, and be active. The programming that focus group participants said they would like to see included Dominoes, more exercise classes, photography, and computer classes.

Other things that participants added include: "Front desk volunteer is so very nice; I love the gift shop"; "They care and they try to keep interesting things available”; "Love it, made friends"; "I still work part time for Homeland Security; I volunteer also for the Port of Portland;” "The center needs more financial help to keep it going. We need leads and suggestions to help us reach that goal.”

During the focus group session, one participant explained:

One thing they do here that I really love, and have signed up for off and on, are day trips. I enjoy doing that because my husband is semi-disabled, and my 87year-old dad lives with us, and we don't go on long drives a lot because my dad can't go with us; I don't like to leave him home alone a lot. So it gives me an opportunity to get out and see things with lady friends. 
She emphasized the importance of this opportunity for people like herself, who have transportation challenges or few opportunities to go out of town.

Several focus group participants explained that they were initially drawn to the center because of the card games (this focus group was composed of a group of participants who regularly meet to play cards). Two participants claimed that they were resistant to the idea of going to a senior center; "You know, the name; 'I'm not old enough for that!'” one participant said, laughing. Another recalled that a participant had approached her and invited her to play cards; she became a regular participant: "I’ve come here ever since. I got into line dancing; I love it, and this is a lot of fun here.” Another participant said that her husband had passed away and she was feeling lost, and after meeting another participant who invited her to play cards, she had been coming whenever she could ever since: “It’s just a matter of: when you meet new people, let them know about these things,” she explained.

One focus group participant emphasized her interest in learning new technology. "I really think they should have a computer room with classes for people that are getting older; a refresher of the most current, up-to-date computers. We need someone to teach us how to use them." Participants also noted that it’s very convenient to have the meal site, even if they don't partake in congregate meals, because some people who come to the senior center really need them.

Case \#3. This senior center is very invested in assisting older adults with aging in place. One staff member said that its purpose is often referred to as "nursing home diversion.” Another described the mission as striving to promote health, independence and well-being for adults aged 55 and older with different interests and needs. 
The center has a contract with the county's AAA that requires it to have certain components of service that are standard for all district centers. It provides some basic social services, information and assistance, and case management; like other senior centers, the programs expand from there. The center owns its own building, which allows staff more flexibility in terms of programming. Staff used the term "focal point" several times to describe the senior center. "They come to us, and they call us from all over; it’s a social hub, as well, for seniors in the area or seniors seeking the particular activities that we have.”

"I see it as a place where people and seniors can meet and socialize but also where they can get help to navigate the system or to get access to the resources that they need,” one staff member explained. She emphasized that the socialization is crucial for preventing social isolation, while the social services are "the first step sometimes towards very-much needed resources to maintain your independence.” Another said:

It's definitely to provide access to seniors and their family members: information, assistance, services, and activities. That's really the main thing; if you need anything, in your home or in the community, this is a place where you can find out how to go about getting it.

The center faces challenges associated with appealing to the boomers and young retirees, as staff discussed at length. When staff have had to prioritize in terms of programs and services, the older, more vulnerable group of adults comes first and foremost. One person said, "There may be an organization that develops that really, their focus is on boomers; I could see that happening.” Staff seemed to agree that the center 
does appeal to a wide range of participants, whether they are looking for resources, social interaction, health and wellness activities, or other recreational activities.

Some of the center's changes over time have been dictated by the contract, whereas other changes have risen out of popularity. There is a greater focus on evidencebased health programming because of increased interest from funders as well as from participants. Classes such as tai chi and brain fitness have become very popular, as well as the steady flow of fresh produce donated by a small gleaning program.

With decreased funding for case management there has been a shift from longterm to short-term case management, often called "options counseling," which provides participants with resources and/or options for obtaining services and support. One staff member explained, "The thought is that it'll be short-term; their needs are met, and they might cycle through the system several times, but it's not the long-term relationships that we've had through the years.” She also described a shift toward behavioral support service and supporting caregivers of people with dementia. She explained:

Any time that the county has approached district centers with, 'Here’s some additional training, here's a pilot project, do you want to be part of it?,' we try. And since I've been here, we have to have that, because you don't know where the trends or where the funding is going to happen.

One challenge for the center that comes with being on a contract is the lack of control over certain parts of the programming. She explained that staff sometimes feel like they are asking individuals to come and assimilate to the programs rather than developing programs around participants' interests. Staff want to see more offerings, especially for different ethnic and cultural groups and communities of color. Staff want to 
continue to seek input from participants about programming and to ensure that the center is staying relevant to current and potential participants. "I think jobs and employment could be a really big piece in helping the senior center be more involved with supporting older adults in re-entering the workforce and linking them to job opportunities,” one staff member said. “And I think caregiver support is going to be huge, too; I can see more programs and services around that.”

The center has a range of fitness activities, including, as one staff member said, “things that I can’t imagine us doing 20 or 30 years ago that are so popular now, like chair yoga or brain fitness.” Staff realize that as the baby boomers retire, demand will increase, and the center could possibly explore more fitness opportunities that cater to the needs of boomers.

The center provides individual computer classes at both of its sites, and staff believe there will be growing interest in learning about technology such as smart phones and tablets.

Many of the center’s participants come for games, such as Bunco, Pinochle, and card games, some of which are more traditionally associated with a senior center. If the boomers do not find these games attractive, staff explained, the groups of participants who come to the center to play games may start to diminish over time.

Staff agreed that having a meal site, as a MOW satellite center, has a lot of advantages; "It feels very cozy; now that we have the meals, that really has increased the feeling of allowing people to interact," one staff member noted. "Whenever you have food and an activity, you have people, and people interact and eat together. That's always true." 
The senior center also has a gleaning program, through which volunteers harvest excess produce from farms and bring them to the senior center, and it is very popular among participants. “Every Monday morning, we’ve got seniors coming from all over to get their produce. And for many of them, that is their vegetable and fruit consumption,” said one staff member. “And they're talking about kale, and they're talking about, 'What is this?' and 'How can I use it?'” The program grew out of a recognized need for improved nutrition for older adults, as there has been a heightened awareness around the connection between eating well and aging well.

Focus Group. On the focus group surveys, participants $(\mathrm{n}=5)$ responded that the primary reasons for attending this center include: volunteering, socialization, and serving on the advisory board. Of the activities in which focus group participants engage, responses included: advisory board, tai chi, MOW, thrift shop, Pinochle, support groups and classes, and "total involvement." These responses seemed to reflect a blend of participation as volunteers and as users. Programming that focus group participants said they would like to see included trips and "single senior social 'mixers' so that seniors can meet each other and hopefully make new friends.” Two other responses indicated that the center's present activities and services are sufficient. Focus group participants also commented that parking needs to be improved for participants, that the center is always looking for ways to increase and improve its services, and that "this is a very good center with things for everyone.”

During the focus group session, participants gave high praise to the center and its management for the rich offerings of activities that are available. One participant said, "We really are quite wealthy here, in terms of classes and activities." Participants agreed, 
one of them explaining, "This center is very open to other activities. Particularly senior advocacy activities; we work very closely with the immediate community here and with the people that have donated, helped us, and supported us. And we've done the same thing for them.”

The participants attributed the center's rich array of activities largely to the management of the center, and how staff have created a welcoming atmosphere despite all of the "political stuff that comes through."

One focus group participant used to teach English to people from the Asian community, but the class was eventually dissolved. "There is a need in the community also for that," she explained. "The need is there, and it sort of has fallen off in recent years. But it's necessary, and I think it's a service we could offer.”

Focus group participants also said that the center may want to offer more activities that attract baby boomers; “And say ‘okay, here’s what are we offering beyond Chair Yoga'; you know, something that's a little bit different!” They suggested ballroom dancing or a social night that would bring in a younger set of retirees. Participants emphasized that they would not take any services away, however; "I think additional is what I'm looking at. Something that would draw people in; the core activities we have here are adaptable for any age,” said one participant. She mentioned that she used to participate in tai chi, for example, and that tai chi participants are "a real cross-section." “We’ve got a 96-year old, and then we're all the way down to younger people. So it’s good!”

One focus group participant concluded the session by saying: 
You know, there are a lot of big money names in town that you see attached to a lot of organizations, including nonprofits; what about 'new avenues for seniors?' What about seniors having the same kind of backing and support from some of these philanthropists, whoever they are? The big, rich companies or big, rich organizations.

Case \#4. This center’s tagline is "recreation for adults 55 'and better.'” Aging in place is a big focus of the center's mission, it seems. There is an underlying focus on the seven dimensions of wellness, explained one staff member: social, emotional, spiritual, environmental, occupational, intellectual and physical wellness. "Recently, that's kind of our mission,” the staff member explained. Another said:

We provide fitness, so we're encouraging them to be very active; every kind of health resource. It’s also cognitive, and artistic, and languages, and I think another huge part of it is the community that it develops. If you've lost your spouse, or your spouse doesn't like to be involved and you like to be involved, you can come and meet people and really develop some close friends and a community. I think that is a huge part of what we do here.

The center has fee-based classes and non-fee-based activities such as the meal, billiards, and games. Out-of-district participants, who are assessed higher fees, often come to this center because of its diversity of classes. "We've kind of got it all centrallylocated; another center has art, and at some of the other places you can take a cooking class; we’ve got everything all together.” Staff will try different activities, reassess them frequently, and decide if they should continue with them or not. 
Participants are somewhat divided into their groups: a group that mostly just participates in the day trips (such as to restaurants, wineries, museums); a group that is involved in mostly health-focused activities; a group that participates in history classes; a group that comes for the Meals on Wheels (which is separate from, but housed at, the center); a group that comes for special events/dances (e.g., Valentine’s Day or Halloween); and a group that comes just for the cardroom activities. Some groups blend across; for example, they enjoy both the dance and fitness.

The center has some programming in the evenings and on weekends for participants who are still working. Other, older participants will take advantage of the daytime activities; some will come in at 8am and stay until late afternoon, participating in a range of activities. As one staff member said, "If you build it, they will come. Depending on your classes and what you're offering, get the word out.”

Staff are trying to stay current with trends and generational shifts; for example, they phased out china painting and macramé when it seemed too outdated. When they introduced yoga, said one staff member, participants thought they were "trying to shove some New Age thing” at them. "It was like, 'Don’t they get into your mind?'” Staff began by offering chair yoga, because participants did not feel comfortable getting on the floor. Now the senior center offers eight different yoga classes.

Fitness is one of the main components of this center. "We're doing a lot of innovative things, that we've been doing for almost ten years, that people are starting to do now,” said one staff member. For example, staff had recently introduced evidencebased research in their fitness programming. A health and wellness program coordinator has designed ways to evaluate fitness class participants based on aerobics, stretching, and 
balance. Participants were reluctant to accept this; “They didn’t like it; it was interruptive, it took a class away from them; they didn’t think it was important. It took about two to three years to convince them that this isn't for us; this is for you." The research allowed staff to tweak the fitness programming; for example, they added more balance-focused classes. This research is something that Parks and Recreation is now starting to get into, one staff member explained.

Another staff member explained that participants are attracted to the fitness center because they see other participants with whom they identify; also, they really get individualized help. They also build community, according to the staff member; "There was a group yesterday, it was their last class and so they were having a little potluck; they were taking a break during class, and they just initiated that.”

The center has gone from offering around 29 fitness classes to over 90 every week; aerobic classes alone increased from six to 20 different classes. "And the participation is up - the classes are filling up, there are people calling right at registration time so they can get in the class they want with the instructor they want," one staff member explained. Zumba and Pilates were unheard about five years ago, but now are popular classes. "We're just starting the outdoor [recreation]; that's what I see is going to be the next trend."

To provide fitness for participants with lower incomes living out in the community, senior center staff developed a mobile fitness program. The program involves the use of a van that is equipped with hydraulic lifts, free weights, stretch bands, and other equipment. Staff teach classes to participants in their homes as an affordable alternative to having them come to the center. The program was designed to "take fitness 
out into the community.” The center partnered with a research institute for a study on the effectiveness of tai-chi exercise, and has access to satellite facilities to which it can bring the van and all of the equipment.

According to staff, while the age group aged around 55 years has been increasingly participating in fitness classes, those aged 65 and older have been increasingly attracted to the trips offered at the center. Once people retire, and any time they move to a new area, the trips are a good way to get to know the area.

As far as programs go, on staff member said, the day trips are among the most popular: "If you can afford it. We do have a foundation that you can get scholarships for, but you have to be very low income; like, around $\$ 1,000.00$ a month.” One staff member voiced concern over the fact that some staff have questioned whether the day trips should continue, saying that there would be an "uproar" if they went away. "They absolutely love it,” one staff member explained. “There's a whole core group; there’s the ones that just like to go to the museum or to the gardens. They love going to the restaurants, they love going to the wineries; they are really a fun group.” She added that if someone is single, the trips are a social outlet. They allow participants who rarely drive to explore and also to plug in to other activities offered at the center.

This center provides technology classes, for example, on smart phones, tablets, digital cameras, and photography, and also has a general computer in the lobby that people can use. One staff member discussed the difficulty of trying to keep pace with new technology:

We had a little lab down here. Unfortunately, with the way that whole scene is changing, it’s difficult. Let’s face it, everyone's going to have computers that they 
can bring and travel with, and that's the way it's going to go. We're not going to have all these PCs, so taking any time to create a huge computer lab like [other centers] is ridiculous. It's a waste of space. I try to keep my mind five years ahead, so that we can maybe facilitate what's coming up and get rid of what isn't. Billiards and games, staff explained, are highly popular and available at the center for no cost. Art classes include different media such as fused glass, stained glass, painting, and drawing. These classes, like the fitness classes, provide a safe, comfortable environment for older adults, staff explained.

This center is also a MOW site. Some participants who come to this senior center do so primarily for meals. On Monday through Friday, the organization prepares food, and participants come to the kitchen to get their meals and sit in the dining room. The MOW deliveries are meant for those in the community who are home-bound. "You might be just coming off of a surgery or getting home from a nursing home or rehab center, and you can't get up and cook. I think their focus is aging in place.”

According to staff, the higher the level of activity among participants, the less likely they are going to stay for the meals. "If you're in a chair class, the more likely you are to stay for lunch; it's the kind of food that's served. It's probably not something that you or I would choose to eat. It's mushy vegetables." When asked whether the MOW program has tried to make strides in focusing on making more nutritious, balanced meals, one staff member replied, “It depends on what age group they're wanting to attract. They're still looking at the 70 and above, and maybe 75 and above, and that's who they're attracting." 
Overall, staff view the senior center as a place where older adults can meet and socialize, but also where they can get help to navigate the system or to get access to the resources that they need. They see it as fairly well-rounded in what it offers. The interpersonal connections are very important for participants’ well-being. "The older you get, the more losses you have, so sometimes you tend to be isolated," one staff member said. The senior center is often the first step towards very-much needed resources for older adults to maintain their independence.

Staff members believe that the center will continue to evolve and grow, as this is the style of the center and also of the Parks district. "I think that we really work hard at trying to be progressive and see what else is out there and how can we improve," said one staff member. "It's kind of a balancing act, because oftentimes they don't like change.” Another staff member said the senior center will continue by "staying relevant and current and ready to evolve and find out what's next.”

Focus group. On the focus group surveys, participants $(n=4)$ responded that the primary reasons for attending this center included: socialization, entertainment, learning, physical fitness, MOW, and volunteering. Of the activities in which focus group participants engaged, responses included much of the same, but more specifically Mah Jong, Pinochle, and an activity for writing your life stories. Programming that focus group participants said they would like to see included Bocce Ball, swimming, housing information for affordable rent, and trips that match participants with others who have already signed up for them.

During the focus group session, participants said that the center is known for its fitness programming, which offers all different levels for participants. For participants 
who have the supplemental insurance under Medicare, the senior center has discounted fitness programs (called Silver Fitness and Silver Sneakers). MOW, trips, and billiards were discussed. One participant said that he has done billiards professionally and semiprofessionally over his life, so coming to the center felt like he was at home right away.

One focus group participant taught Mah Jong, which he said draws a large group. In the Pinochle group, one participant said, "There is a couple that are over 90; I think one of them is 97. It's so good for the brain to play those kinds of games.”

Participants agreed that the center has quite a variety in its programming, which changes each semester. "I was surprised at the variety of things that they have here," one participant said. Another added, "Whatever you want to do, there are all kinds of things to do and a variety of things to do; and new people to meet." Some of the participants felt that the prices should be re-evaluated (lowered), particularly the out-of-district policy.

Regarding the MOW meals, said one participant: "They say the meal is okay, and I say 'it's better than okay! Come over and try it!' We have a salad bar here; a lot of places don’t have salad bars. We've got soup with every meal.” One focus group participant said that he works in the kitchen every week; "We have an excellent cook, but he needs a lot of help. We have 20 routes and serve about 240 people a day. We feed $80-$ 100 people a day [in the dining room].” He continued, “You can’t buy a meal for less than $\$ 6-8.00$ around town! And our meal costs us $\$ 5-6.00$, and we only charge $\$ 3.00$, which is a donation.”

Regarding future programming, one focus group participant wanted to see more outdoor games offered at the senior center. Another participant was involved in singing in the choruses at the senior center. "And the one I'm in now, it's called Cabaret; we do a 
couple rehearsals and then we go out to [assisted living centers] in the community and we give them concerts.” Focus group participants discussed the music that baby boomers would want to hear, such as the Rolling Stones, Led Zeppelin, and the Beatles. "Our dances are getting down in numbers; we have got to get new people. We're thinking about, for every other dance, having ballroom dancing and disco.” Some of the participants said that the dances should be offered at no cost, though another disagreed because the income helps to pay the band.

Case \#5. This center essentially has three separate areas of programming: meals and activities, human services, and classes through Parks and Recreation. Regarding the meal site, one of this senior center's staff members explained, the first role is to feed older adults: "We are for seniors 60 and above. We also serve people if they want to pay. And then we serve people here who live in the building; they're able to eat here." The meal service, which is both on-site and delivered, is also a "well-check for everyone every day," she said. The meal program, which includes several delivery routes downtown, is largely volunteer-driven. The meal site is open in the mornings for participants to get coffee and pastries and to socialize or read the paper until lunch is served at 11:30am.

Another staff member explained that the center's vision includes MOW's vision to prevent hunger and social isolation among older adults - as well as to develop participation and ownership among participants by providing a positive, interactive environment. "This is a place to belong,” she said. "That’s all." 
The social services staff explained that a big part of the organization's mission is to help older adults remain independent in the community for as long as they can or prefer:

The socialization component here, or in-home services, information and assistance...they might be able to latch on to some services they might not have been aware of, or that they're in need of: dental care, prescriptions, health, those types of things. It's a part of staying vital in your aging years.

One staff member said, "This center is probably not quite as heavy on activities as other centers are, or on trips, but we do both out of the center here. The exercise programs, I think, are probably the second most popular thing here.” Parks and Recreation provides the exercise programming, which involves trained instructors teaching fee-based classes such as aerobic exercise, yoga, and Qigong. Class participants come from different parts of the city. One staff member explained:

I personally have seen a lot of talk about evidence-based programs as opposed to just having an exercise program. We've seen more of that. I would expect that we'd see either a shift in our classes or an addition to the classes with that.

The center has a Wii and a ping pong table as well. There is a computer room, too, with six computers available for registered participants.

According to staff, different groups of participants will only use certain types of programming: "It's an interesting thing, how the [groups] are juxtaposed to each other. They're in the same building, but they're not mixing. If they do, they are people coming from exercise to volunteer to help serve,” one staff member explained. Another staff member explained that meal participants often do not even know about the other services 
in the building. "There are no people that I know of, who eat here and congregate here, who are interested in the exercise, yoga and Qigong. They [the fitness participants] come from outside,” she said. Staff also said that participants who come to use the computers rarely come for the meal. Participants seem to either exercise and volunteer, come for the meals, or come to access the computer or social activities.

The social services organization is "sort of a brokerage for all the different nonprofits that are available for seniors," one staff member explained. "Like rides, [help] paying utility bills, all kinds of aid; all the things that are offered for seniors." It provides a phone, also, for participants to use. One staff member explained that she is both a Case Manager and an Options Counselor. "And so it just depends on what the need is, but basically everybody starts as options counseling. Until we meet with them, and then we determine if what they're needing help with is just finding resources for long-term purposes.” Depending on the needs, staff will refer clients over to the appropriate case manager through the AAA.

Staff speculated that the aging of the baby boomers would place increased demand on the senior center's programming, and it will be more important to build partnerships to help fill the needs for activities and services. "They [the center staff] are always trying to evolve as the demographic evolves. The senior demographic group is growing like crazy, so we have to definitely react to that,” one staff member explained. "And that older senior demographic, we want to kind of keep an eye on.” Another said that she just hopes that the number of programs will increase.

Focus Group. On the focus group surveys, participants responded that the primary reasons for attending this center included: meals, socialization, being downtown, 
being in a safe place, and hanging out. One respondent said that his reasons are reading the newspaper, charging his phone, and getting away from the "wingnuts.” Activities in which respondents participate included: meals, reading, socialization, computers, rest, and, for one respondent, to "pick up cigarette butts and trash from our sidewalks and watch for those who may need assistance.” Programming that focus group participants said they would like to see included: more books and magazines; more/clear television; talks; bus tours; computer training; legal advice; bowling; wine tasting; and disco dancing. Focus group participants also commented that they want to see more people like the center manager; that the center is "an essential part of my meager support system" and "a wonderful resource for seniors in an urban setting"; and "I love the holiday atmosphere, the friendly attitude of the staff.”

One focus group participant said:

You probably know about the activities, exercise classes, and Qi-Gong classes. I don't know of anybody here who's involved in them, but there's that stuff which I would say is important, even though I do some of those things on my own. I think they're an important offering. I don't know what the other ones are; they have a calendar...but you know, health and activity-related endeavors.

Participants agreed that there is a need for dental and vision services, especially among individuals at this center. One participant said, "I’d say probably 75 or higher percent of the elders in here have bad teeth; and some of them can barely eat.” Another said, "Eye exams are hard to find, too; they're not covered under Medicaid," and another participant responded, “They want you to pay a lot of money and get on a waiting list.” 
Participants mainly discussed their use of the center as a place to come and feel welcome:

- "I come here primarily for the food and to give me a space where I get off the streets, away from police; a place where I can sit out of the rain. It's part of my routine. Also for the few friends that I do have here; I know three to four people pretty well here, and they're pretty good people. I don’t expect much from the center in terms of support, but what they do is very important as it is. The fact that I get a meal a day, coffee, I have a cigarette connection, and I get to read and take books with me.”

- "I come here for reasons that many people come here, for comradeship. There are some very nice people here. And the staff try to be.”

- “[I come] to get off the street and wait. It’s a nice, safe place to come to; it’s warm, and the people are nice. You get snacks and watch football during football season. It’s a real nice place to come to. You can get coffee.”

- "I thought it would be a nice thing to be around people my age, and I had a little interruption in my lifestyle, but I did receive an invitation to come to senior meals at this location.”

When asked, "Is there anything that anyone can think of that you wish was offered at this center that is not currently offered?” a participant responded, "Weekly money for each of us; an allowance on a weekly basis. Thank you.” This was, of course, followed by a burst of laughter. 
Strengths. Some of the strengths related to programming, activities, and services that emerged from this research included:

- Variety and flexibility in programming. Many of the staff and participants in this study alluded to the broad range of services and activities their centers provide for people across income and fitness levels. This was largely a result of the "hands-off" approach with the management of the center. Providing programming throughout the day, on all days of the week, with plenty of opportunities for participating and volunteering, helped build the success of several of these senior centers. Key Informant \#1 noted, “I think it’s going to be important as our population ages to provide different activities that are adaptable and appealing to younger seniors.”

- Providing meals. As many staff members and volunteers pointed out, the provision of meals, or at least a meal site that is conveniently located, such as with Case \#2, is a highly-valued resource for participants. The importance of including delivered meals for the senior center's homebound participants was evident.

- Providing trips. At the senior centers where trips were provided, they were discussed as favored components of the senior centers' programming. A shuttle for the senior center is important not only for providing short transportation trips but also trips to get out of the city and to natural, beautiful areas outside of the city, such as those that Portland has available to it. 
- Providing technology programming. Technology moves at a swift pace in our society, and many older adults want to keep up with the most up-to-date devices, software, programs, and other types of technology. The technology center at Case \#1 provided a unique, successful example of how a center can be effectively run to adapt and meet the needs of new generations.

- Providing fitness programming. It was evident in every case that fitness classes, such as yoga and tai chi, are increasingly in demand. In order for senior centers to continue to facilitate older adults in staying vital in later life, it is important to provide fitness programming, especially programming that is evidence-based and/or classes led by qualified instructors, with individualized help and guidance for senior center participants. This vital, active approach to programming may help bring baby boomers to urban senior centers. Key Informant \#2 agreed that this is a trend for senior centers; she said, "I think some of the images are changing. Some people have the notion that [the senior center]'s kind of an old-school; it doesn't apply to them. But then I think there are some centers that are having more of a brighter outlook, more positive approach - healthy aging, active aging.”

- Providing games. Another strength among the centers related to the groups of participants who gathered for games. Though games are largely selforganized, it was seen as important for the senior centers to provide space for these groups to develop. Many people perceive Bingo as an outdated, stereotypical part of senior center programming, though it has survived in 
some centers. Billiards and other games, particularly Bridge and other structured card games, may be of increasing interest to the older population. In Pardasani and Sackman’s (2014) study of New York senior centers, card games were the most commonly offered program with $99 \%$ of respondents, who were senior center directors and administrators, selecting this option as a program offered at the center, followed by Bingo at $97.2 \%$. "The high frequency of participation in these activities is reflective not only of their popularity among older adults but also of the low level of resources required to offer them,” the authors concluded (p. 207).

Challenges. Some of the challenges related to programming, activities, and services that emerged from this research included:

- Services being cut or eliminated due to lack of funding. The social services component of senior centers, which are primarily publicly-funded and intended to serve the most vulnerable older adults, demonstrated numerous challenges. Staff struggle to try to expand these services, especially those who are already at capacity for space, time, and resources. Staff at centers with AAA contracts expressed a perceived lack of control over this area of programming. The meal programs, in particular, faced numerous challenges. One challenge specific to Case \#1 was the type of congregate meal program that it provides, which is unusually large and includes food prepared on-site that can be expensive. Case \#2 staff mentioned that without having a meal program within the center, staff do not have a captive audience of participants for whom to provide additional programming. Staff at Case \#5 discussed the 
lack of interaction between the congregate meal and other social services participants, many of whom would benefit by accessing both types of programming.

- Providing programming that the community sees as unique, attractive, and relevant to future older adults. One of the staff members made a salient point about senior centers in Portland and their programming:

Portland is interesting, just the way that senior services are contracted out. There are a lot of senior programs. Many churches have a senior program where they have services that they're receiving and they're working with a senior congregation, or there might be a particular organization that has some kind of elder focus. Or it might be like the [Name of center], which is connected with the Salvation Army; their focus is really on meals and trips, and they're not social-service oriented. So I think it's different than some other [places] - even like in Washington, where you just have more senior centers.

Because a lot of older adult programming is offered elsewhere in Portland, there is a high level of competition with, for example, residential facilities. The community needs to be able to see that the senior center makes unique contributions. This can present challenges to staff, many of whom are uncertain of what the baby boomers will want. For example, will congregate meals, which are important now though participation is waning, be attractive to the baby boomers? Case \#1 staff mentioned the particular benefits of attending Information and Assistance meetings, as well as conferences, webinars, and other events, to help 
understand these changing demands. Case \#3 highlighted the importance of trying to pursue any opportunities, such as pilot projects through the city or with another partner, to explore successful ways of planning for the boomers while also maintaining programming for their core participant group. Participants are often resistant to change, but change may be necessary to address some of the challenges associates with programming, activities, and services. 


\section{Chapter Four: Key Findings and Recommendations}

This study was designed to investigate and develop an understanding of: (a) the variations or differences among urban senior centers; (b) how these differences related to the centers' challenges and/or constraints; (c) how these differences related to the centers' strengths and successes; and (d) how urban senior centers can be adaptive and supported in the future. Four dominant themes emerged, among which several different challenges and strengths were identified. The following section provides an overview of the key findings and primary recommendations that emerged for each theme from this study.

\section{Participation and Community Engagement}

Senior center staff are often concerned about how they can improve the experiences of current participants while reaching out to and attracting non-participants. The following recommendations may be useful for senior centers and their communities to find ways to be more inclusive, community-involved, and apparent as places for older adults who are seeking some combination of socialization, services, and recreation.

Inclusivity and involvement. Much discussion throughout the interviews and focus groups in this study focused on how inclusive the senior centers were of different groups and interests. It was apparent that senior centers should provide at least some activities and services at no cost to meet the needs of participants at different income levels, and that these activities and services should be provided without any scrutiny. Senior centers, by nature, do not conduct means-testing and are meant to be inclusive. It seemed that if affordable programming was offered, discussions around what the senior center provided were more positive. Even if the fee structure is inflexible, it is important 
for senior centers to provide scholarships to participants who face challenges due to the programming costs.

Accessibility in senior centers is another important factor for making the center open and inclusive of everyone, regardless of their abilities. Interestingly, as demonstrated by Case \#2, senior center participants don’t always socialize with older adults who have disabilities, especially if there are separate programs for those individuals. This should perhaps be addressed among urban senior centers, as diversity in ages and abilities in participants sharing time and physical space can be beneficial.

As Case \#1 demonstrated, when participants are given the option to provide information about having a disability, disorder or disease, staff can use this confidential information to ensure that programming is accessible and inclusive to meet their needs. Senior centers that provided evening classes were able to accommodate working older adults, many of whom are baby boomers that have financial constraints.

Previous research has explored and discussed many of the issues and strategies for senior center staff members wanting to increase ethnic, cultural, sex and gender, and diversity. As Turner (2004) discussed, senior centers will need to produce different marketing and group activities if they intend to increase senior center participation by males. Walker et al. (2004) suggested that senior centers could reach out to faith-based institutions to increase participation, provide special interest activities to respond to group size, list activities and events in more places (including websites), and provide more transportation alternatives and more frequent transportation services. Some senior centers, as Hooyman and Kayak (2008) pointed out, have located in neighborhoods of color and have successfully attracted older adults who would not participate at centers 
outside their own neighborhoods. Pardasani’s (2004) study of senior service organizations in New York State revealed that increasing the representation of ethnically diverse staff members and providing appropriate programming were associated with greater participation of minority older adults. Staff and communities can work to build strategic partnerships between senior centers and organizations that may have similar target groups, which is often more effective than starting from scratch.

Participants who want to volunteer should be recognized and valued as important resources for senior centers. Tapping older adults who want to volunteer and placing them in meaningful, fulfilling roles not only helps the senior center reduce some of its burden but builds community by integrating volunteers and participants (and possibly encourages volunteers to become participants). This may be the key to encouraging increased participation by men who have recently retired and are seeking new, purposeful roles. It is helpful, as demonstrated by focus group participants in Case \#1, to create a resource (e.g., a blog) for older adults to access and connect to potential volunteer opportunities.

Strengthening communication and information channels about where to go for resources, such as volunteer opportunities, is critically important. Senior centers should work with their partner organizations to build these channels and create two-way communication, as older adults need to both receive knowledge of what is available and contribute input as to what they want to see available. Staff may also want to increase opportunities for participants to provide feedback by hosting listening sessions, as Case \#3 does, or perhaps by asking older volunteers to help them survey participants and perhaps friends of volunteers who don’t participate. 
Intergenerational programming. One of the key findings from this research is that while staff may improve their centers by adding some intergenerational programming, it is critically important that these centers do not become multigenerational or community centers. Older adults receive many benefits from spending time with younger generations and vice versa; they can share their talents and resources and support each other in relationships that have individual and communitywide benefits. Intergenerational activities can increase emotional support, stimulate learning, reduce negative stigmas, enhance social skills, and improve health (Generations United, 2007). These activities, either as specific programs at the senior center or out in the community, should be encouraged; however, the participants in this study, staff and older adults alike, felt that senior centers should not become community centers.

Staff made this point clear, for example, at Case \#1 by explaining how transforming the senior center to a community center would require a significant amount of planning and resources, and that current senior center participants value having their own building. In Case \#2, focus group participants discussed at length the value of coming to place where they can be around people of their own age with whom they can relate. In Case \#3, a staff member said, "For our seniors that come to the center, many of them come here because they want to be surrounded by peers. And they're not comfortable going into a community center setting.” A staff member at Case \#4 felt strongly about the commitment to serve the older adult population and that plenty of recreation centers already offer intergenerational programming. Focus group participants at Case \#2 echoed this sentiment, saying that having children nearby was a good thing, but that having them in the center throughout the day would be "totally inappropriate." 
These findings verified research on generation identification discussed in the literature review that posits that older adults benefit by interacting and identifying with other older adults, which helps them to cope with age-related changes and fosters a positive image of self (Weiss \& Lang, 2012).

Defining image and the term "senior center." Another key finding from this research is that staff and participants commonly perceived the term "senior" as problematic, with the exception of a staff member from Case \#3 who noted that the name "senior center" helps new, unfamiliar residents seek out the place with which this name is traditionally associated. Focus group participants suggested marketing to "people who have grandkids" or using "social center;" the two cases in this study that do not use "senior center" in their name have similarly generic names, and staff at these senior centers acknowledged that these names don't quite convey the image or identity of the center appropriately. One of the staff members in this study said: "It's kind of hard to come up with a name...you know, you don’t want to say “aging”; what can you come up with that has a positive spin?”

Harwood (2007) explained that using the term "older adult" is "about as vanilla as you can get (p. 44).” Perhaps confronting age stereotypes, and attempting to reverse the stigma of the word "senior" would be a better approach than changing the name altogether. As Key Informant \#1 explained, "You can either change the definition of the word or you can change the word. It all depends on how you want to go.” She noted that many people not only identify with the word "senior," but take pride in it. She used the word "liberal" as a comparison: 
Many people thought of liberal as a dirty word for a long time; that was an insult to people to say, 'Oh well, you are a liberal.' And then there was a point where there was a turn, in the early aughts; people were like, 'I'm a liberal!' And it just created this group of people who were okay with identifying with that. And you're not going to create one universal word that everyone will identify with. More importantly, it seems useful for senior centers to clarify their purpose and advertise their full scope of programming and impact to the community. NCOA accreditation can be a useful tool (especially to those who need a strategic plan and lack a strong network of partners) to improve senior centers' community recognition and engagement; however, this seems possible only at centers where staff can take on extra responsibilities, funding is available to complete the process, and several passionate volunteers are available to serve on the accreditation board.

Combatting age denial and stigma may continue to be an uphill battle involving the creation of marketing materials that depict younger, active older adults; bridging gaps between groups and organizations with sustained, interactive partnerships to help raise awareness; and promoting education at all levels about the damaging, hurtful consequences of perpetuating negative stereotypes.

It is important for senior centers to make everyone feel welcome, and strive to be open, inclusive places, but they also need to define their purpose and foster awareness of senior centers as safe, inviting spaces where people of a certain age (to be determined by staff) can gather to socialize, share resources, and thrive. 


\section{Administrative Structure and Funding}

Senior centers remain important and relevant. They need more support and, as John Krout said, should not deny or forget their history but continue to build on their strengths (Niles-Yokum \& Wagner, 2011). Some of their biggest successes - such as the fitness, technology, and support groups - have arisen from unique administrative and funding structures, and their ability to be innovative and flexible to change. They will clearly need to continue adapting to meet the needs of boomers while continuing to serve the Silent Generation for some time, which means maintaining their current services and structures but making the appropriate adjustments to meet the needs and interests of future generations.

In the context of this study, in which the cases vary drastically in their administrative structures and funding, the following recommendations may be helpful, for both staff and for the communities associated with urban senior centers, in building on the challenges and strengths of senior centers to achieve a high level of excellence in administrative structure and funding.

Strong community support system. This study demonstrated the importance of developing a strong support system, including advisory board members, community advocates and partners, who can cheer on, represent, and champion the efforts of senior centers in the face of threats. Many senior centers are structured in ways that present obstacles and prevent them from overcoming these obstacles. A strong network of partners in aging services can help them achieve their goals and alleviating some of the responsibilities of staff at urban senior centers. 
Senior centers and communities should also recognize the importance of a strong volunteer base for the centers; volunteers are not only engaging in meaningful, purposeful work but can step in to help with certain areas that staff cannot, such as marketing, grant writing, and research/reporting on current legislation. Boards of directors should comprise a variety of participants, business members, community members, and government officials; they should be dynamic and innovative and focus on fundraising as a single component of a range of ways that senior centers can be supported.

If urban senior centers choose to be co-located with other older adult services or programs, they could benefit by potentially capturing new participants and perhaps partnering with the co-located entities. Agreements need to be established about, for example, sharing space and maintaining security. Co-locating may be a good option for senior centers that have volunteers who can serve as a bridge between the organizations. However, if urban senior centers are not co-located, there are certain advantages for senior centers occupying their own buildings, such as flexibility in the use of the space.

Another finding from this research is that urban senior centers, at least in this study, do not have an umbrella organization that connects them well. Staff seemed to be aware of, and occasionally meet with, staff from other senior centers; however, a lot of benefits may be gained from senior centers in the same region connecting to one another and sharing resources.

Flexible, positive staff environment. The cases in this study also demonstrated the benefits of management including consensus-based decision-making, teamwork, cross-training, face-to-face interaction, institutional memory, and morale-building. It 
was important to staff of these senior centers that they were allowed to be creative and to work without feeling micro-managed.

Case \#1 provided an example of how a retreat can be useful for building staff morale and creating a fresh start for the senior center every year. For a positive staff environment, offices should be arranged with some shared space for face-to-face interaction, but also some private space, especially for case managers who are providing sensitive information to their senior center participants.

Urban senior centers set up as nonprofit organizations could potentially be managed largely by volunteers, but as Case \#2 demonstrated, they need to have at least one paid staff member to ensure continuity. Case \#4 exemplified how staff with backgrounds and/or certifications in aging and gerontology can bring great value to the management of the center.

Multiple revenue sources. As demonstrated through the literature and throughout this study, it is important that urban senior centers do not rely solely on public funding. They should continually seek out donations, which may be obtained more successfully if centers can demonstrate the need for donations to the public by being transparent about their impact. This may be possible, also, if volunteers are available and willing to commit unpaid time to grant writing and public relations. Staff in publicly-funded senior centers should strive to publicize the full scope of their work in order to gain support and reduce pressure on those staff who are most visible to the public. Urban senior centers should perhaps affiliate with recognizable organizations, such as MOW, to help attract support from community members. It was also evident from this research that fundraisers can be 
great community-builders and engaging events for participants, even if they aren’t substantial revenue-generators

\section{Transportation and Physical Environment}

Many urban senior centers will face even greater issues with regard to transportation and physical space than those in the present study, since Portland is a relatively new city compared to many others and is often lauded for its unique, welldesigned transportation system. In a report that ranked metropolitan areas based on the percentage of older adults that are projected to have poor transit access in 2015, results confirmed that across the U.S. and regardless of the size of the metropolitan area, older adults are going to find themselves without adequate public transportation (Ball, 2003).

As one would expect, there seems to be a correlation between younger age, better health, and driving (Ball, 2003). As transportation plays a crucial role in accessing senior centers, they best serve their target population when they are closer to higher concentrations of older adults or future older adults. Ideally, senior centers should also be flexible, so that as populations change, they can serve a range of ages. Accessibility should ideally be integrated for the entire trip to the senior center, as close proximity to a senior center offers little benefit if accessibility along the way is not provided.

The following recommendations may be useful for senior centers to find ways to improve the transportation and physical infrastructure associated with urban senior centers.

Specific funding opportunities. Senior center staff may be successful in seeking out revenue from funding sources that can be used specifically for transportation and building improvements and upgrades. As Case \#3 demonstrated, transportation 
assistance is a huge value for participants. This kind of assistance, such as donated transit passes, should be pursued as a way to alleviate some of the transportation costs for participants who are living on limited incomes. If possible, urban senior centers should work with their community partners to raise money for purchasing and operating shuttles. Even if such shuttles can operate only within a relatively small boundary, they can make the difference for some participants in whether they are able to participate in the senior centers or not. Shuttle service should be accessible and an affordable option for participants, especially when there are few public transportation options. Day trips, if they can be offered, are a highly valued part of senior center programming. Another innovative example revealed in this study was a senior center shuttle that provides mobile fitness to satellite facilities and serves further out, homebound participants.

Volunteers and partnerships. Harnessing the power of volunteers who drive can be a powerful option for addressing transportation needs of urban senior center participants. Volunteers can bring participants to the center or to other services (e.g., medical appointments), or they can provide for home visits to help reduce social isolation among homebound participants. Senior centers can also partner with organizations, for, as Case \#4 exemplified, additional parking or to connect participants who are homeless and/or have mental illness to more appropriate resources. It could be beneficial for urban senior centers to explore building space in which they could co-locate with partners, as demonstrated by Case \#2, which benefits from accessible building space and close proximity to other resources for older adults. Partnerships can also help senior centers advocate for affordable aging in place strategies within their communities and ensure that services and resources are available for older adults to continue to live independently. 
Creativity with the space. Though more space is often desired within senior centers, a lack of options for expanding may require staff to be creative with the use of existing space. Keeping accessibility at the forefront as a priority, staff can explore ways to repurpose rooms and perhaps add outdoor elements. Even if the center cannot be expanded to include space outdoors, staff may want to be innovative in bringing outdoor elements into the space by, for example, allowing natural light and adding plant life. Rooms that are multi-purpose are much more useful and efficient, as demonstrated throughout this study, than rooms that serve single purposes. Interior design experts can be helpful in exploring ways that urban senior centers can design and transform their spaces to meet their needs without expanding.

\section{Programming, Activities, and Services}

As senior center staff and communities consider the issues, challenges, and ideas discussed in the previous three sections, they must also continue to contend with the central components and purposes of senior centers: the programming, activities, and services these centers provide. The following recommendations cull findings from this research and provide ideas about maintaining and shaping programming so that urban senior centers can be adaptable moving forward.

Explore, learn, and try new things. One of the ways that senior centers may be able to learn about participants' interests - aside from administering surveys, holding listening sessions, and establishing an advisory board - is to implement a tracking system such as the example of key tags in Case \#1. Many current online businesses, such as Amazon or streaming music services such as Pandora, track and analyze data in order to advertise or suggest additional products and services to their users. Senior center staff 
may find similar innovative ways to track and analyze the activities and services that new and existing participants are using. This may even allow them to maintain or attract funding by demonstrating the need for those activities and services.

Staff at the cases in this study also found it helpful to meet with staff at other organizations, such as other information and assistance staff, as well as to attend webinars and conferences. Through these meetings and events, staff can find out what other centers are offering, what can be improved, and where their centers can fill gaps. They should also consider regularly checking resources such as the NISC website to obtain updated information about senior centers nationwide.

Aside from numerous other benefits mentioned earlier, it is also important for senior center staff to connect with organizations and home and community based services in the community to understand what they are offering and work together as partners rather than competitors. As Turner (2004) suggested, senior centers may, perhaps, better address the needs of older individuals by acting as bases of operations to link residents to other services and activities in their communities, rather than relying on the creation of new activities to attract new members.

Above all, it is important to move forward in trying new things but be open to change later (for example, don’t become a community center, but offer intergenerational programming and assess how it fits with the center's mission). Staff should, when possible, say “yes” to new projects, including research or pilot projects. Importantly, as this study demonstrated, urban senior centers that market themselves as multi-purpose should strive for a balance so that they are not providing new activities to the detriment of services (and vice versa). 
Services. Services that seem to be most in demand, based on the findings from this research, include caregiving services, in-home services (including delivered meals), workforce or employment opportunities, support groups, heath services (e.g., foot clinic), and information and assistance (e.g., tax aide, fraud protection, navigating federal programs).

Preventive health programming, in particular, seems to be desired, though affordable health promotion activities should be added (see below). Congregate meals may not be as attractive to baby boomers, but activities that encourage gathering and socialization (e.g., games) are likely to be. Meals need to be attractive and nutritious if baby boomers are going to come to congregate meal sites. They might be interested in meal sites anyway, as food is a natural gathering mechanism; however, other options may also need to be considered, such as pre-packaged foods that people can take home and heat up themselves.

Of increasing importance for home and community based services is the coordination of health and housing, which assists people with aging in place. Traditionally, health and housing services are separated into different professional and service sectors; therefore, they are not coordinated to address the needs of older residents in a holistic manner. Older adults' health and housing needs are often inseparable, however. and local governments can coordinate with senior centers and pool resources to facilitate this coordination of health and housing services (Ball, 2003). The example provided by Case \#3, in which home visits combine case management with wellness visits, demonstrate how housing and health can be addressed together and how senior centers can facilitate this process. 
Activities. Activities that seem to be most in demand, based on the findings from this research, include health and wellness programming, new technology, and day trips. Staff members may want to explore ways to provide evidence-based exercise options for people at every level of physical ability, and ways to make these options affordable through Medicare or private insurance plans. Particular exercises, such as tai chi, are beneficial to older adults because they emphasize strength and balance for falls prevention. Future participants may be increasingly interested in functional fitness assessments that allow them to learn about the most appropriate classes and levels for them to take. Fitness should also be individualized and comfortable, as these characteristics have been appealing to senior center participants who found these lacking at all-ages gyms. Partnering with health organizations and perhaps universities that have fitness certification programs may provide opportunities to bring in volunteer fitness instructors to provide classes, assessments, or both.

Volunteers may also be available to help with setting up and operating a technology center, similar to the one at Case \#1 or the classes offered at Case \#4. It seems that having at least one computer is useful, especially for participants who are coming in to use the computer as a resource for, as an example, submitting job applications.

Space should also be available for activities such as billiards and games, and perhaps activities such as outdoor games (such as Bocce) or the Wii that help promote physical activity. Partnering with other organizations, such as Parks and Recreation departments, may open up access to space for these types of programming.

As mentioned earlier, day trips are also increasingly valued. A variety of trips may be offered to provide affordable options, such as trips to cultural centers or 
museums, as well as more expensive, longer trips, such as weekend trip to the coast; however, senior centers will likely need increased funding, staffing, and partnerships in order to make these successful.

Other types of programming, as listed in the Pardasani and Sackman (2014) study of New York senior centers, may potentially include (as examples): movie or book appreciation clubs, dancing, arts and crafts, story-telling, foreign-language clubs, fashion shows, and bowling. The needs and desires of the baby boom generation and the generations that follow will, of course, guide the development of new senior center activities in the future. 


\section{Chapter Five: Conclusion}

As the population age structure changes, and as the unique generation of baby boomers reaches older adult age, cities are being challenged to provide supportive environments for their older residents who want to continue to age in place. Portland is

among many U.S. cities that are witnessing growth in the number of older adults within urban cores and their periphery areas. Ongoing efforts, such as the Age-Friendly Portland initiative, are focusing on the home and community based services and resources available to help older residents continue to live active and independent lives full of meaning.

Senior centers have played a critical role, and will continue to play this role, as focal points providing socialization, recreation, services, activities, and other resources in an environment in which older adults share common identities. Although they are facing numerous challenges, and their continued necessity and existence has been in question, there are increasingly numerous examples of innovation and reinvention of senior centers for them to adapt to their changing circumstances. It is important for senior centers to develop broad, inclusive programming to meet the needs of a range of older adults, including the baby boomers and future generations, while maintaining the components that make them most unique: "total concern for older people" and "concern for the total older person”(Niles-Yokum \& Wagner, 2011, p. 36).

Will future cohorts of older adults use senior centers? Arguments can be made that they will, especially as senior centers continue to adapt according to the needs of current older adults. People are naturally drawn to social interaction, and gerontology theories suggest that older individuals benefit by remaining active and maintaining roles 
and social relationships. Like generations before them, they will continue to seek out and orchestrate environments that allow them to thrive. Because senior centers originate within and reflect their communities, programming will emerge including to what is most demanded. Senior center leaders will need to strive for a balance to meet the needs and interests of their participants experiencing frailty and low incomes as well as participants who are seeking active, engaged roles. The latter group of participants may be critical to the success of future senior centers, as they may be able to volunteer as staff, as advocates, and as the primary resources for the maintenance and operation of the centers.

Some of the senior centers' biggest challenges, such as attracting new and diverse participants, political and financial threats, and transportation and accessibility issues, can be approached by harnessing the power and support of their volunteers and partners. Much of the ability of senior centers to be successful hinges on their funding. The strengths and successes with regard to funding - as demonstrated in this research - are often dependent on the ability to attract new funding sources and/or affiliate with large, successful organizations such as city departments or successful nonprofits with philanthropic support. Senior centers can garner support by applying existing guidelines and standards to their operations, and new models of senior centers may offer some potential pathways for future development. It is important that centers designed specifically for older adults continue to exist with clarity of purpose for those they want to serves. Overall, senior centers and their communities can work collaboratively to build up the strong network of resources needed for senior centers to be successful, to engage their new and diverse participant population, and to design programming that fits the needs of all older generations in the coming years. 


\section{Study Contributions}

Theoretical. Research on senior center participation has not been guided by a particular theoretical or conceptual framework; however, this study contributes to ongoing research of what senior centers are/should be, whom they serve/should serve. It also contributes to the conceptual frameworks of activity theory and continuity theory. The research demonstrates how senior centers apply activity theory by providing opportunities for older individuals to maintain social roles and interaction. It also demonstrates how senior centers apply continuity theory by providing activities that allow older individuals to maintain self concepts, relationships, and ways of living. The continuation of senior centers is important as they facilitate the process of active aging and aging in place.

Practical. This research helps to inform the changing roles of these centers in home and community based services as they help older adults age in their communities. It provides a unique, holistic perspective of senior centers that may assist senior center administrators and staff in shaping their centers to be adaptive and flexible, and in demonstrating the relevance of their centers to policymakers and funders. The research also offers ways that initiatives, such as creating age-friendly communities, can utilize and build on the work of senior centers to advance their initiatives. In addition, the research demonstrates how community leaders, planners, policymakers, and funders can support senior centers to facilitate the aging in place of their community residents. 


\section{Study Limitations}

This research was limited by the following aspects:

- This study focused only on urban senior centers; senior centers were selected within the urban growth boundary that is managed by Metro, the elected regional government for the Portland metropolitan area. This boundary separates urban land from rural land according to Oregon law (Metro, 2015). As a result, the study findings cannot be generalized to rural settings.

- This was a bounded case study that limited the number of cases; only two cases were used to represent each senior center conceptual model, and only one case was used to represent a nationally accredited senior center (as it is the only one in the Portland metropolitan area). No single-purpose senior centers were included in the research.

- Research participants lacked cultural and ethnic diversity, so findings may not be applicable to more diverse senior centers.

- This study involved more than one case, so the overall analysis was diluted, limiting the depth of data collection for each case (Creswell, 2007).

- This study was strictly qualitative; it therefore lacked the robustness of using a mixed-methods approach. 


\section{Future Research}

This study revealed many themes that should be explored more deeply. For example, it would be beneficial to map senior centers and services with an overlay of the demographics of a region, along with the locations of amenities such as public transportation stops and community-based care facilities. Combined with survey research of a broader sample of senior center staff and participants, a future study could examine the relationships between various factors, such as access to frequent bus lines and participant characteristics. A more in-depth analysis of staff and participant characteristics in general might be useful to compare with previous research to understand how senior center participants and staff may be changing over time. In a similar vein, it would be useful to conduct a longitudinal study of the senior centers in this study to understand how their challenges and strengths are manifesting over time. Perhaps an intervention, such as the accreditation process, could be used to explore whether a senior center's experiences are better, worse, or the same after enduring the process of accreditation.

It would be beneficial to collect data from a diverse sample of baby boomers to help forecast their needs and desires with regard to senior centers. Additionally, research is needed on senior center leadership profiles and organization philosophies, especially as future staffing of senior centers remains an unknown and important issue. 


\section{References}

AARP. (2009). 2009 AARP-United Nations briefing series on global aging. AARP Office of International Affairs. Retrieved from http://www.globalaging.org/elderrights/world/2009/AARPbriefing\%20series.pdf

Aday, R.H. (2003). The evolving role of senior centers in the 21st century. Report to Senate Special Committee on Aging. Murfreesboro, TN: Middle Tennessee State University. Retrieved from http://www.indiana.edu/ leisure/module2/unit3_LA2/readings/AdayRole\%20of\%20Sr\%20Ctrs.pdf

Aday, R., Kehoe, G., \& Farney, L. (2006). Impact of senior center friendships on aging women who live alone. Journal of Women Aging, 18(1), 57.

Administration on Aging. (2006). Unofficial compilation of the Older Americans Act of 1965. Retrieved from http://www.aoa.gov/AOA_programs/OAA/oaa_full.asp Administration for Community Living. (2015). Administration for Community Living. U.S. Department of Health and Human Services: Washington, D.C. Retrieved from http://www.aoa.acl.gov/

Age-Friendly Portland. (2015). Background information. Retrieved from http://agefriendlyportland.org/about/background-information/

Age-friendly Portland Advisory Council. (2013). Action plan for an age-friendly Portland. Portland, OR: Portland State University. Retrieved from http://www.aarp.org/content/dam/aarp/home-and-family/livablecommunities/2014-01/age-friendly-portland-action-plan.pdf 
Alt, P. M. (1998). Future directions for public senior services: Meeting diverging needs. Generations, 22, 29.

Atchley, R.C. (1989). A continuity theory of normal aging. The Gerontologist, 29(2), 183-190.

Bailey, L. (2004). Aging Americans: Stranded without options. Surface Transportation Policy Project: Washington, D.C. Retrieved from http://www.apta.com/resources/reportsandpublications/Documents/aging_strande d.pdf

Ball, M.S. (2003). Aging in place: A toolkit for local governments. A Project of the Atlanta Regional Commission. Atlanta, Georgia. Retrieved from http://www.aarp.org/content/dam/aarp/livable-communities/plan/planning/agingin-place-a-toolkit-for-local-governments-aarp.pdf

Berg, B.L. (2007). Qualitative research methods for the social sciences (6 ${ }^{\text {th }}$ Ed). Boston, MA: Pearson Education, Inc.

Calsyn, R. \& Winter, J. (1999). Who attends senior centers? Journal of Social Service Research, 26(2), 53.

Carstensen LL. (1986). Social support among the elderly: Limitations of behavioral interventions. The Behavior Therapist. 6, 111-113.

Carstensen LL. (1987). Age-related changes in social activity. In L.L. Carstensen \& B.A. Edelstein (Eds.), Handbook of clinical gerontology (pp. 222-237). New York: Pergamon Press. 
Carstensen LL. (1989). A longitudinal analysis of social and emotional dimensions of interpersonal relationships. Paper presented at the annual meeting of the Gerontological Society of America: Minneapolis, MN.

CDC (Centers for Disease Control and Prevention). (2013). Healthy places terminology. Retrieved from http://www.cdc.gov/healthyplaces/terminology.htm

City-Data Forum. (2015). New Census county population estimates for Oregon (released March 2014). Retrieved from http://www.city-data.com/forum/oregon/2085203new-census-county-population-estimates-oregon.html\#ixzz3Sh5xvW8d Colby, S.L. \& Ortman, J.M. (2014). The baby boom cohort in the United States: 2012 to 2060. Current Population Reports, pp. 25-1141. U.S. Census Bureau: Washington, D.C.

Cox, C. \& Monk, A. (1990). Integrating the frail and well elderly: The experience of senior centers. Journal of Gerontological Social Work, 115(3/4), 131-147.

Creswell, J.W. (2007). Qualitative inquiry and research design: Choosing among five approaches (2nd Ed). Thousand Oaks, CA: Sage.

Cumming, E., \& Henry, W.H. (1961). Growing old: The process of disengagement. New York: Basic Books.

Dal Santo, T.S. (2009). Senior center literature review: Reflecting \& responding to community needs. California Commission on Aging. Retrieved from http://www.ccoa.ca.gov/res/docs/senior-cntr_1/Literature_Review.pdf

DeGood, K. (2011). Aging in place, stuck without options: Fixing the mobility crisis threatening the Baby Boom generation. Transportation for America: Washington, D.C. Retrieved from http://t4america.org/docs/SeniorsMobilityCrisis.pdf 
DeLaTorre, A., DeLaTorre, T., Neal, M., Carder, P., Weinstein, J., DeShane, M., \& Wilson, K.B. (2012). Planning for our aging society. Metroscape, Winter 2012, $14-20$.

Fitzpatrick, T.R. \& McCabe, J. (2008). Future challenges for senior center programming to serve younger and more active baby boomers. Activities, Adaptation \& Aging, 32, 3-4.

Foley, D., Heimovitz, H., Guralnik, J., \& Brock, D. (2002). Driving life expectancy of persons aged 70 years and older in the United States. American Journal of Public Health, 92(8).

Fredrickson, B. L., \& Carstensen, L. L. (1990). Choosing social partners: How old age and anticipated endings make people more selective. Psychology and Aging, 5(3), 335-347.

Fredriksen-Goldsen, K. I., Kim, H.-J., Emlet, C. A., Muraco, A., Erosheva, E. A., HoyEllis, C. P., Goldsen, J., \& Petry, H. (2011). The aging and health report: Disparities and resilience among lesbian, gay, bisexual, and transgender older adults. Seattle, WA: Institute for Multigenerational Health.

Gardella, L. (2011). The Life and Thought of Louis Lowy: Social Work through the Holocaust. Syracuse, NY: Syracuse University Press.

Gelfand, D.E. (2006). The aging network: Programs and services. New York, NY: Springer Publishing Company.

Generations United. (2007). Fact sheet: The benefits of intergenerational programs. Retrieved from 
http://www.gu.org/LinkClick.aspx?fileticket=71wHEwUd0KA\%3D\&tabid=157\& $\operatorname{mid}=606$

Hooyman, N.R., \& Kiyak, H.A. (2008). Social gerontology: A multidisciplinary perspective ( $8^{\text {th }}$ Ed.). New York, NY: Pearson.

IOM (Institute of Medicine). (2011). The health of lesbian, gay, bisexual, and transgender people: Building a foundation for better understanding. Washington, DC: The National Academies Press.

Kane, R.A. (2012). Thirty years of home-and community-based services: Getting closer and closer to home. Generations, 36(1), 6-13.

Kastenbaum, R. (1993). Disengagement theory. In R. Kastenbaum (Ed.), Encyclopedia of adult development (pp. 126-130). Phoenix, AZ: Oryx Press.

Keenan, T. A. (2010). Home and community preferences of the $45+$ population. AARP: Washington, D.C.

Kent, D. (1978). The how and why of senior centers. Aging, 281-282, 2-6.

Kinsella, K., \& He, W. (2009). An aging world: 2008 (U.S. Census Bureau Publication No. P95/09-1). Washington, DC: U.S. Government Printing Office.

Krout, J. (1987). Rural-urban differences in senior center activities and services. Gerontologist, 27, 92-97.

Krout, J. (1988). The frequency, duration and stability of senior center attendance. Journal of Gerontological Social Work, 13, 3-19.

Krout, J. (1990). The organization, operation and programming of senior centers in America: A seven year follow-up. Fredonia, NY: Unpublished. 
Krout, J., Cutler, S., \& Coward, R. (1990). Correlates of senior center participation: A national analysis. The Gerontologist, 30, 72-79.

Lawler , K. (2011). Transforming senior centers into 21st century wellness centers. AARP Louisiana. Retrieved from http://www.aarp.org/livablecommunities/act/civic-community/info-12-2012/transforming-senior-center-into21st-century-wellness-centers.html

Lawton, M.P. (1987). Environment and the need satisfaction of the aging. In L.L. Carstensen \& B.A. Edelstein (Eds.), Handbook of clinical gerontology (pp. 3340). New York: Pergamon Press.

Lemon, B.W., Bengston, V.L., \& Peterson, J.A. (1972). An exploration of the activity theory of aging: Activity types and life expectation among in-movers to a retirement community. Journal of Gerontology, 27, 511-523.

Litman, T. (2015). Land use impacts on transport: How land use factors affect travel behavior. Victoria Transport Policy Institute (with Rowan Steele). Retrieved from http://www.vtpi.org/landtravel.pdf

Meals on Wheels People. (2015). Loaves and Fishes Centers. Retrieved from http://www.mealsonwheelspeople.org/

Microsoft. (2010). Virtual senior center connects homebound seniors to community and family. Retrieved from http://www.microsoft.com/enus/news/press/2010/mar10/03-10vscpr.aspx

Morgan, D.L. (1997). Focus groups as qualitative research (2nd. Ed). Qualitative Research Methods, Series 16. Thousand Oaks, CA: Sage Publications. 
Morgan, L.A. \& Kunkel, S.R. (2011). Aging, society, and the life course (4 ${ }^{\text {th }}$ Ed). New York, NY: Springer Publishing Company.

National Council on Aging. (1979). Senior center standards: Guidelines for practice. Washington, DC: National Council on Aging.

National Council on Aging. (2012b). Senior center fact sheet. Retrieved from http://www.ncoa.org/assets/files/pdf/FactSheet_SeniorCenters.pdf

National Council on Aging. (2015a). Older Americans Act reauthorization. Retrieved from http:/www.ncoa.org/public-policy-action/older-americans-act/

National Council on Aging. (2015b). National Institute of Senior Centers: Standards and accreditation. Retrieved from http://www.ncoa.org/national-institute-of-seniorcenters/standards-accreditation/

National Council on Aging. (2015c). National Institute of Senior Centers: Benefits of accreditation. Retrieved from http://www.ncoa.org/national-institute-of-seniorcenters/standards-accreditation/benefits-of-accreditation.html

National Research Council. (2004). Critical perspectives on racial and ethnic differences in health in late life. In N.B. Anderson, R.A. Bulatao, \& B. Cohen (Eds.), Panel on Race, Ethnicity, and Health in Later Life. Committee on Population, Division of Behavioral and Social Sciences and Education. Washington, DC: The National Academies Press. Retrieved from http://www.ncbi.nlm.nih.gov/books/NBK25528/

Neal, M.B., DeLaTorre, A.K., \& Carder, P.C. (2014). Age-Friendly Portland: A University-City-Community Partnership, Journal of Aging \& Social Policy, 26:12, 88-101, doi: 10.1080/08959420.2014.854651 
Netherland, J., Finkelstein, R., \& Gardner, P. (2011). The age-friendly New York City project: An environmental intervention to increase aging resilience. In B. Resnick, L. Gwyther, \& K. Roberto (Eds.), The handbook of resilience in aging: The key to successful aging (pp. 273-287). New York, NY: Springer Publishing.

Niles-Yokum, K. \& Wagner, D.L. (2011). The Aging Networks: A Guide to Programs and Services (7th Ed). New York, NY: Springer Publishing.

Oregon Health Authority. (2014). CD summary, Vol. 63 (No. 15). Oregon Public Health Division. Retrieved from http://public.health.oregon.gov/DiseasesConditions/CommunicableDisease/CDSu mmaryNewsletter/Documents/2014/ohd6315.pdf

Metro. (2015). Urban Growth Boundary. Retrieved from http://www.oregonmetro.gov/urban-growth-boundary

Ortman, J.M., Velkoff, V.A., \& Hogan, H. (2014). An aging nation: The older population in the United States. Current population reports, pp. 25-1140. U.S. Census Bureau. Washington, D.C.

Palmore E. (1981). Social patterns in normal aging: Findings from the Duke Longitudinal Study. Durham, NC: Duke University Press.

Pardasani, M. (2004). Senior centers: Focal points on community-based services for the elderly. Activities, Adaptation \& Aging, 28(4), 27-44.

Pardasani, M., \& Thompson, P. (2012). Senior centers: Innovative and emerging models. Journal of Applied Gerontology, 31: 52 
Pardasani, M., \& Sackman, B. (2014). New York City senior centers: A unique, grassroots, collaborative advocacy effort. Activities, Adaptation \& Aging, 38:3, 200-219.

Pruchno, Rachel. (2012). Not your mother’s old age: Baby boomers at age 65. The Gerontologist 52(2), 149-52.

Quadagno, J. (2011). Aging and the life course: An introduction to social gerontology (2 ${ }^{\text {nd }}$ Ed.). New York, NY: McGraw-Hill.

Ralston, P. A. (1991). Determinants of senior center attendance and participation. Journal of Applied Gerontology, 10(3), 258-273.

Ralston, P. \& Griggs, M. (1985). Factors affecting utilization of senior centers: Race, sex, and socioeconomic differences. Journal of Gerontological Social Work, 9, 99111.

Ride Connection. (2015). About Ride Connection. Retrieved from http://www.rideconnection.org/ride/AboutUs.aspx

Schulz, J.H. \& Binstock, R.H. (2006). Aging nation: The economics and politics of growing older in America. The John Hopkins University Press. Baltimore, MD.

Skufca, L. (2008). Is the cost of gas causing Americans to use alternative transportation? AARP. Washington, D.C.

Taietz, P. (1976). Two conceptual models of the senior center. Journal of Gerontology, 31, 219-222.

Taylor, P. (2014). The next America: Boomers, Millenials, and the looming generational showdown. New York, NY: Public Affairs. 
Trela, J.E., \& Simmons, L.W. (1971). Health and other factors affecting membership and attrition in a senior center. Journal of Gerontology, 26, 46-51.

TriMet. (2015). Maps and schedules. Retrieved from http://trimet.org/schedules/index.htm.

Turner, K.W. (2004). Senior citizens centers: What they offer, who participates, and what they gain. Journal of Gerontological Social Work, 43, 37.

Wagner, D. (1995). Senior center research in America: An overview of what we know. In D. Shollenberger (Ed.), Senior Centers in America: A Blueprint for the Future. Washington, D.C. The National Council on Aging. Accessed at ncoa.org/nationalinstitute-of-senior-centers/research-promising-practices/

Wahl, H-W., \& Weisman, G.D. (2003). Environmental gerontology at the beginning of the new millennium: Reflections on its historical, empirical, and theoretical development. The Gerontologist, 43(5), 616-627.

Walker, J., Bisbee, C., Porter, R., \& Flanders, J. (2004). Increasing practitioners’ knowledge of participation among elderly adults in senior center activities. Educational Gerontology, 30(5), 353-366.

Weiss, D. \& Lang, F.R. (2012). The two faces of age identity. GeroPsych: The Journal of Gerontopsychology and Geriatric Psychiatry, 25(1), 5-14. Retrieved from http://dx.doi.org/10.1024/1662-9647/a000050

Whitborne, S.K. \& Whitborne, S.B. (2011). Adult development \& aging: Biopsychosocial perspectives ( $4^{\text {th }}$ Ed.). Hoboken, NJ: John Wiley \& Sons.

World Health Organization. (2007). Global age-friendly cities: A guide. Geneva: World Health Organization Press. Retrieved from 
http://www.who.int/ageing/publications/Global_age_friendly_cities_Guide_Engli sh.pdf

Yin, R.K. (2002). Case study research: Designs and methods ( $3^{\text {rd }}$ Ed.). Thousand Oaks, CA: Sage Publications.

Young, T. (2006). Centers (don't say senior) look to get hip. Where to retire, 15(1). 


\section{Appendix A:}

\section{Portland State University Institutional Review Board Application}

\section{IRB Application}

\section{Formatting Guidelines}

The IRB application has three parts:

1. Investigator's Assurance cover sheet (Section I)

2. Narrative application (Sections II-X)

3. Appendices (Section XI)

Applications must be written in at least 12 pt font. Applications must be page numbered. Please submit complete applications with Investigator Assurance form to hsrrc@pdx.edu.

\section{Investigator's Assurance}

This form, located here on page 5, is separate from the narrative guidelines below. This form serves as the researcher's contact information page and signature of assurance. This form must be filled out completely and accompanied by the proper signatures. Electronic signatures will be accepted from @pdx.edu email accounts.

(See Page 2) 


\section{Section 1: Investigator's Assurance}

Principal Investigator (or faculty advisor)_Sy Adler__ E-Mail ___ d3sa@pdx.edu___
Co-Principal Investigator __N/A__ E-Mail $\_$

Other Personnel (GA, Project Mgr., etc.) E-Mail

Dept. __Urban Studies and Planning Campus Mail Code ___ USP Preferred Phone \# _ 970-310-

8627

Title of Proposal ___ Senior Centers in the Portland Metropolitan Area: How are They Positioning Themselves Amid Changing Conditions?_

Mailing Address IOA, P.O. Box 751, Portland, OR 97201-0751

Proposed Duration of Project (months/years) _ 18 months Anticipated Start Date _

Type of Funding (Federal/Federal pass-through/State/Foundation/Other/None) __ None

Funding Agency: N/A PIAF \#

If funded: Have the PI/co-PI completed the annual financial conflict of interest in research disclosure?

yes $\_$no

Does this project create any changes to the current disclosure?

yes $\_$no

PLEASE NOTE THAT DATA COLLECTION CANNOT BEGIN UNTIL APPROVAL IS GRANTED BY HSRRC. 


\section{Investigator's Assurance}

A. I will promptly report changes in the proposed study and any unanticipated problems involving risk to subjects, including adverse reactions, to the Human Subjects Review Committee. In case of DHHS supported activities, I will also report these problems to the Department of Health and Human Services (through the respective granting office).

B. I assure that documentary evidence of informed consent will be retained for at least three years after the proposed study has been completed or discontinued.

C. Since the Committee is obligated to review this activity at least on an annual basis, I will furnish it with a progress report approximately six weeks prior to the expiration of my project’s approval.

D. I, the undersigned, will be responsible for the ethical standards of this project, and for protecting the rights and welfare of the subjects.

\section{- Sy Adler}

Signature of Principal Investigator or Faculty Advisor

Date

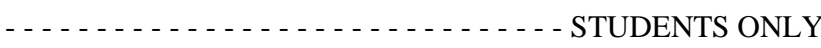

Student ID \# $\mathbf{9 8 0 7 2 0 0 6 1} \quad$ Master's Thesis $\quad$ PhD Dissertation (Approval Date: $5 / 31 / 13)$

Other:

*Projects and studies that do not meet the definition of human subjects research may not require HSRRC

over

Under advisement from the above faculty member, I verify that I will conduct this research in accordance with PSU's Human Subjects Research Review Policy.

Student (print and sign)__Melissa Cannon Email___mcan@pdx.edu

Please submit completed applications to RSP (srrc@pdx.edu). 


\section{Project Title \& Prospectus}

In 300 words or less, clearly identify the research question and provide a summary of the project and its significance, including a brief description of the methods and procedures to be used. Use neutral, unbiased language and do not use jargon. Define any acronyms used.

\section{Research Question:}

What is the variability among different senior centers in the Portland metropolitan area of Oregon with regard to their challenges, strengths and future plans, and how are these senior centers positioning themselves for changing conditions?

\section{Background:}

The Baby Boomers, i.e., those born in the United States between 1946 and 1964, are reaching the traditional retirement age of 65 years at the rate of around 10,000 each day until 2030, contributing to a growing and increasingly diverse older population. Senior centers, of which there are currently nearly 11,000 in the U.S., have generally represented two dominant conceptual models: social agency, designed primarily to meet the needs of low-income and socially isolated older adults, and voluntary organization, designed for older people who are active in voluntary organizations and strongly attached to their communities. This study examines five senior centers in the Portland metropolitan area; two have been selected to represent the social agency model, two others have been selected to represent the voluntary organization model, and one has been chosen because it is unique in that it has achieved meeting the national accreditation standards for senior centers. This research will contribute to a better understanding of the changing experiences of urban senior centers and, using resilience indicators, of what the centers are doing that may 
help them be resilient in the near future. Potential strategies will be offered for urban senior centers to best serve their current and future members as they face changing conditions.

Methods:

This multiple-case study examines five senior centers through interviews with senior center administrators and staff members, and with experts in aging services. The study will also include focus groups with senior center participants and a review of literature and primary site content.

\section{Type of Review}

If you are unsure which level of review is needed, please skip this section. If you are familiar with levels of review, provide a rationale for the level of review requested (exempt, expedited, or full committee review-- see link to categories $\underline{\text { here). }}$. Applicants are not penalized for under- or over-estimating the anticipated level of review. The final determination of review level will be made by HSRRC.

When thinking about categories of review for studies without identifying information of human subjects, please note that anonymity means that the subject's/respondent's identity is unknown (in other words, that responses cannot be linked to individuals); confidentiality implies that, while the researcher can identify each subject and his/her responses, the identity of the subject will be kept private, and not revealed to others.

Expedited Review:

1. This research involves the collection of data from voice, video, digital, or image recordings made for research purposes. 
2. This involves research on individual or group characteristics or behavior (including, but not limited to, research on perception, cognition, motivation, identity, language, communication, cultural beliefs or practices, and social behavior) or research employing survey, interview, oral history, focus group, program evaluation, human factors evaluation, or quality assurance methodologies.

\section{$\underline{\text { IV. Subject Recruitment }}$}

This section should provide a description of the subject population, including the number of participants which the researcher expects to recruit, the characteristics of that population, which can include age, gender, ethnic background and health status, and the methods to be used for their recruitment. A description of how subjects are selected, approached and invited to participate in the research must be included (i.e., email, flyer, phone calls, etc.). Criteria for inclusion and exclusion should be detailed; justification is required if the subject population is restricted to one gender, age or ethnic group, as the federal government strongly encourages investigators to include women, children and ethnic minorities in their research. If different subject groups are to be included in the research, recruitment information must be included for each group.

Online information or snowball sampling (recruiting subjects from among acquaintances) will be used to identify administrators and staff members of senior centers, and snowball sampling will be used to identify senior center participants and non-participant experts in the aging services field who may be willing to interview. Open calls and invitations will be used to schedule semistructured interviews at each case site. For focus groups, an appropriate date and time will be set at each site with the hope of recruiting eight to ten participants. Most focus group participants 
will be invited in person, though some may learn about the opportunity through advertising (e.g., a flyer) or word of mouth. Focus group participants will be asked to notify the interviewer by phone or email of their willingness to participate, if they have not done so in person.

\section{Informed Consent}

Both federal and university regulations require researchers to obtain informed consent from their subjects before they may be part of research, unless otherwise permitted by the IRB. Describe both by whom and in what manner consent will be obtained from each appropriate sample category (see below) and include a copy of the informed consent form(s) or cover letter (s). If requesting a waiver of signed consent or alteration of the process, a justification must be included (see consent samples and information about altering or waiving the consent process here).

\section{Sample Consent Categories:}

- Adult subjects (includes persons 18 years of age and over)

- Child subjects (includes all persons under 18 years of age) will require written parent/guardian permission, as well as verbal or written assent/consent from the subjects themselves.

- In some cases, vulnerable subjects, such as prisoners and mental health patients, may require the consent of an appropriate witness in addition to that of the participant him- or herself.

- When the researcher seeks to use a passive consent process, the Committee must determine that research is one in which a waiver of signed consent is appropriate. If the research and passive consent process is being done in an in an educational setting, the Committee must be assured that the passive consent process has been approved by an appropriate school 
official. When writing the passive consent form, the researcher should give the subjects (and parent/guardian if subject is a minor) ample time to decline participation and must offer a variety of ways in which the researcher can be contacted to decline participation. The method of declining participation or opting out must be clearly stated in the passive consent document.

The research will involve only adult subjects of 18 years of age and over. Consent will be obtained by the researcher before collecting any data, after a participant has expressed willingness to take part in the study either in person, by phone or by email (see Appendices A-H for informed consent documents, including the interview instrument).

\section{$\underline{\text { VI. First-Person Scenario }}$}

Provide a short paragraph that presents the experience from the subject's point of view (e.g., "I received a letter last week in the mail which described a new research study... Once I decided to participate, I set up an appointment to meet the researcher...I was seated at a table with the investigator and...I participated in the following activities... at the end of the study I was happy to have been invited to participate”). This scenario should begin when the subject is first contacted, whether by letter or in person, should describe each activity in which he or she is required to take part, and should conclude only with the end of the subject's participation. If different subject groups are to be included in the research, a scenario must be included for each group. 


\section{Interview}

"I was approached yesterday by Melissa Cannon, a student at Portland State University, who was referred to me by my boss. She was asking if I would be willing to participate in her dissertation research about senior centers. I felt that I would be able to provide some useful insight, so I agreed to participate in the research, and we set up a time for Melissa to come back to my office to conduct an interview. A few hours later, Melissa emailed me an overview of the questions that she would cover during our meeting, and she asked me to review them and think about my answers ahead of time. After reading the questions I made some notes to discuss during the interview. When Melissa arrived at my office, she explained the process, confidentiality, etc. She had a digital recorder and said that she would be recording the conversation for this research, but no one else would hear it. I then read and signed a form that said I understood and agreed to participate, and Melissa gave me a copy to keep for my records. We proceeded to discuss the structure, processes, challenges and plans of the senior center at which I work. We also talked about potential opportunities and strategies to address challenges, mostly regarding funding cuts and changing demographics. The interview lasted about an hour, and I was able to refer Melissa to another staff member and a participant who would be great to interview. She thanked me and said that I could always call if I needed to correct or add anything or had any questions or concerns. It will be interesting to read her findings.”

\section{Focus Group}

"Earlier this week while I was having lunch at the senior center, I was asked by Melissa Cannon, a student at Portland State University, to participate in her dissertation research about senior centers. Her interest was in the details of my attendance at the senior center and my thoughts about how the senior center operates, how it has changed, and what the future holds for it. I 
thought it sounded interesting, so I agreed to participate in a focus group that she was setting up in about a month. The focus group would be with what she called my 'peers;' that is, other senior center participants. She assured me that the focus group would not cover sensitive issues, but rather what I thought about certain issues associated with running a senior center and setting up programs. Melissa handed me a list of potential days and times for the focus group. I gave several options, because I have a pretty flexible schedule. About a week later, I got a letter in the mail confirming a date and some questions that we were going to cover during the focus group meeting. Melissa had asked me if I wanted to receive this through the senior center or by mail or email. Anyway, the letter said that she wanted me to review the focus group questions and think about my answers ahead of time. After reading the questions I made some notes on the paper so that I could remember my thoughts during the focus group. Melissa arrived at the senior center before I did and had the room all organized, with refreshments even. When each person arrived, he or she read and signed a form agreeing to participate, and we all got copies. Melissa gave us each a short survey to fill out. First I chatted with some of the others who I spend a lot of time with at the senior center, then I filled out the survey - it mostly just had questions about my age, sex, how long I had been coming to the center, things like that. Melissa then started the discussion and explained the purpose of the research and that everything would be kept confidential, but that she would record the conversation for her purposes only. Melissa then went over the rules about focus groups (being respectful, not talking over each other, keeping information shared among those of us in the room only, and so forth). She then asked us questions about the senior center. Melissa did a good job of keeping us on track. The focus group lasted about an hour and a half, which we had been told was how long it would last and which was fine, because bingo was canceled that day anyway. When the focus group was over, Melissa thanked us and told us that our contributions to the research project were very important. She also said that we could call her if we had any questions or concerns or additional thoughts to share following the focus group." 


\section{Potential Risks and Safeguards}

The risk/benefit ratio for subjects is particularly crucial to a human subjects review. Some research cannot be approved unless the possible benefits to participants or to humanity outweigh the possible risks. Please describe any potential physical, social, psychological, employment, legal, economic, risk of coercion, or other risks to subjects, including discomfort or embarrassment (e.g., nature and seriousness of risk, incidence of probability, etc.). Also describe the safeguards which will be adopted to eliminate or manage these risks, and/or the steps to be taken to detect and treat any injury or distress incurred by subjects. Even if there are no anticipated risks, this must be justified and explained in the application. There must be a statement about risks and safeguards, including all those mentioned in the application, in the consent document—even if risks are expected to be minimal.

No major risks are anticipated for this research. There may be potential reticence on the part of senior center administrators around revealing the budget, certain challenges, or other details about the facility, but participants may choose not to offer this information. No risks for senior center participants are anticipated, other than possible concerns expressed about the future of the center due to, for example, budget cuts or potential program changes. It is possible that interview subjects may experience feeling tired or upset at some point during the interviews, but they have the option of stopping at any point.

\section{Potential Benefits}

Describe briefly the anticipated benefits of participation in the study. Subjects might benefit directly, such as having an opportunity to share their story, or indirectly, as the results of a study 
of blood donors leads to a better-marketed blood drive and, therefore, increased blood bank stores. If a form of compensation is offered for participation in research, it should be described as a token of appreciation for participating, not as a benefit of the research. Benefits should not be overstated.

The anticipated benefits of participation in the study may be direct, in that senior center administrators will be asked to assess the challenges and constraints facing their centers and potential strategies to address these challenges, and they may be inspired to take preventative, corrective or proactive action for their centers to be more resilient. Mostly the benefits will be indirect, as the collected data will be used to investigate how different types of senior centers around Portland vary in their challenges, strengths and future plans, as well as potential opportunities and adaptation strategies amid changing demographics. Ultimately this research will lead to recommendations for those who advocate for and manage senior centers, as well as recommendations for those working in senior centers and dealing with organizational change and adaptation. It will also expand the existing literature on organizational resilience. The findings will serve as a resource to community leaders who are searching for ways to provide opportunities for personal, economic and social growth among older adults. The results of the dissertation research will be shared with research participants.

\section{$\underline{\text { IX. Confidentiality, Records \& Distribution }}$}

Discuss procedures which will be used to maintain subject confidentiality, including the implementation of any codes or pseudonyms to conceal identities, both during the course of research and in the period thereafter. Regarding confidentiality in a group setting, the researcher must address, both in person and in the consent process, the risk that confidentiality 
cannot be guaranteed in a group setting. Also, explain records storage and access methods, the description of which must include information regarding where and for what length of time data provided by subjects will be stored. Describe whether data will be transported, and if so, how data will be kept secure during transit. If possible, records should be securely stored at PSU and/or on a secure PSU network. If subjects will be audio- or videotaped during their participation, the purposes of such recordings must be explained, as well, both in this section and on the consent document. Federal guidelines suggest that data and records shall be kept on file for a minimum of three years after the completion of research. The manner in which records will be destroyed and the timeframe should be specified.

During the course of research, pseudonyms will be used to conceal the identities of individuals. The researcher may have private information and/or data about specific individuals on record, but this information will be kept secret and not disclosed to anyone else. Because the study involves a small sample size, there is a risk that characteristics of an individual story could lead to identification of a subject in materials published or shared from this study. Regarding confidentiality in a group setting (i.e., focus group), confidentiality cannot be guaranteed. Participants will be asked to respect each other's privacy by not talking about who attended or what the group said. Data will be stored on the researcher's computer hard drive, a secure PSU network that is password-protected in the Institute on Aging, which has an office coordinator at the front desk and automatically locks after hours. Subjects will be digitally audio-recorded during interviews and focus groups so that the researcher may transcribe and analyze the data, and the recordings will be stored securely with all other data on the hard drive. These recordings will be destroyed after the dissertation has been defended and no other changes to the final document are needed. 


\section{$\underline{X . T r a i n i n g ~ a n d ~ E x p e r i e n c e ~}$}

State any of the researchers' specialized training, education, or experience that would help to minimize the risks of research, particularly if working with vulnerable populations and/or sensitive topics. Alternately, if the researcher will be advised by an expert, note this information in the application. A helpful human subjects research training can be found through NIH at http://phrp.nihtraining.com/users/login.php.

The graduate student researcher will be advised by faculty members who are experts in research methods and qualitative data collection and analysis.

\section{$\underline{\text { XI. Appendices }}$}

All recruitment materials and flyers, survey instruments, telephone and email introductory scripts, focus group guides, interview questions and informed consent documents must be included and clearly labeled in your application.

\section{A Email introductory script for interview}

Hello ___ [insert name],

I am a doctoral candidate at Portland State University in the Urban Studies program. For my

dissertation research, I am trying to learn about challenges, strengths and future plans of senior centers, and how are they might be positioning themselves for changing conditions. 
I am emailing you because you have been identified as someone with unique knowledge and experience in the aging services field (if applicable: as a senior center administrator $O R$ as a staff

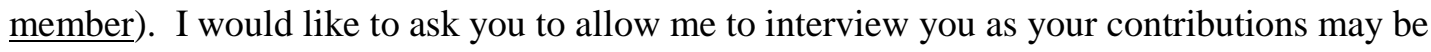
important in completing my research. The interview should take approximately one hour and I would like to have it at a place and time that is most convenience for you.

Overall, the interview is intended for me to learn about your opinions of the senior center at which you work $O R$ senior centers in Portland. Would you be willing to set up an appointment to talk with me?

Please let me know as soon as possible if you are willing to participate in an interview and if you have any other questions regarding the study. You may send me an email to mcan@pdx.edu or call me anytime at 970-310-8627 and we can arrange a time and location that works best for you.

Sincerely,

\section{Melissa Cannon}

Doctoral Student - School of Urban Studies and Planning

Graduate Research Assistant - Institute on Aging

Portland State University

970.310 .8627 


\section{B Telephone or in-person introductory script for interview (for those identified in snowball sampling):}

Hello [insert name], my name is Melissa Cannon and I received your name from a participant in a research study that I am conducting. I am a doctoral candidate at Portland State University in the Urban Studies program. I'm trying to learn about challenges, strengths and future plans of senior centers, and how are they might be positioning themselves for changing conditions.

I am calling/approaching you because you have been identified as someone with unique knowledge and experience in the aging services field (if applicable: as a senior center $\underline{\text { administrator }} O R$ as a staff member). I would like to ask you to allow me to interview you as your contributions may be important in completing my research. The interview should take approximately one hour and I would like to have it at a place and time that is most convenient for you.

Overall, the interview is intended for me to learn about your opinions of the senior center at which you work $O R$ senior centers in Portland. Would you be willing to set up an appointment to talk with me?

[If respondent answers “yes," read the statement marked (yes); if the respondent answers "no," skip to the statement marked (no)] 
(Yes) Great! Is there a particular time next week that would work for you? [Allow respondent time to answer] I can be available . [Provide possible times] Where would you like to meet? [Allow respondent time to answer]

Do you have any questions about the project or anything else? [Allow respondent time to answer]

Thank you and I look forward to speaking with you soon.

(No) Thank you for your time. Goodbye. 


\section{Telephone or in-person introductory script for focus group (for those identified in snowball sampling):}

Hello [insert name], my name is Melissa Cannon and I received your name from a participant in a research study that I am conducting. I am a doctoral candidate at Portland State University in the Urban Studies program. I'm trying to learn about challenges, strengths and future plans of senior centers, and how are they might be positioning themselves for changing conditions.

I am calling/approaching you because you have been identified as someone with unique knowledge and experience as a senior center participant. I would like to ask you to participate in a focus group as your contributions may be important in completing my research. The session should take approximately an hour and a half at the senior center and I would like to find a time that is most convenient for about eight participants.

Overall, the focus group is intended for me to learn about your opinions of the senior center at which you participate. Would you be willing to be part of the focus group?

[If respondent answers "yes," read the statement marked (yes); if the respondent answers "no," skip to the statement marked (no)]

(Yes) Great! Is there a particular time next week that would work for you? [Allow respondent time to answer] I can be available [ [Provide possible times] 
Do you have any questions about the project or anything else? [Allow respondent time to answer]

Thank you and I look forward to speaking with you soon.

(No) Thank you for your time. Goodbye.

D Focus Group Recruitment Flyer

\section{Be Part of a Focus Group!}

Come share your thoughts and opinions about being an attendee of this senior center!

[Date]

[Time]

[Location]

Refreshments will be provided.

This focus group will contribute to dissertation research through Portland State University. Please contact the doctoral student, Melissa Cannon, if you are interested or would like more information.

Phone: 970-310-8627

Email: mcan@pdx.edu 


\section{E Focus Group Participant Survey}

Please fill in the blank or place an $\mathrm{X}$ in the box that best describes you.

1. How many people live in your household?

2. In what year were you born?

3. What year did you begin coming to this senior center?

4. Are you:

- Male

Female

Other

5. In general, would you say that you are:

Unhealthy

Somewhat unhealthy

Somewhat healthy

Healthy

Refuse to answer

6. Do you use a special mobility device, such as a cane or a wheelchair?

No

Yes

Refuse to answer

7. What is the highest level of education that you have completed?

Some high school or less

High school diploma or GED 
Some college

Trade or vocational school

Associates Degree

Bachelors Degree

Masters Degree

Advanced Degree (Ph.D, M.D., J.D.)

8. Which do you consider yourself to be? (Please check ALL that apply)

Asian/Asian American

Black/African American

Hispanic/Latino

Native American/American Indian

Native Hawaiian or Other Pacific Islander

White/Caucasian

Other. Please Specify:

9. What is the primary language spoken in your household?

Chinese

English

Filipino

Japanese

Korean

Russian

Spanish

Vietnamese

Other. Please Specify: 
10. What type of transportation do you typically use to get to the activities at this center?

11. About how long does it take you to get to this center? hours minutes

12. What are the primary reasons that you attend this center?

13. What activities do you participate in at this center?

14. About how many times per year would you say that you come to this center?

15. Do you attend faith-based organizations outside of this center?

Frequently

Sometimes

Rarely

$\square$ Never

16. What activities would you like to have at this center?

17. How would you rate your past and current experiences at this center?

Excellent

Good

Neutral

Fair

Poor

18. Thank you! Is there anything else you would like to add about the center and its activities? 


\section{F Focus Group Participants: Informed Consent}

\section{Challenges and Resilience of Senior Centers: Serving a Growing and Increasingly Diverse Population in the Portland Metropolitan Area}

You are invited to participate in a research study conducted by Melissa Cannon, a doctoral candidate from Portland State University. The purpose of this research is to understand the variability among senior centers in the Portland metropolitan area of Oregon with regard to their challenges, strengths and future plans, and how senior centers might be positioning themselves for changing conditions.

You were selected as a possible participant in this study because you have knowledge and experience of the senior center of which you are a part. If you decide to participate, you will be asked to engage in a focus group with other users of the senior center. The researcher will ask you questions about your personal experiences and thoughts about the senior center. The entire session will be audio recorded and should take about an hour and a half.

While taking part in this study, it is possible that you will be exposed to ideas or communication styles that you find upsetting or that you may become tired. To minimize this risk, the facilitator of the focus group will strive to maintain a safe, respectful and engaging atmosphere for discourse, including setting ground rules for discussion. If for any reason you do feel uncomfortable, please let the facilitator know so that she may correct the situation, or if that is not successful, you may exit the conversation and the room at any time. Your participation is voluntary, so you do not have to take part in this study, and whether or not you participate will not affect your relationship with Portland State University.

You may not receive any direct benefits from taking part in this study, but the study may help to increase knowledge that will help others in the future. Ultimately it will lead to recommendations for those who advocate for and manage senior centers, as well as recommendations for those working in senior centers and dealing with organizational change and adaptation. The findings will serve as a resource to community leaders who are searching for ways to provide opportunities for personal, economic and social growth among older adults. The results of the dissertation research will be shared with research participants.

Due to the group nature of this research, confidentiality around any comments you make during this session cannot be guaranteed, but all participants are cautioned not to talk about what is shared during the focus group. The researcher will seek to minimize any adverse risks by removing any identifiable information in the final transcripts used for data analysis and in any and all final papers, presentations, or publications resulting from this study. If any information about abuse, neglect or harm to a minor or elder is shared, the investigator is required by the state of Oregon to report this information to the authorities. No information about you will be shared with your peers, your family, or any other person or organization. All information will be stored on the researcher's computer hard drive, a secure network that is password-protected and limits access to the researcher. 
If you have concerns about your participation in this study or your rights as a research subject, please contact Portland State University's Human Subjects Research Review Committee at hsrrc@pdx.edu, Market Center Building, 6th floor, 1600 SW 4th Ave., Portland, OR 97201, (503) 725-4068. If you have questions about the study itself, please contact Melissa Cannon at the Institute on Aging, Portland State University, P.O. Box 751, Portland, OR, 97207, 970-310-8627, mcan@pdx.edu.

Your signature indicates that you have read and understand the above information and agree to take part in this study. Please understand that you may withdraw your consent at any time without penalty, and that, by signing, you are not waiving any legal claims, rights or remedies. The researcher will provide you with a copy of this form for your own records.

\section{Signature Date}

Print name

Interviewer Signature Date

\section{G Key Informant Interview: Informed Consent}

\section{Challenges and Resilience of Senior Centers: Serving a Growing and Increasingly Diverse Population in the Portland Metropolitan Area}

You are invited to participate in a research study conducted by Melissa Cannon, a doctoral candidate from Portland State University. The purpose of this research is to understand the variability among senior centers in the Portland metropolitan area of Oregon with regard to their challenges, strengths and future plans, and how senior centers might be positioning themselves for changing conditions.

You were selected as a possible participant in this study because you have knowledge and experience of the senior center of which you are a part and/or of the aging services field. If 
you decide to participate, you will be asked to participate in a face-to-face interview. The researcher will ask you questions on the topic of how the senior center operates, how it has changed, and what might happen in the future. With your permission, the interview will be audio recorded. The entire process should take about an hour of your time and will be scheduled at your convenience.

While taking part in this study, it is possible that you will become upset or tired; if so, you may stop the interview to take a break, stop it entirely, or reschedule it to be completed at another time. You may not receive any direct benefits from taking part in this study, but the study may help to increase knowledge that will help others in the future. Ultimately it will lead to recommendations for those who advocate for and manage senior centers, as well as recommendations for those working in senior centers and dealing with organizational change and adaptation. The findings will serve as a resource to community leaders who are searching for ways to provide opportunities for personal, economic and social growth among older adults. The results of the dissertation research will be shared with research participants.

Any information that is obtained from you in connection with this study will be kept confidential. That means that your name or the name of any organization with which you are associated will not be used in any papers, presentations, or publications resulting from this study. An alpha-numeric code or pseudonym will be used where necessary. If any information about abuse, neglect or harm to a minor or elder is shared, the investigator is required by the state of Oregon to report this information to the authorities. No information about you will be shared with your peers, your family, or any other person or organization. All information will be kept confidential.

Your participation is voluntary. You do not have to take part in this study, and whether or not you participate will not affect your relationship with Portland State University. You may also withdraw from this study at any time without affecting your relationship with the university.

If you have concerns about your participation in this study or your rights as a research subject, please contact Portland State University's Human Subjects Research Review Committee at hsrrc@pdx.edu, Market Center Building, 6th floor, 1600 SW 4th Ave., Portland, OR 97201, (503) 725-4068. If you have questions about the study itself, please contact Melissa Cannon at the Institute on Aging, Portland State University, Portland, OR, 97207, 970-310-8627, mcan@pdx.edu.

Your signature indicates that you have read and understand the above information and agree to take part in this study. Please understand that you may withdraw your consent at any time without penalty, and that, by signing, you are not waiving any legal claims, rights or remedies. The researcher will provide you with a copy of this form for your own records.

\section{Signature Date}


Print name

\section{Interviewer Signature Date}

\section{H Interview Protocol}

\section{Opening comment:}

Hello, I'm Melissa Cannon, a doctoral candidate at Portland State University in the Urban Studies program. I am doing research about senior centers in the Portland area and how they might be adapting to changing conditions.

I called/approached you because you have been identified as someone with unique knowledge and experience in the aging services field/as a(n) (choose appropriate category: administrator or staff member of this senior center).

For administrators and staff:

The purpose of this interview is to discuss the following topics: first, your thoughts about the history of this senior center and its role in the aging services network; and second, any changing conditions that this senior center may be experiencing and how the center might be preparing for and adapting to changes.

For non-participants/experts in aging services:

The purpose of this interview is to discuss the following topics: first, your thoughts about the role of senior centers in the aging services network; second, your thoughts about who does or does not participate in senior centers and how this may change in the future; and third, your thoughts about 
any changing conditions that senior centers may be experiencing and how these centers might prepare for and adapt to these changes.

[Review informed consent form]

Do you have any questions or need any clarification before we begin? [Allow respondent time to ask questions]

Please sign this form. [Hand over consent form] I will give you a copy for your records. [Hand participant an unsigned copy of the informed consent form]

\section{a Beginning of interview: Administrators and Staff Members}

I am going to begin recording the interview now, ok?

1. In your opinion, what is the role of this senior center in the aging services network in the Portland metropolitan area?

- How is this senior center similar to other senior centers in the area?

- How is this senior center different from other senior centers in the area?

2. How would you describe the characteristics of the people who use this center?

- What would you say is the average age of people who use this center?

- What kinds of interests would you say they have?

- Do you think the people who use this center live in the neighborhood?

- Are the people who use this center similar to or different from people who used it in the past?

- How is this center doing with regard to attracting and retaining users?

o How does the center advertise its services to the community?

- Have the programs and services offered at this center remained the same over time?

- Do you think the programs and services offered at this center will remain the same in the future? 
3. Have you ever gathered any information about potential customers who do not currently participate in this senior center?

- For those who could, but do not, currently participate in this senior center, why do you think they do not use your services?

- For those who may participate in this senior center in the future, what do you think would attract them?

4. Has this senior center faced challenges in past years?

- How were these challenges addressed?

- Were the challenges resolved?

5. What are your thoughts about current challenges for this senior center?

- Can you tell me a little more about that?

6. What are your thoughts about the potential challenges for this senior center in the next 5-10 years?

- Do you have plans for addressing these challenges?

- How might this senior center handle potential challenges or crises?

- Can you tell me a little more about that?

7. How would you describe the mission of this center?

- How does this center carry out its mission?

- What specific programs or resources would you like to have in an ideal world to fulfill the center's mission?

- How are decisions made?

- If the center manager is unable to be at the center, how is the management of the center handled?

8. How would you describe the staff engagement of this center?

- How is information shared among staff members?

- Do all the staff members seem to be working toward the same goal?

- What do you think is the image that this senior center projects to people who do not work at or participate at the senior center?

- Is this the image you think this senior center should project? Why or why not?

9. Does this senior center partner with other community organizations?

- [If yes] What are some examples of existing partnerships? 
- Are there other community organizations that you feel this senior center could partner with in the future?

10. Do you know about the national accreditation standards set by the National Institute of Senior Centers?

- [If yes, proceed; if no, explain the standards and provide a handout]

- Do you think it would be desirable for this senior center to be accredited at some point?

- What do you think would keep this senior center from seeking accreditation in the future?

\section{b Beginning of focus group: Senior center participants}

I am going to begin recording the focus group now, ok?

(Please be respectful throughout the conversation and allow one person to speak at a time. To signal that you have something to say while another person is speaking, please raise your hand).

1. When did you start coming to this senior center?

2. Can you tell me about how or why you started coming to this senior center?

3. What sorts of activities do you participate in at this senior center?

4. What are some things you wish were offered at this senior center?

5. What benefits have you received by attending this center?

6. Who do you think comes to this senior center?

- Do you think this will change in the future?

- In what way?

7. Do you know older people who do not come to this senior center?

- Why do you think they don't come?

- How well do you think the senior center advertises its services to the community?

8. Does this senior center provide ethnically or culturally diverse services or programs?

- If so, what are some examples? 
9. How do you feel about this building and how it serves current participants?

- What about for future participants?

10. How do you feel about transportation options for getting to this center?

- Do you have any difficulties getting here?

- Do you think there will be any issues with transportation to the center (for yourself or others) in the future?

11. Are there particular things that you might suspect would change for this center in the near future?

- What are your thoughts about ways for this senior center to prepare for these changes?

\section{Beginning of interview: Non-participants/service providers}

I am going to begin recording the interview now, ok?

1. What is your assessment of the role of senior centers in the aging services network?

2. What do you think is the image that senior centers project?

3. What kind of image do you think senior centers should try to project?

- Why is that?

4. We are now going to discuss senior centers that depend on aging services funding and serve older adults who tend to be socially isolated and have limited incomes.

- Specifically, do you think these centers face challenges with programming?

- Do you think they provide enough ethnically or culturally diverse services or programs?

- Do you think they are experiencing difficulty with attraction or retention of users?

- How well do you feel they advertise their services to the community?

- What are your thoughts about challenges with budget constraints? Transportation for users? Recruitment of new users? Other challenges?

- What are your thoughts about the potential challenges in the next 5-10 years?

- Are there particular things these senior centers might do to address these challenges? 
5. We are now going to discuss senior centers that find other sources of funding (e.g., membership fees, Parks and Recreation) and serve older adults who are more active and have higher incomes.

- Specifically, do you think these centers face challenges with programming?

- Do you think they provide enough ethnically or culturally diverse services or programs?

- Do you think they are experiencing difficulty with attraction or retention of users?

- How well do you feel they advertise their services to the community?

- What are your thoughts about challenges with budget constraints? Transportation for users? Recruitment of new users? Other challenges?

- What are your thoughts about the potential challenges in the next 5-10 years?

- Are there particular things these senior centers might do to address these challenges?

6. Do you know about the national accreditation standards set by the National Institute of Senior Centers?

- [If yes, proceed; if no, explain the standards and provide handout] What do you think about the benefits of meeting national standards?

- Do you think it would be desirable for senior centers to strive for national accreditation?

- What do you think would keep senior centers from seeking accreditation in the future? 


\section{Appendix B:}

\section{National Institute of Senior Centers Standards}

\begin{tabular}{|c|c|}
\hline Standard & Objectives \\
\hline 1. Purpose & $\begin{array}{l}\text { The center should have a written statement of its mission } \\
\text { consistent with the senior center philosophy, as well as a } \\
\text { written statement of goals and objectives based on its } \\
\text { mission and the needs and interests of older adults in its } \\
\text { service area. }\end{array}$ \\
\hline 2. Community & $\begin{array}{l}\text { The senior center should participate in cooperative } \\
\text { community planning, establishes service delivery } \\
\text { arrangements with other community agencies and } \\
\text { organizations, and serves as a focal point in the } \\
\text { community. }\end{array}$ \\
\hline 3. Governance & $\begin{array}{l}\text { The senior center should be organized to create effective } \\
\text { relationships among participants, staff, governing } \\
\text { structure and the community in order to achieve its } \\
\text { mission and goals. }\end{array}$ \\
\hline $\begin{array}{l}\text { 4. Administration and Human } \\
\text { Resources }\end{array}$ & $\begin{array}{l}\text { The center should have clear administrative and human } \\
\text { resource policies and procedures that contribute to } \\
\text { effective management of its operation. It should be } \\
\text { staffed by qualified people - paid and unpaid - who are } \\
\text { capable of implementing its programming. }\end{array}$ \\
\hline 5. Program Planning & $\begin{array}{l}\text { The center should provide a broad range of group and } \\
\text { individual activities and services that respond to the } \\
\text { needs and interests of older adults, families and } \\
\text { caregivers. }\end{array}$ \\
\hline 6. Evaluation & $\begin{array}{l}\text { The center should have appropriate and adequate } \\
\text { arrangements to evaluate and report on its operation and } \\
\text { program. }\end{array}$ \\
\hline 7. Fiscal Management & $\begin{array}{l}\text { The center should practice sound fiscal planning and } \\
\text { management, financial record keeping, and reporting. }\end{array}$ \\
\hline
\end{tabular}




\begin{tabular}{|l|l|}
\hline 8. Records and Reports & $\begin{array}{l}\text { The center should keep complete records required to } \\
\text { operate, plan and review its program. It should regularly } \\
\text { prepare and circulate reports to inform its governing } \\
\text { structure, its participants, staff, funders, public officials } \\
\text { and the general public about its operation and } \\
\text { programming. }\end{array}$ \\
\hline 9. Facility & $\begin{array}{l}\text { The center should make use of its facilities to promote } \\
\text { effective programming and provide for the health, safety } \\
\text { and comfort of participants, staff and community. }\end{array}$ \\
\hline
\end{tabular}

Retrieved from http://www.ncoa.org/national-institute-of-senior-centers/standardsaccreditation/nisc-self-assessment.html\#1 